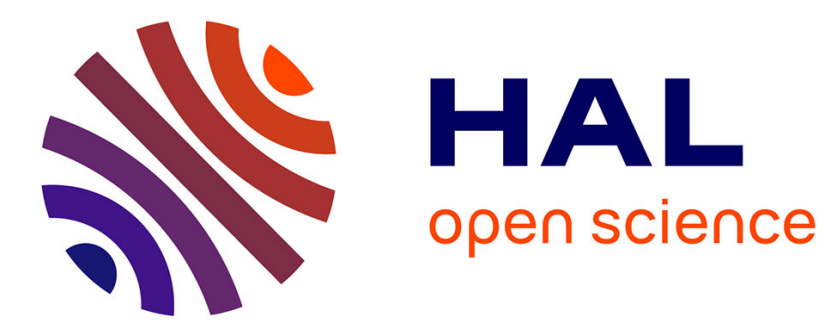

\title{
Céramiques gauloises et gallo-romaines de Roanne (Loire)
}

Jean Cabotse, Robert Périchon

\section{To cite this version:}

Jean Cabotse, Robert Périchon. Céramiques gauloises et gallo-romaines de Roanne (Loire). Gallia - Fouilles et monuments archéologiques en France métropolitaine, 1966, 24 (1), pp.29-75. 10.3406/galia.1966.2437 . hal-01934390

\section{HAL Id: hal-01934390 \\ https://hal.science/hal-01934390}

Submitted on 26 Feb 2020

HAL is a multi-disciplinary open access archive for the deposit and dissemination of scientific research documents, whether they are published or not. The documents may come from teaching and research institutions in France or abroad, or from public or private research centers.
L'archive ouverte pluridisciplinaire HAL, est destinée au dépôt et à la diffusion de documents scientifiques de niveau recherche, publiés ou non, émanant des établissements d'enseignement et de recherche français ou étrangers, des laboratoires publics ou privés.

\section{(이) $\$$}

Distributed under a Creative Commons Attribution - NonCommercial - NoDerivatives| 4.0 


\title{
CÉRAMIQUES GAULOISES ET GALLO-ROMAINES DE ROANNE (LOIRE)
}

\author{
par J. CABOTSE et R. PÉRICHON
}

\begin{abstract}
La ville de Roanne. l'anlique Rorlumna. pose de véritables énigmes it l'archéologue. Les vestiges architerturaux gaulois et gallo-romains y sont rares el modestes. On n'a recueilli à Roanne qu'un seul document épigraphique. Pourtant, ce fut pendant un certain temps un site imporlant, car le sous-sol des vieux quartiers regorge de morceaux de céramique qu'on peut dater des siécles avoisinant le début de l'ere chrétienne. On trouve des vases et des coupes qui proviennent d'Italie et des ateliers de la (iaule méridionale, des poteries de fabrication locale, des terres cuites sigillées et surtout de ces rases peints, si nombreux dans la région. (On est en droit de se demander quel a été le ròle de Rodumna et dans quelles limites chronologiques l'activité de la ville s'est déployée. Il semble, en effet, qu'il y ait une décadence à la fin du $\mathrm{I}^{\mathrm{er}}$ siècle. C'est à ces questions que tentent de répondre, en reprenant et en multipliant les études inaugurées par. Joseph Déchelette, les membres du Groupe de recherches archéologiques de Roanne. Ils ont profité des possibilités offertes par l'ouverture de chantiers de construction et de travaux d'urbanisme pour recueillir des quantités de tessons et d'autres objets. Ils ont ensuite procédé à une étude scientifique du matériel dans le local aménagé en laboratoire, situé dans les caves du Musée. Line des plus importantes de ces trouvailles est celle faite sur le terrain où devait s'élever le nouvel Hoòtel des Postes. Lá, deux des animateurs du Groupe, M.M. Robert Périchon et Jean Cabotse, ont pu opérer des sondages, amasser le matériel archéologique qu'ils ont ensuite éludié patiemment avec une grande rigueur scientifique. C'est le résultat de leur travail qu'ils présentent ici. On doit admirer les qualités de méthode dont ils font preuve, le soin dans l'illustration, la variété des comparaisons. Leurs conclusions sagaces et prudentes apportent du nouveau et nous rapprochent de la solution de ce probleme roannais, que nous évoquions plus haut.
\end{abstract}

Adrien Brinhl,

Direcleur de la Circonscriplion des Anliquiless hisloriques de la region de I.yon.]

L'étude du site de la Nouvelle Poste de Roanne porte essentiellement sur les trouvailles faites lors du creusement des fondations de cet édifice. En 1959, l'administration des P.T.T. décidait la construction d'un Hòtel des Postes à l'emplacement d'un groupe de bâtiments situés place Georges-Clémenceau, face au Palais de Justice. Ce projet présentait. un intérêt certain pour l'archéologie locale car, de par sa situation, le chantier allait se trouver dans une zone dont le sous-sol renferme de nombreux vestiges du passé ; certains ètaient apparus, au cours des temps, à l'occasion de découvertes plus ou moins fortuites. 
L'ampleur de ce chantier at les moyens méaniques mis en arure permirent une vue d'ensemble tres etendure du sous-sol de er quartier ainsi que le sauretage d'un important. matériel archéologriçue.

Placé dans le quadrilatere formé1 par les rues Alexandre-Roche. des Fossés. d'Hareourt et des Thermes romains. ce chantier se trouve situé à une centaine de mètres au nord de la place du chateau, cette dernière représentant le centre do l'enceinte médiévale de Roanne, délimitée de ce còté par la rue des Fossés qui marque l'emplarement des anciennes douves de la ville fortifiée. La rue des Thermes romains doit son nom aux restes d'un élifice gallo-romain situr a proximite et baptisé "thermes". Au nord de ces "Thermes "s'etend le quartier de la livatte, dont le sous-sol a fourni de tout lemps de nombreux vestiges gaulois el gallo-romains.

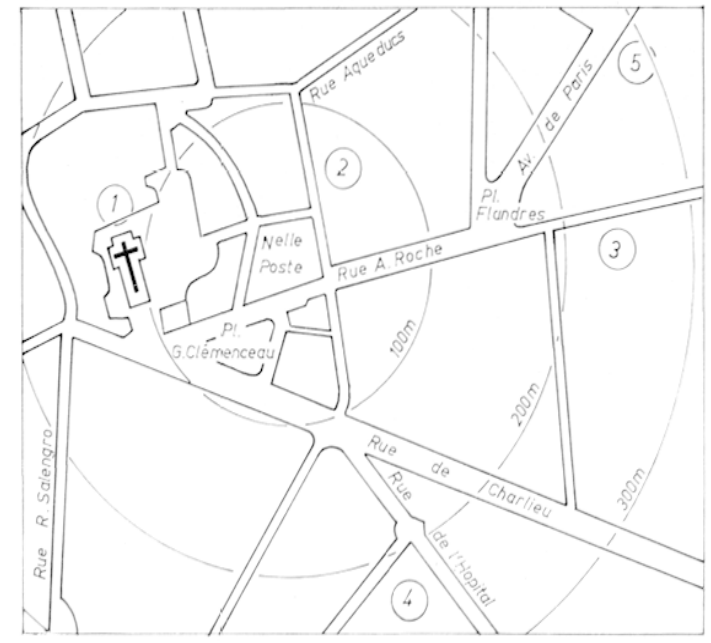

1. Pan de situation des foulles de la Nomvelle poste a Hoanne. 1, chantier "Roanme-ladore": 2, emplacement des "Thermes"; 3. Institution Saint-Joseph: 1, tromballes de Baticoop-longuentin: 5, caserme Werle. Le nordest à droile de la fierure.
Le secteur dont la Nouvelle Postr represente le centre a livé, sur un rayon de quelques centaines do mètres, les vestiges suivants ${ }^{2}$ :

a) Cité sud : les trouvailles de la place du Chàteau consistent principalement en de nombreux sarcophages dont la pierre porte rarement un décor ${ }^{3}$; il y arait aussi des pans de mur epi formaient l'enceinte d'un ustrinum4. Lin maints endroits furent decouvertes de la céramique des legulae el des monnaies (de César a Charlemagne). In rhantier de fouilles actuellement ouvert dans la cour de l'bicole de Musique livre un matériel homogrine de l'époque Claude-Méron. (Firg. 1, no 1 ). Plus au sud. vers la rue Benoit-Malon, s'étend la nécropole décrite par Joseph Déchelette.

b) Coité ouest : Irois rangées superposees de sarcophages de pierre munis de leur couvercle, le rang inférieur de ces sarcophages élant encast ré sous la muraille du chateau. Lucune arme ou polerie ne les accompagnail : il $y$ avail seulement quelques fragrments de tegulae.. In sondage effectué a la limile nord-ouest de la Youvelle Poste ${ }^{8}$ fail apparaitre a environ 1 metre de profondeur, une couche importante de tegulae au-dessous de laquelle. sur une epaisseur de $20 \mathrm{~cm}$, se trouvent de nombreux ossements d'animaux et des tessons de céramique, ces derniers, de facture tress proche de ceux de la Youvelle Poste. Ce sondage a fourni aussi des morceaux d'enduit peint. (Fig. 1, no 2 ).

1) Parcelles 33:25 a 3337 de la section I) du cadastre de Roanne.

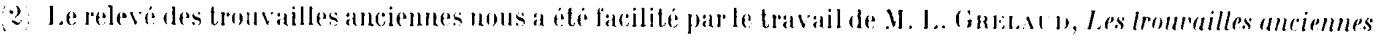

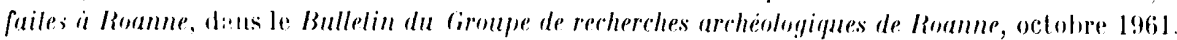

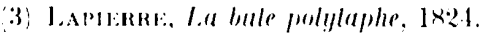

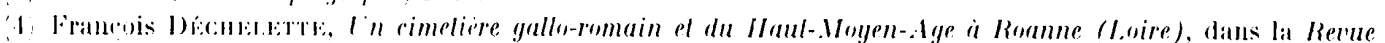

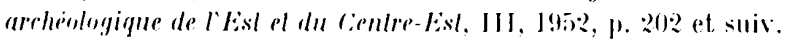

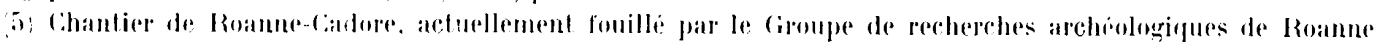
(G.R.A.R.:

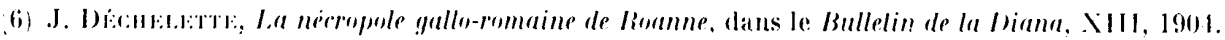

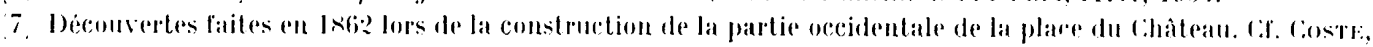

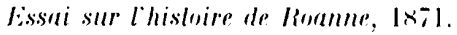

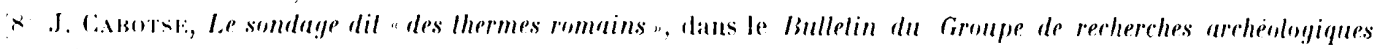
de Rumme, 1961 . 


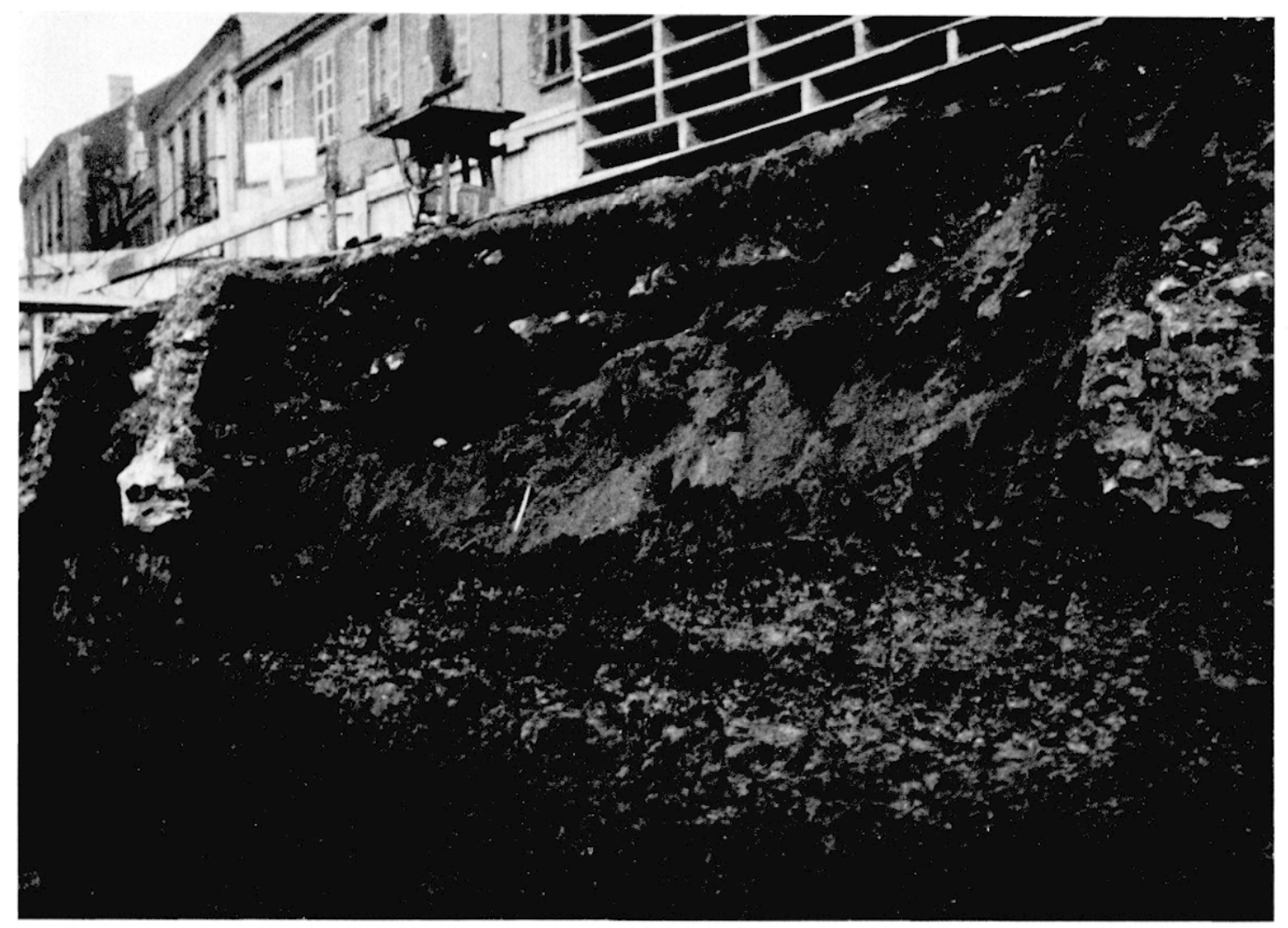

2. Vile de lat compere est.

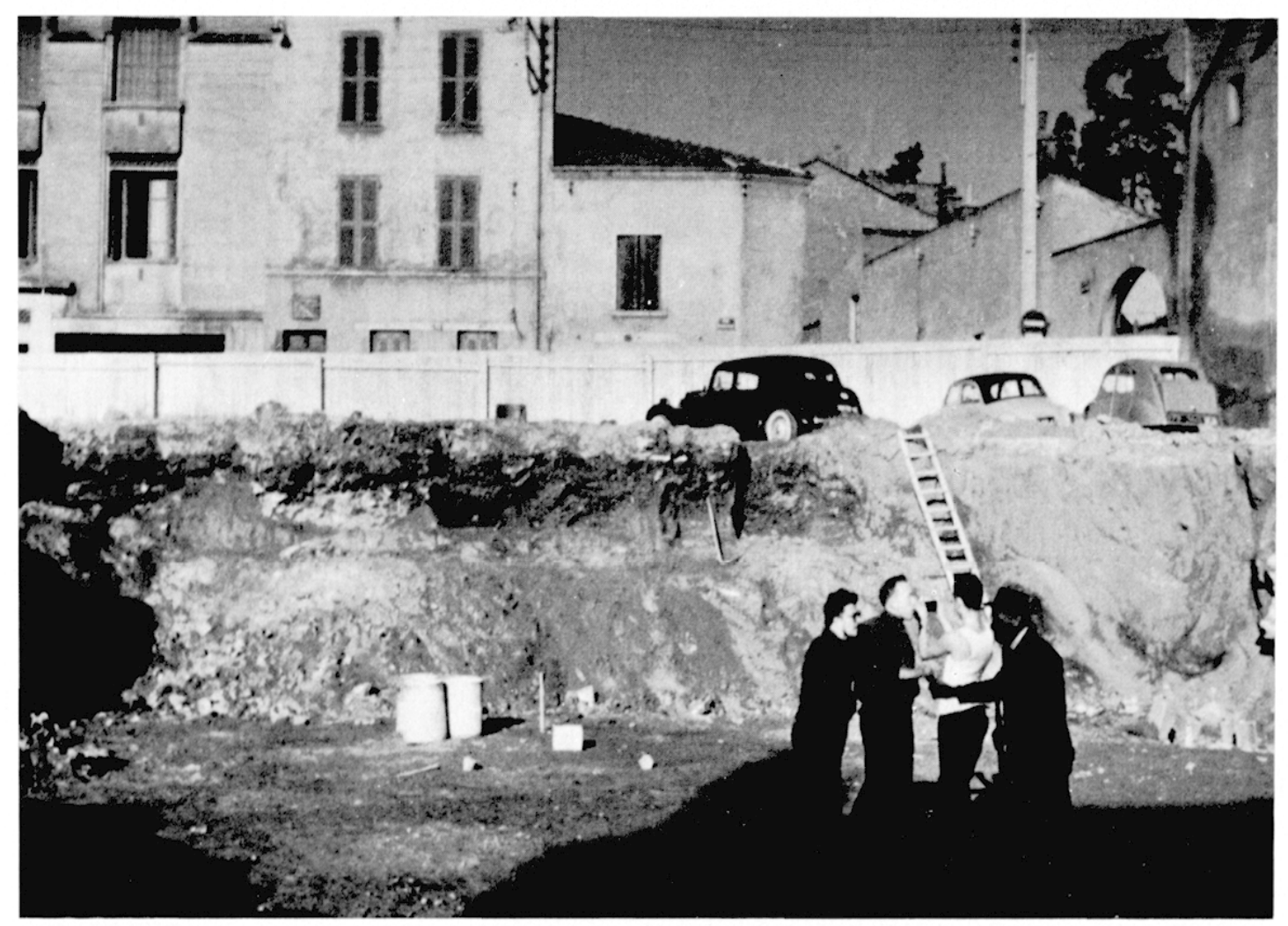

3. Vue de la conpe ouest. 
c) Còté est: la place du Palais de Justice ainsi que la route de Charlieu jusqu'à hauteur de l'hòpital ont fourni un grand nombre d'amphores ${ }^{9}$. lors de divers travaux de terrassement effectués en 1961 el 1962. Plus a l'est. la construction d'immeubles a provoqué la découverte d'un puits dont le curage permil la récupération ${ }^{10}$ d'un matériel comprenant de nombreux tessons d'amphores, de céramique commune el de sigillée du ${ }^{\text {er }}$ au ${ }_{11}{ }^{\mathrm{e}}$ siècle. (Figr. 1, no 4).

d) Còté nord : c'est en direction du nord qu'apparaît la zone archéologique la plus dense et, a la lumière des données actuelles, il semble que ce soit dans cette zone qu'il faille situer le centre de l'agglomération gauloise et gallo-romaine. Immédiatement à la suite du chantier, outre les vestigres de construction gallo-romaine dont la destination controversée ${ }^{11}$ nous oblige a lui conserver l'appellation de "thermes", le sous-sol, à une faible profondeur. est riche en vestigres céramiques du début de l'ère chrétienne. Des travaux effectués à la caserne W'erlé12 révélèrent l'existence d'un four de potier et mirent au jour un tronçon de voie romaine. Le secteur le plus riche est sans conteste celui de la livatte où divers travaux ${ }^{13}$ firent apparaître des vestiges de villa ainsi que des mosaïques. Ln sondage effectué dans une propriété privée ${ }^{14}$ a fourni, entre autres objets, de la sigillée lédozienne ainsi que des monnaies du II $^{\mathrm{e}}$ siècle. Actuellement, un chanlier en cours d'étude, établi sur les terrains de l'Instilution st-Joseph ${ }^{15}$, met en évidence une continuilé d'habitat depuis la période de l'Indépendance jusqu'au me siècle. (Fig. 1. nos 3 et ‘)).

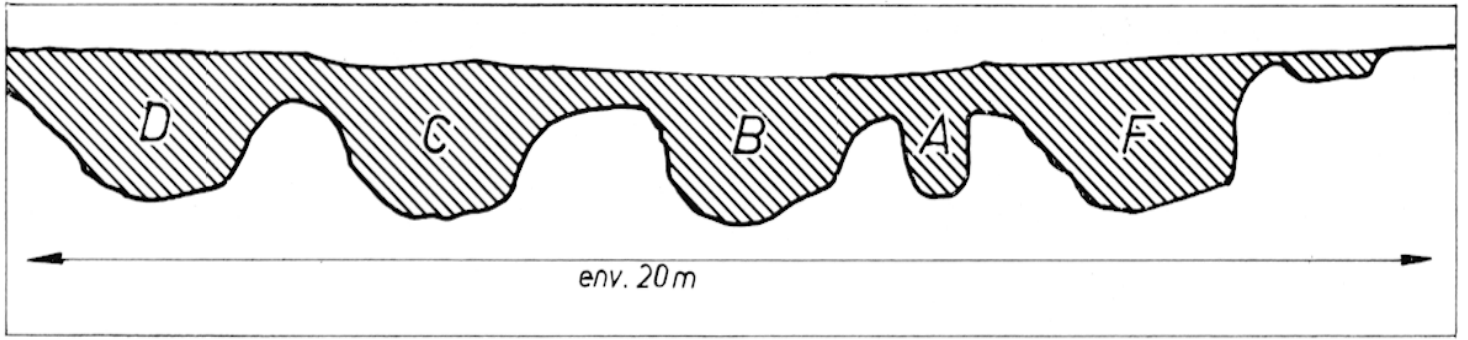

4. Aspect des poches sur la coupe ouest (fig. 2).

Les travaux de terrassement nécessaires à l'édification du Nouvel Hôtel des postes conduisirent les entrepreneurs à creuser le sol, sur une profondeur de plusieurs mètres, sur toute la surface des futurs bâtiments, ce qui represente quelques 10000 mètres cubes de déblais (fig. 2 ot 3). (ce quartier de Roanne se caractérisant par une continuité d'habitat constante, une certaine surface du sous-sol se trouvait remaniée par des implantations anciennes et la présence de caves sur une partie du chantier nous a obligés à rechercher les endroits vierges de constructions. Les coupes effectuées dans ces surfaces ont mis en évidence non pas une couche archéologique régulière mais une succession de dépòts se présentant sous forme de poches. Ces poches, creusées à même le sable, contenaient, intimement mélangés, des tessons de céramique et des ossements d'animaux, le lout mêlé à une lerer de couleur sombre.

(9) Matériel déposé dans les locaux du G.R.A.R., au Musée Joseph Déchelette; étude en cours.

(10) I. GREIAID, Les Irourailles de Baticuop-Fontquenlin, non publices.

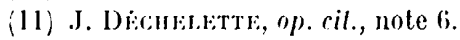

12) A. Braxand, Descriplion du pays des Ségusiaves, 1858 : A. (osts, op. ril., note 7.

(13) Le matériel recueilli au cours de ces travaux est exposé au Musé Joseph Déchelette, à Roanne.

(14) Sondage effectué par I.. Grelaud dans la propriété de M. Lauxérois en 1961.

(15) Chantier dirigé par M. l'abbe Bessoul. 
L'idée selon laquelle ces poches seraient les vestiges de fonds de cabanes ${ }^{16}$ n'a pu ètre démontrée de manière affirmative mais lrur profusion (fig. 4), dans un secteuriz où les vestiges d'habitations sont rares, semble militer an faveur de cette hypothèse. Le seul vestige d'habitation découvert au cours de ces fouilles fut un angle de construction en pierres maçonnées, à l'intéricur duquel subsistait encore un dallage composé de chaux of de débris de céramiquess ${ }^{18}$.

\section{I. .-. LA CERAMIQUE SIGILLEE}

Les conditions difficiless dans lesquelles re matériel archéologique a été recueilli n'ont guère facilité les roleves stratigraphiques. Le present travail souftre de cette insuffisance. Cependant. quedques observations fragmentaires permettent de rompléter utilement les éléments de datation que nous offre lo lot de céramiques sigillées livré par ce site.

Cine éturle sommaire ${ }^{19}$ faisait apparaitre un pourentage relativement élevé de céramiques d'origine italique ainsi qu'une certaine quantiti d'éléments provenant du sud de la Gaule. Quelques fragments en provenance de la daule entrale avaient éte egalement observés. Cne statistique établie en nombre de vases nous donne, selon les origines, les pourcentages suivants:

$$
\begin{array}{ll}
\text { Céramique italique : } & \text { (6), } 4 \% \\
\text { Céramique du Sud de la ciaule : } & 25,6 \% \\
\text { Céramique du Centre de la ciaule : } & 9,6 \%
\end{array}
$$

Le tableau ci-dessous précise cotte statistique en indiquant la quantité de vases par formes. Hans un certain nombre de ras, il ne s'agit que de fragments; les dimensions en sont cependant suffisantes pour se prèter à une determination sîre. Sauf pour les fragments originaires du Cientre de la Ciaule, dont nous savons qu'ils ont été recuejillis à des niveaux proches de la surface du sol et hors des poches que nous avons décrites ${ }^{20}$, l'ensemble provient de la série des porbes A, B, (. I). E et F, ainsi que de l'égout de la rue d'Harcourter. Certains fragments ont éte recueillis dans différentes décharges qui recevaient la terre évacuée du site.

16) IE. II Aon, Gallische Ansiedelung mil Gräberfelil bei Lasel, 19.10, 1. 9 à 11.

(17) Le chantier de Roanne-Cadore (cf. note 5) presente les mèmes particularitis.

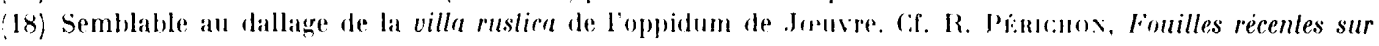

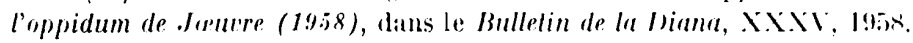

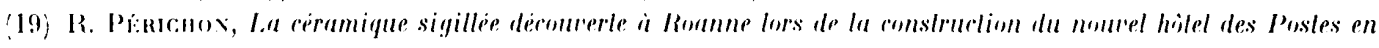

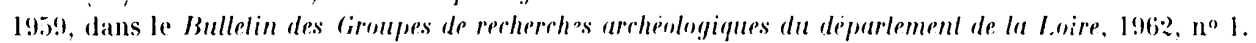

20) I.e fragment no 2017 de notre inventaire dit. $x, n^{\circ} 3$ a cte recueilli dans la grande coupe longeant la rue Nexandre-Roche fig...., a a 0,20 m environ au-dessous du niveau actuel de cettr rue.

(21) L'assietle no 2037 de notre inventaire lig. $7, n^{\circ} 2$ ) provient du creusement de cet igout. 


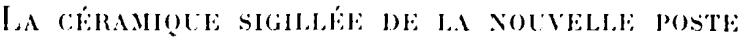

\begin{tabular}{|c|c|c|c|}
\hline Formes & ItALigue & $\begin{array}{l}\text { SUD DE LA } \\
\text { GAULE }\end{array}$ & $\begin{array}{c}\text { Centre de } \\
\text { La Gaule }\end{array}$ \\
\hline 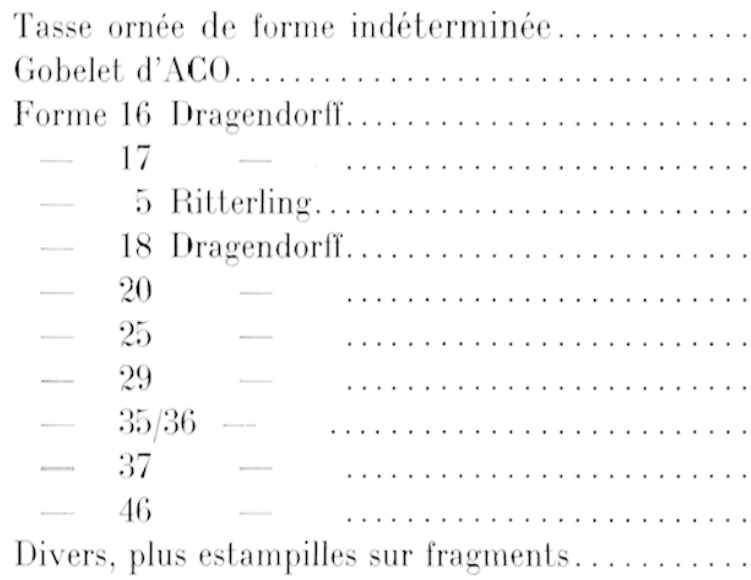 & $\begin{array}{l}1 \\
2 \\
2 \\
4 \\
8 \\
\\
5 \\
2\end{array}$ & $\begin{array}{l}3 \\
2 \\
2 \\
3 \\
1 \\
\\
4\end{array}$ & $\begin{array}{l}4 \\
1\end{array}$ \\
\hline 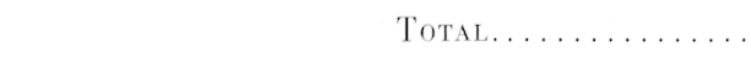 & 32 & 15 & 5 \\
\hline$\% \ldots$ & 61,5 & 28,9 & 9,6 \\
\hline
\end{tabular}

A. Cínamote ITALIQTE

1. Vasess ornés. - İn seul fragment orné, fabriqué au moule, est d'origine italique : une tasse ansée incomplète ( fig. $5, n^{0} 1$ ) présentant un décor de feuilles et de glands. Le motif semble se répéter cinq fois sur le pourtour du vase. Ln rang de petits motifs coniques limite en haut et en bas le motif principal. Les oves sont remplacées par des cercles concentriques. Ces deux motifs, petits cones et cercles concentriques, se rencontrent sur d'autres vases de fabrication arretine ${ }^{22}$. Deux lettres d'une signature en relief sont visibles ${ }^{23}$.

La hauteur de ce vase est de 0,07 $\mathrm{m}$ et son diamètre de $0,08 \mathrm{~m}$ environ. Le départ de l'anse est visible et quelques fragments nous en ont été conserves. La coloration, comme relle des vases que nous décrivons ci-après, est d'un rouge orangé ; les pâtes sont rosées mais rlaires.

2. La céramique d'Aro. - Jusqu'à ce jour, la céramique du potier Ac'O n'était pas représentée a Roanne. Ieux fragments appartenant aux prorluctions prêtées à ce potier ont été découverts. Ie fragment $n^{\circ} \stackrel{2}{2}$ (fig. 5, $n^{0} \stackrel{2}{2}$ ) est de pâte rougeattre. Son ornementation est composée d'une guirlande foliacée disposée horizontalement et orientée à droite. Au dessous est un semis de petites aspérités triangulaires, la pointe en las, disposée en quinconce par zones horizontales très rapprochées.

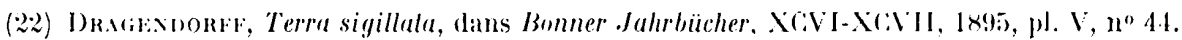

(23) Il semble possible de lire TH, lies. II s'agit peut-être de l'estampille en relief de XANTIVS. 
Le fragment $n^{0} 3$ (fig. 5, no 3) est en pâte jaune. Le seul décor visible est un semis de Jetites aspérités disposées en quinconce. Cies aspérités sont plus grossières que celles représ'ntées sur le vase précédent.

3. Les formes lisses. - Les produits lisses italiques sont plus abondants que les produits ornés. Jous disposons en particulier de toute une série de plats ainsi que de nomhreuses coupes coniques ou hémisphériques.

Cimupes (fig. 5) :

No 4 : roupe à panse arrondie. Le col semble prolonger la courbure de la panse. Il est orné de slries à peu près verticales et possède, pour servir d'anse, un petit colombin appliqué sur la paroi et terminé par des volutes. Il s'agit d'une forme 25 de I)ragendorff. ()n comparera cetle coupe à celles présentées par Ohlenroth ${ }^{24}$ et $P$. Karnitsche ${ }^{25}$. La hauteur du vase est de $0,064 \mathrm{~m}$ et son diamètre maximum de $0,154 \mathrm{~m}$. Le vernis est brillant.

No 5 : fragment de coupe, variante de la forme 2425 de Dragendorff. Le col, orné de stries, est vertical et n'est pas situé dans le prolongement de la rourbe de la panse.

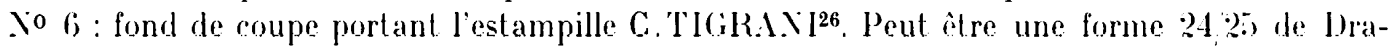
gendorfit.

\section{Coupes coniques (fig. 6) :}

No 1 : c'est pratiquement le seul vase rencontré intact sur ce site. Cetle petile coupe, de type Ritterling $5^{27}$, porte l'estampille (BEL ${ }^{28}$ apposée sur le fond interne du vase et présente, ainsi que les fragments nos $2,3,4,5,6,7.8$, un col très mouluré, dont la partie supérieure est ornée de fines stries. La hauteur de la coupe $\mathrm{n}^{0} 1$ est de $0,048 \mathrm{~m}$ : son diametre au col, de $0.090 \mathrm{~m}$. Les autres fragments décrits sur la mẹme planche semblent de dimensions un peu plus importantes mais leur fragmentation ne permet pas de donner des chiffres précis.

Nos 9 et 10 : il s'agit d'un autre type de coupe, is col et rebord peu moulurés. Seule une rainure horizontale orne l'extérieur du récipient. La paroi interne est également ornée d'une rainure. Ces vases sont des variantes de la forme 36 de Dragendorff. Il semble que nous soyons en présence du type 7 a de Loeschcke ${ }^{29}$.

Plals et assielles (fig. 7-8) :

Fig. 7 , no 1 : fragment de vase plat, variante de la forme 16 de I)ragendorff. Il semble que cette pièce appartient au service I d'irezzo ${ }^{30}$, à lèvre retombante. Son diamètre est de $0,30 \mathrm{~m}$.

Fig. $7, \mathrm{n}^{\mathrm{os}} 2,3$ et $4:$ ces trois fragments appartiennent au mème type que le plat $\mathrm{n}^{0} 1$, avec quelques variantes cependant dans les moulures intérieures. Lá également, nous nous trouvons en présence de fragments dont le diamètre est difficile à préciser.

Fig. $7, n^{0} 5$ : plat de grand diamitre ì levre retombante. Le vernis rouge orangé et la pàte de couleur claire nous laissent supposer une origine ilalique. Les fouilles de Gergovie semblent avoir livré une coupe de profil identique ${ }^{31}$.

(21) OLnExnotn, Ilalische Sigillata mit Auflagen aus Rälien und den römischen Cermanien, dans Berisht der römisch-germanischen Kommission 193.1/35, p. 244, fig. 3.

(25) P. Karxitsche, Ihe Reliefsigillala von Ovilala (Linz, 1959), pl. I, no5 7 et 9.

(26) Voir p. 46.

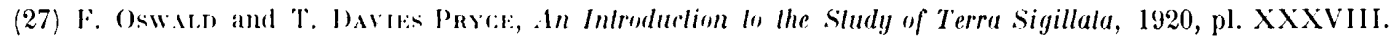

(2x) Voir p. 46.

(29) Jorscucke, Keramische Funde in Hallern, 190!!, pl. X.

(30) I.okscincke, op. cil., n. 29, pl. 1, no 5 .

(31) M. I. ankor sse, l.es fouilles de (ieryotie, dans Giallia, VIII, 1950 ; ceramique italique, p. 20, fig. 49, 168. 

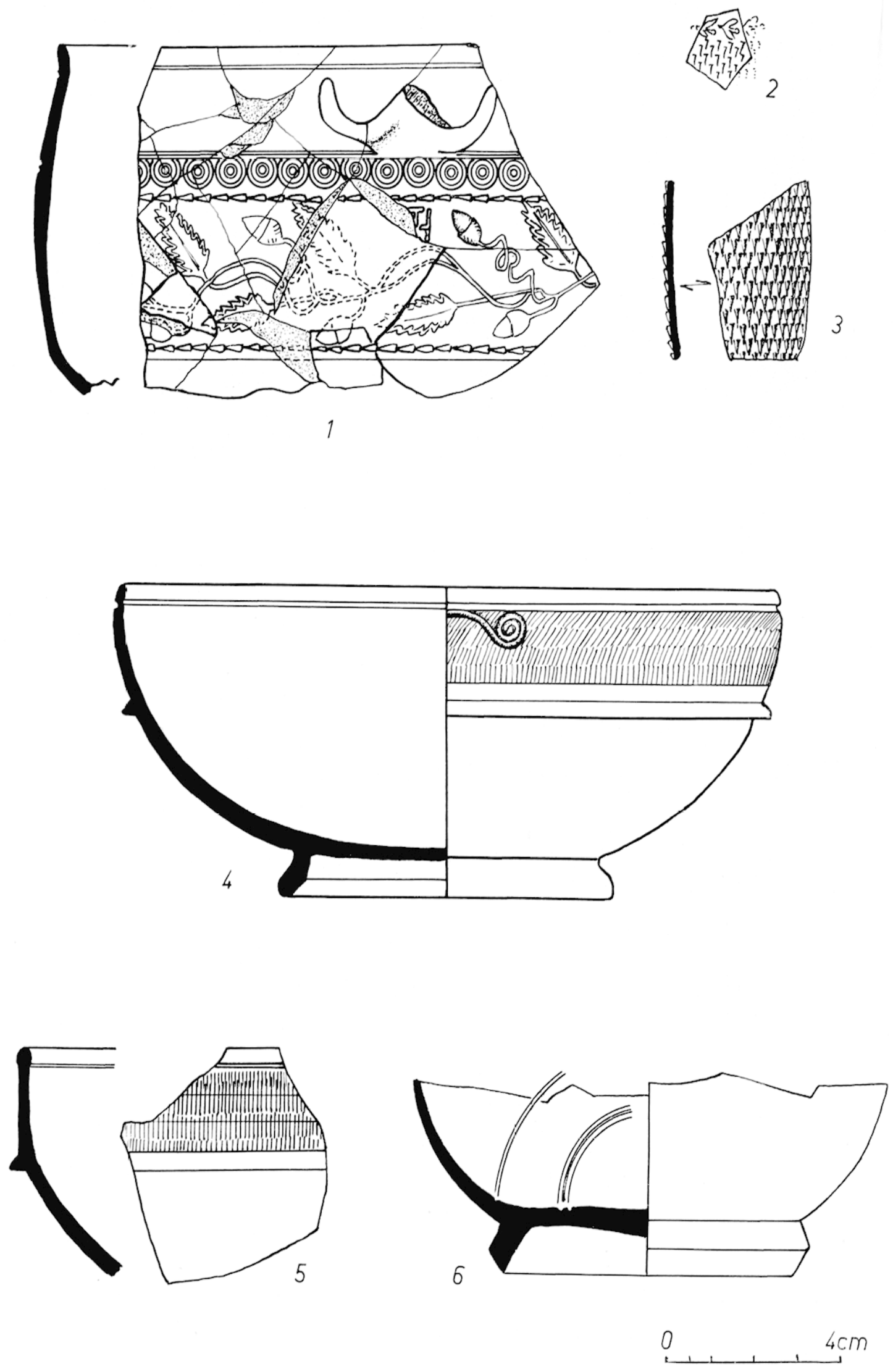

5. Céramique sigillée italique. 

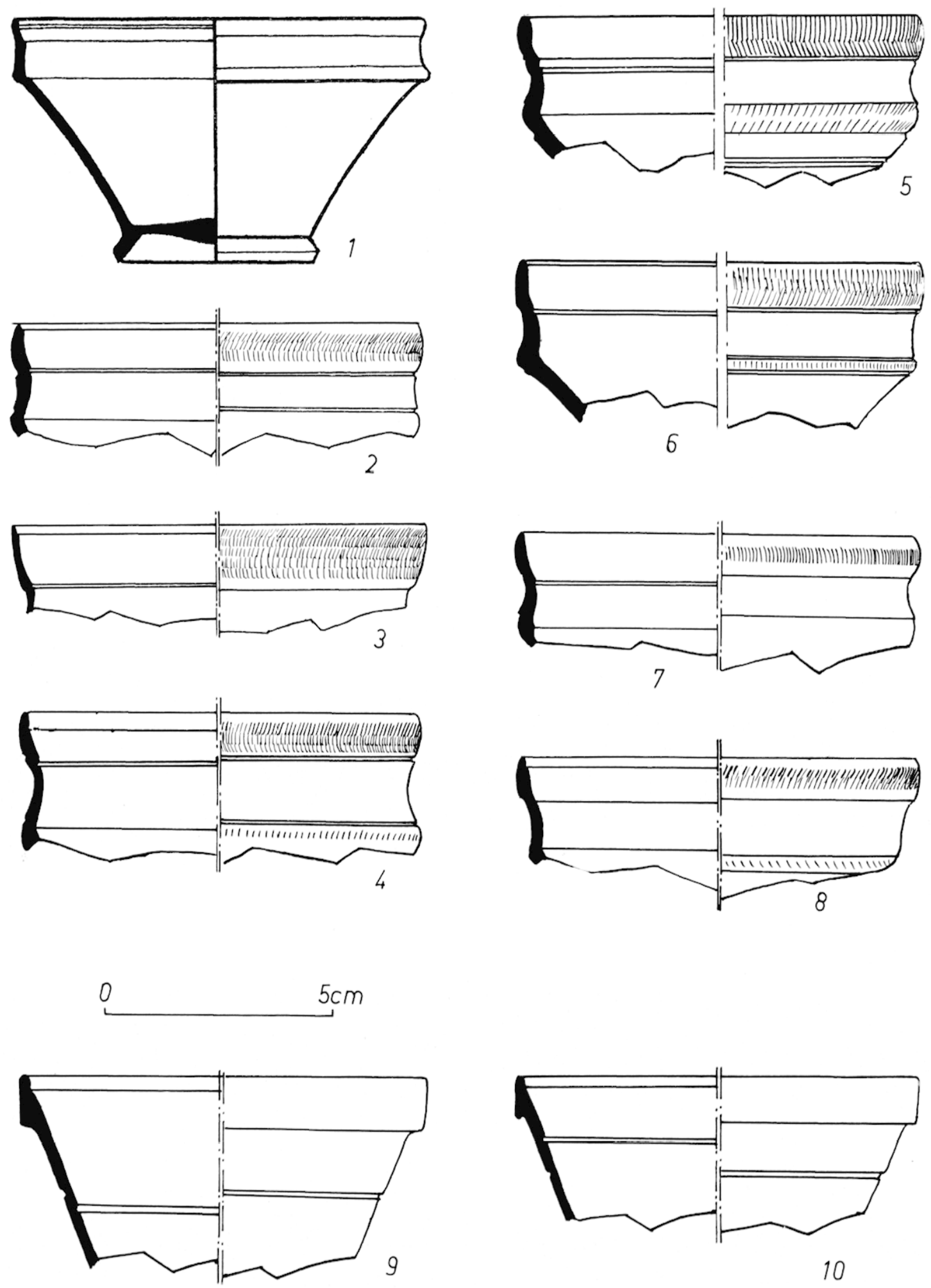

6. Céramique sigrillée italique : coupes coniques. 
Fig. 8, n0 1 : fond de plat ou assiette portant en son centre l'estampille I)(o) ${ }^{32}$. L'inlirieur de ce vase est orné de deux séries de cercles concentriques.

Fig. 8, no 2 : fond de plat ou assiette portant en son rentre l'estampille 1.TYRsil33. L'interieur est orné d'une série de cercles concentriques. Aucun des fragments de rebords décrits plus haut ne se rapporte aux fonds de vases nos 1 et 2 , fig. 8 .

Fig. $8, n^{0} 3$ : fragment de rebord de vase plat qui semble ilre une varianle de la forme 17 de Dragendorf ${ }^{34}$. On peut le comparer à celui découvert a Hofheim et décrit par Rillerlingrg.

Fig. 8, $\mathrm{n}^{0}$ ) : fragment de plat de grand diametre : variante de la forme 17 de Dragendorfl ; Oswald et Pryce précisent cetle forme dans leur Inlroduclion ${ }^{36}$.
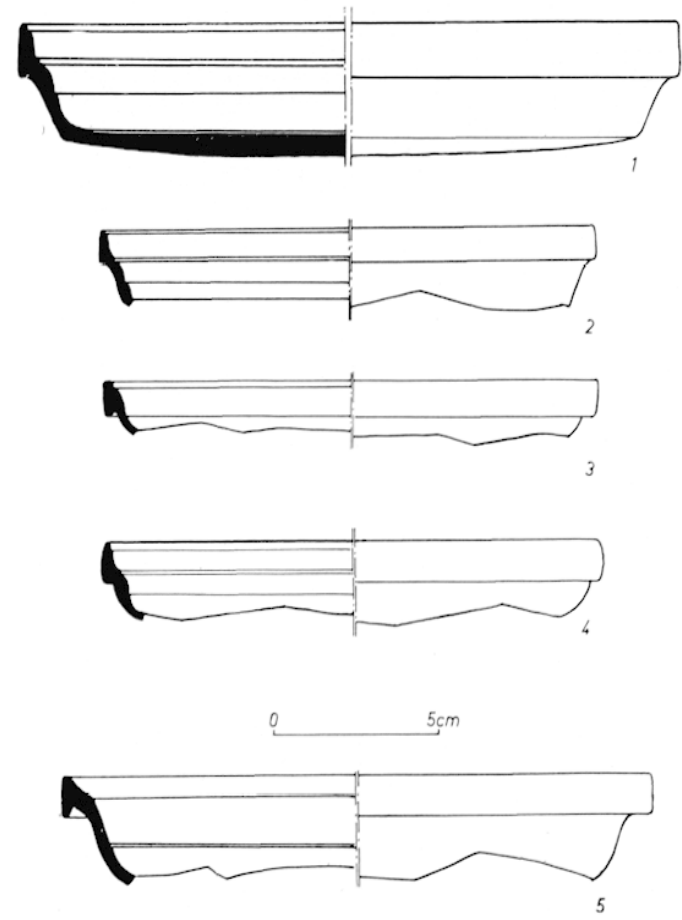

7. Céramique sigillée italique : plats.

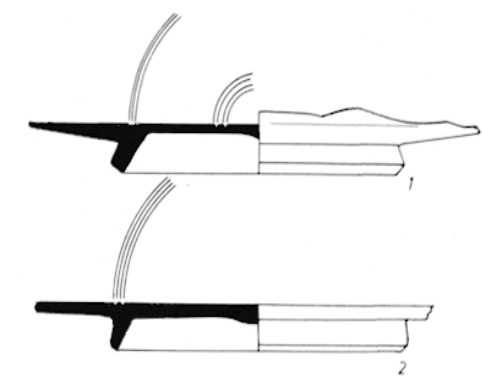

$5 \mathrm{~cm}$
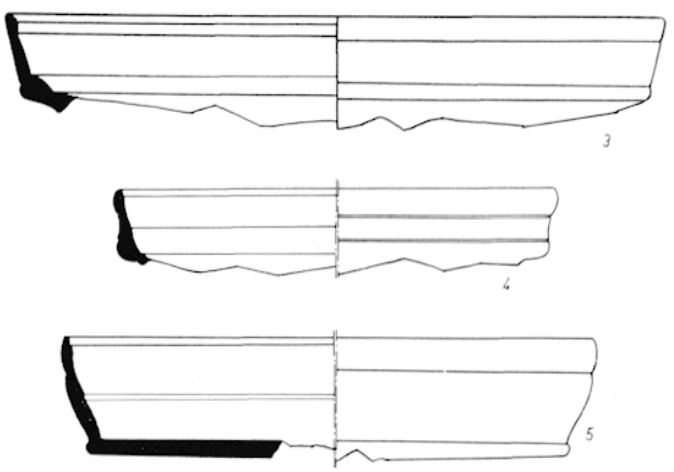

x. Ceramique sigillée italique : plats ou assiettes.

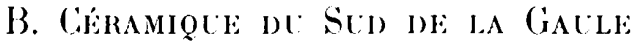

1. Vases ornés

Formes 29 (fig. 9).

o 1 : les sept fragments se rapportant a celte figure appartiennent a un vase de forme 29 Dragendorfl' et présentent une série de petils médaillons figurés, séparés par des liges portant des glands. In rang de perles sépare les médaillons de la moulure supérieure. dont quelques cannelures seules sont visibles. Ies motifs. a l'intérieur des medaillons, sont surcessivemenl : un canard

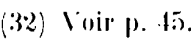

33 linir p. 16;

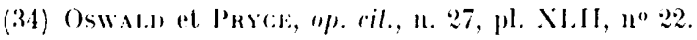

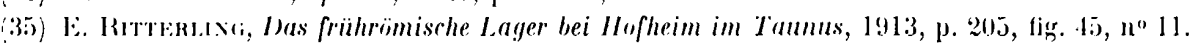

(36) Osw:Alu et Pricis, op. cil., n. 27, pl. XI.II, no 8 . 
Lourné à gaurhe. un cygne tourné il gauche qui est probablement le motif no 1003 de Jéchelette ${ }^{37}$ et 22:8 doswald ${ }^{38}$, un canard tourné is droile. Nous supposons que ces motifs élaient orientés alternativement is gauche et at droite. Cet ensemble ornail la partie inférieure du vase et on remarque le rang de grrosses perles et la moulure cannelée qui séparaient ces décors des motifs supérieurs. Houlures et perles sont. d'aprés Kinorr. raractéristiques de ces productions sous le règne de Caligula et du début de celui de Claude ${ }^{39}$. Le motif ornant la tige des glands a l'endroit ou les médaillons se tourchent pourrait itre le "lendrill binding" $\mathrm{n}^{0} 24 \mathrm{~d}^{\prime}()_{\text {swald }}^{40}$.

Io 2 : fragment de vase appartenant a un rebord de forme 29 Jragendorit. Ce lesson nous montre un motif en forme de fougìre à feuilles dentelées ainsi qu'un chien courant à droite et poursuivant un lapin. Ine fougiere identique se rencontre sur un vase 29 de la collection Roach smith ${ }^{41}$. Le chien ne semble pas figurer dans la série de motifs décrits par Oswald ou Déchelette. Ln rapprochement peut cependant itre tenté entre notre molif et les molifs 1968 d'Oswald ${ }^{42}$ et 922 de Iéchelette ${ }^{43}$. Le rebord supérieur de ce fragment est orné de trois moulures cannelées. II semble qu'il s'agisse d'une production des ateliers rutines, période des Flaviens.

No 3 : deux fragments appartenant is un rebord de forme 29 de Dragendorff. Ils présentent un décor de feuilles liées par un norud. l'n rang de grosses perles sépare le décor de feuilles de la moulure cannelée qui orne le rebord du vase.

\section{Vases lisses}

Coupes (fig. 10).

No 4: coupe a panse arrondie, variante de la forme 24/25) Dragendorft. Elle diffr̈re de la coupe italique (fig. 5. no 4) par la forme du col qui est vertical et ne se situe pas extérieurement dans le prolongement de la courbe de la panse. Les stries qui ornent le col sont presque verticales et très régulières. La coloration de ce vase est également différente de celle de la coupe fig. 5. $\mathrm{n}^{0} 4$ : elle est d'un rouge plus sombre. La pàte est d'un rose relativement foncé. sòn diamìtre maximum est de $0.128 \mathrm{~m}$ et sa hauteur de $0,0 \% 2 \mathrm{~m}$.

No 5) : fragment de coupe très dégradée. Sion profil est assez semblable ì celui de la pièce $n^{0} 4$. Une petite moulure orne extérieurement le haut du col. La couleur de ce fragment est d'un rouge trìs orangé mais bien différent de la couleur des vases arrétins.

Concernant ces formes, les ateliers du sud de la Gaule ont produit des vases de ce type en quantités consillérables, en particulier pendant la période Claude-Néron et Vespasien ${ }^{44}$.

To 1 : coupe conique portant sur son fond interne l'estampille EPIDIV $s^{45}$. Il s'agit d'un vase de type Ritterling $5^{46}$. Son plus grand diamìtre - au col ... est de $0.109 \mathrm{~m}$ et sa hauteur de $0,080 \mathrm{~m}$.

Nos 2-3 : fragments de coupes de mème types. La coloration du vernis ainsi que celle de la paite nous les a fait associer à la pièce ci-dessus.

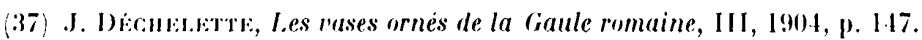

3x) F. Oswa.s, Inder of figure-lypes on Terra Sigillata, 1936/37, pl. LXXXV.

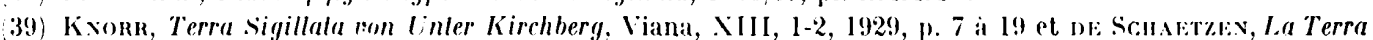

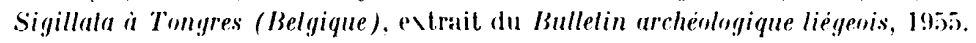

(10) Oswat. et P'H

11. H. B. Win.ters, Calnlogue "f the Roman Pollery, Brilish .Mnseum, 1908, p. 108, fig. 110 et pl. XXIII, no 364.

(2) (Iswat1), up. ril., n. 3x, pl. LXXTIII.

43 .J. Decometetre, "p. cil., n. 37, p. 139.

14, Oswat.s et Pricke, up. ril., n. 27, pl. .il.

(5) Voir p. 45.

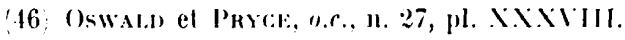



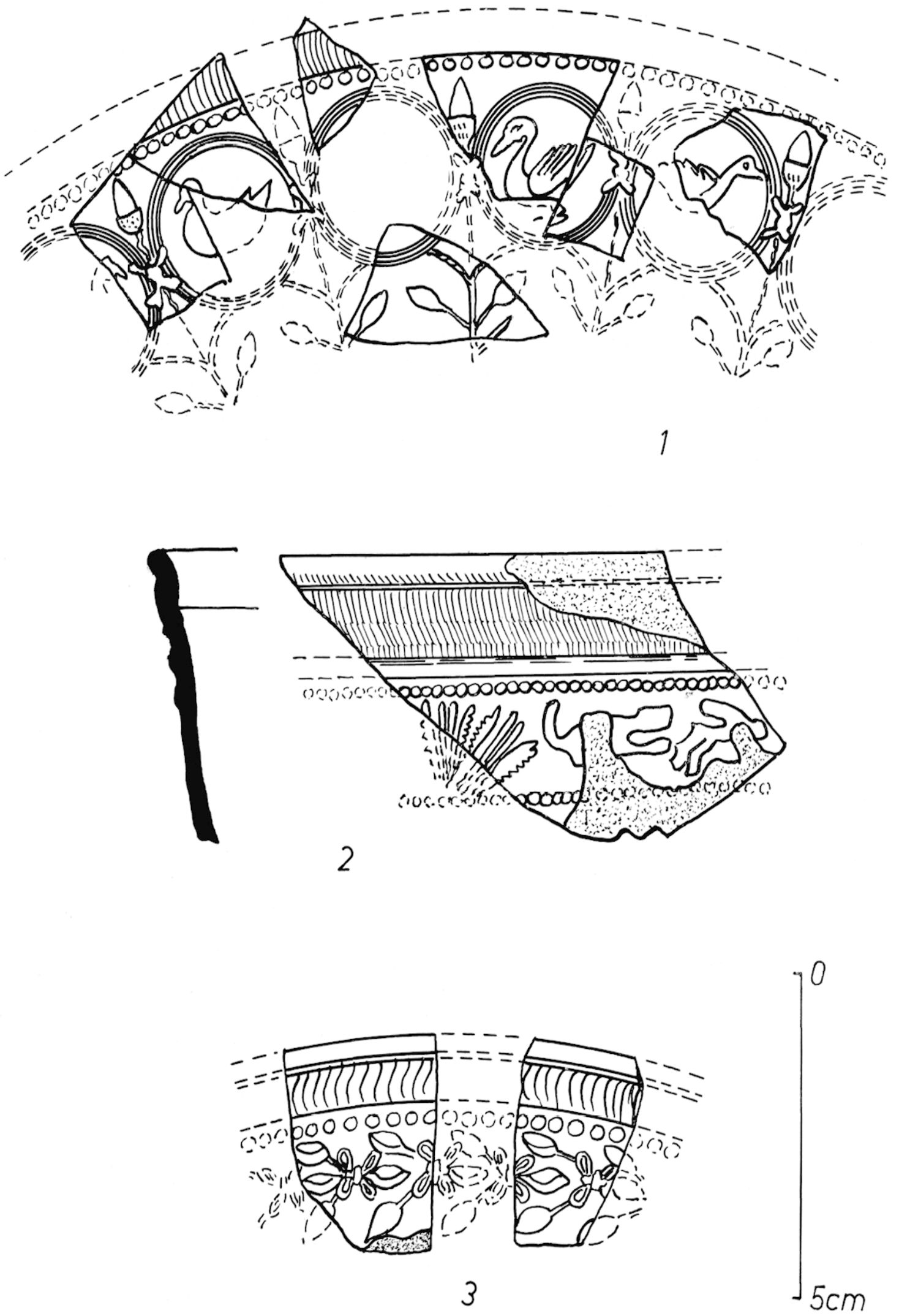

9. Céramique sigillée du sud de la (iaule : vases ornès. 

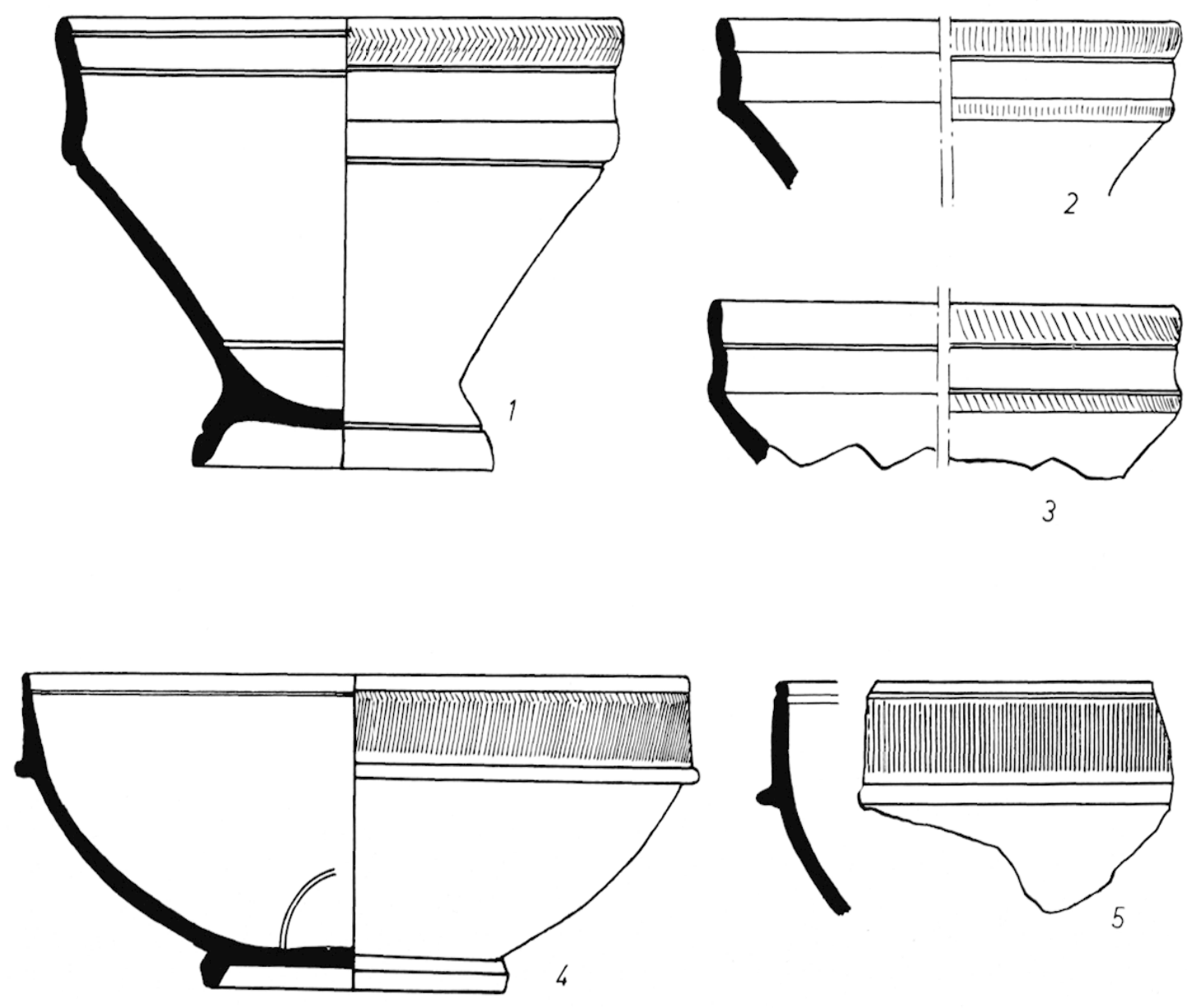

. $5 \mathrm{~cm}$
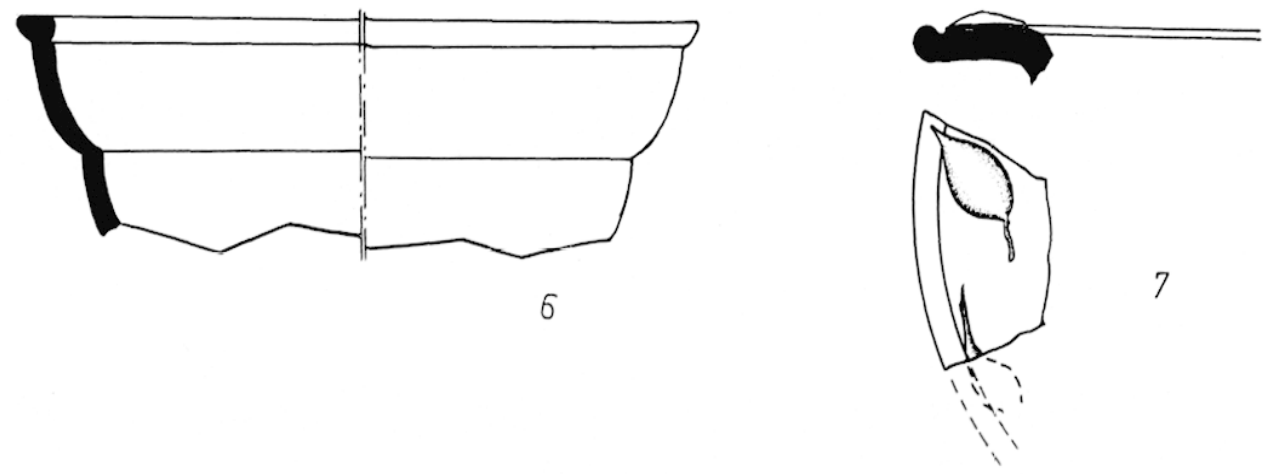

10. Ciramique sigillèe du Sud de la Gaule : vases lisses ou ornés à la barbotine. 
De par la coupe signée EPII)IVs, nous nous trouvons en présence de produclions du Sud de la (iaule pendant la période de Claude.

No 6 : fragment de coupe de forme Inagendorlf 27 . Oswald précise que l'on date cette forme de la période de Claude ${ }^{47}$.

ㅇ 7 : fragment de forme 35 ):36 Dragendorfi orné a la barboline. Production du Sud de la (iaule, probablement pendant la période Claude-Néron?

Plals el assielles (fig. 11):

No 1 : grand plat de forme 18 I)ragendorff. L'estampille GOTVL( $0^{48}$ est apposée a l'intérieur
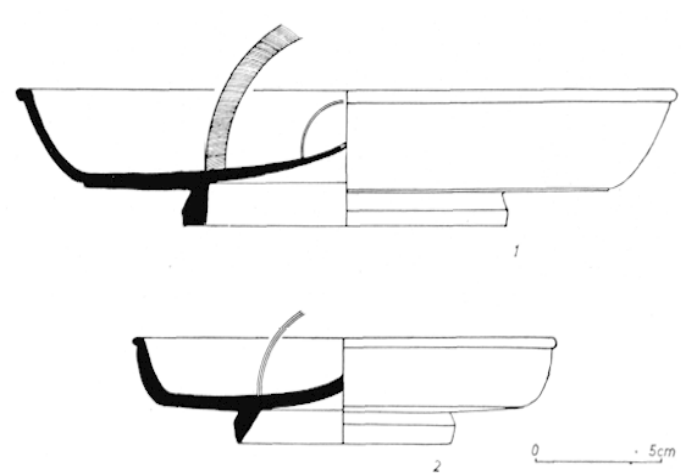

11. Céramique sigillée du Sud de la Gaule : plats et assiettes. et au centre du vase. Une couronne striée orne le fond. Le plus grand diamitre de ce vase est de $0,260 \mathrm{~m}$. Il provient probablement des ateliers de La Ciraufesenque, production de la période de Claude a Vespasien ${ }^{\mathbf{9}}$.

No 2 : petite assiette plate de forme 18 Dragendorfi. Elle porte en son centre l'estampille MODEST. F50. sur le fond extérieur, un graflite pouvant représenter la lettre I) a été tracé. Deux petits cercles concentriques ornent le fond interne. Le diamètre extérieur est de $0.128 \mathrm{~m}$. Ce vase semble provenir également des ateliers de la Graufesenque, production de la période ClaudeNéron ${ }^{51}$.

\section{Géramige de Gintre de la Gatee}

1. Vases ornes. - Les quelques fragments recueillis et provenant des officines du Centre appartiennent exclusivement à des vases de forme 37 I)ragendorff (fig. 12).

No 1 : deux fragments appartiennent au mème vase. L'un présente un décor à médaillon el demi-médaillon : le médaillon est, orné d'un masque barbu tourné à qauche, probablement le motif 711 de Déchelelte ${ }^{52}$. Dans le demi-médaillon est inscrit un vase a larcre panse en forme de croissant, prohablement le motif 10\%) bis de I)échelette ${ }^{53}$. In motif indéterminé a été apposé sur l'extrémité du croissant formé par la panse du vase. L'autre fragment montre une ove à deux arceaux, incomplete. Le vernis est de mauvaise facture et peu brillant, dégradé par endroits. Il pourrait s'agrir d'une production de Lezoux de la seconde moitié du II $^{\mathbf{e}}$ siècle.

>0 2: fragment d'un vase 37 orné de métopes. Le fragment de motif visible à gauche du tesson apparlient a un Jupiter nu, assis, tenant le foudre dans la main gauche; il s'agit du motif 4 de Décheletle ${ }^{54}$, visible sur un moule de Lezoux du musée de Rochechouart (Haute-Vienne) ${ }^{55}$. Le molif central appartient à un ornement en forme de caducée (motif 1116 de Déchelette) ${ }^{56}$. surchargé ì

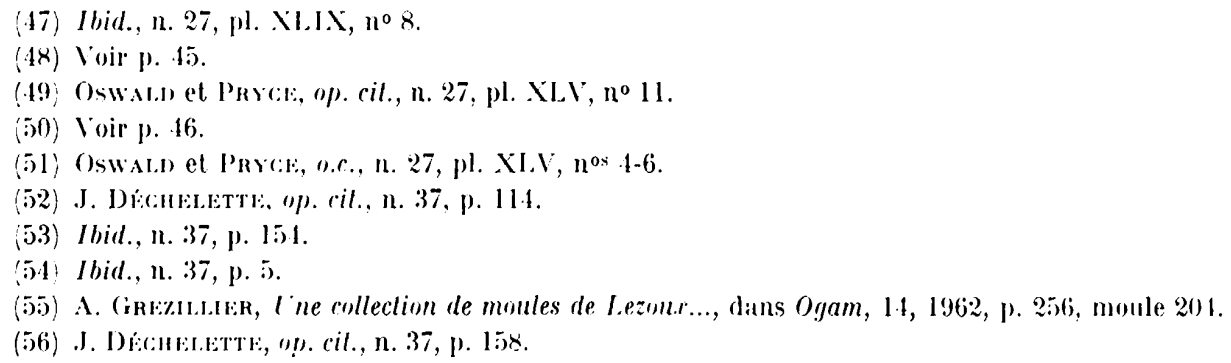



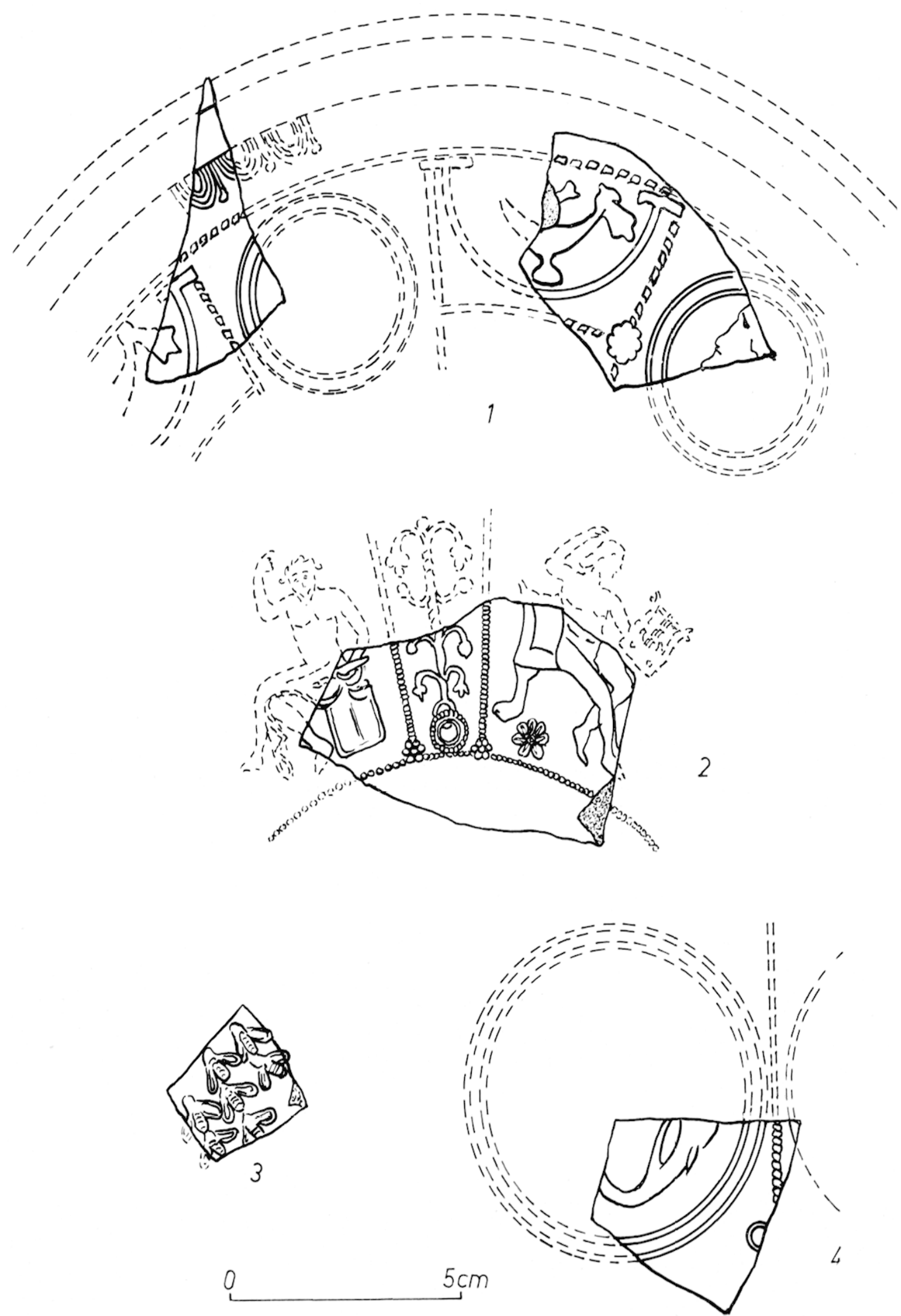

12. Ciramique sigillée du Centre de la Gaule : vases ornés. 
sa base par une couronne (1182 de l)échelette $)^{57}$ formée de deux cercles concentriques. Le cercle extérieur est perlé. A droite du tesson est un personnage viril assis sur une calhedra : il s'agit d'Apollon jouant de la lyre (motif 8.3 d'()swald) ${ }^{58}$. Entre les jambes du personnage et le pied visible du siège, on distingue une rosace a sept pétales. Les motifs ci-dessus se rencontrent sur des produits de Lezoux et sur des fabrications allant de la période de Trajan à celle d'Antonin.

No 3 : fragment orné d'un semis d'abeilles, disposées en diagonale.

lo 4 : fragment de vase 37 à décor à grand médaillon. Dans la seule partie de médaillon visible est représenté un animal marin.

2. Vases lisses. - Les fragments de vases lisses qu'il est possible d'attribuer avec certitude aux officines de Lezoux sont rares. Cependant, un fond de forme 77 Loescheke ${ }^{58}$ pourrait appartenir aux productions précoces de Lezoux ${ }^{60}$ de la période Auguste-Tibère. Il s'agit d'une imitation ${ }^{61}$ plus ou moins adroite de terre sigillée. Le vernis, rouge sombre, est peu adhérent et dépourvu de lustre. La pâte est grise. Lne estampille est apposée sur le fond interne du vase; rectangulaire, elle est composée de trois lettres : nous lisons, difficilement, ARA (v. ci-dessous).

\section{I). Estampilites}

\section{$\triangle \overline{Q Q Q}$ \\ AR A}

Sur fond interne de vase type Loeschke 77, probablement d'origine lédosienne. Comme nous sommes en présence d'une production précoce de Lezoux, cette estampille pourrait être une reproduction maladroite d'estampille arrétine. (V. ci-dessus).

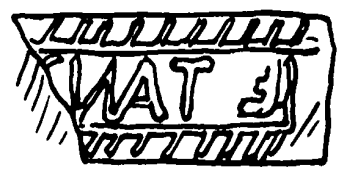

$\mathrm{C}\langle\mathrm{N}\rangle . \wedge \mathrm{T}(\mathrm{ei}) \ldots$

Cette estampille se présente dans un cadre rectangulaire orné de petits traits en diagonale. sauf sur le coité droit de la signature où le cadre se confond avec une lettre inversée, $\mathrm{E}$ ou $\mathrm{F}^{62}$. Quant au prénom, seule une partie de la leltre C est visible; la lettre $\mathrm{N}$ est inversée. Il semble difficile de rapprocher cette estampille, cependant fréquente en ('aaule ${ }^{63}$, d'une variété connue. Les productions des ateliers italiens de $C$. Aleius se placent sous le règne d'Auguste, vers les premières années de notre ère. Mais l'origine italique de certains produits signés de ce potier peut être contestée. Trois estampilles d'Ateius ont été trouvées à Roanne ${ }^{64}$.

(57) Ibid., n. 37, p. 165.

(58) F. Oswa L.D, op. cil., n. 3\$, pl. VI.

(59) LoEschcke, op. cil., n. 29, pl. XIV.

(60) II. VLRter, Les vases caliciformes gallo-romains de Roanne el la chronologie des fabriques de terre sigillec de Lezomx au debul du Jer sierle, dans Callia, XX, 1962, p. 35I-380.

(61) An sujet des imitations, voir p. 47.

(62) C.I.I., XV, 2, p. 703, type d'encadrement $n^{\circ} 7$.

(63) C.I.L., XIII, $10009-1 \%$.

64) J. Décusterte, Decouverles gallo-romaines dans la ville de Roanne, 1903, p. 3 et fonilles de .1. l'abbri Bessou a l'Institution Saint-Joseph, 1962. 


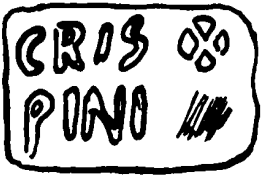

C R I S P I N I

Estampille de C. CRISPINVS, dans un rectangle sans entourage. I.inscription est sur deux lignes, les lettres ont peu de relief. A la hauteur de la première ligne, dans l'angle supérieur droit, on voit une sorte de rouelle a quatre rayons. Cette estampille s'est rencontrée fréquemment sous la forme présente ; elle a cependant été trouvée en Gaule sous des formes diverses ${ }^{65}$ : citons particulièrement l'exemplaire trouvé au Mont-Beuvray, dans les travaux de l'aqueduc de la CòmeChaudron ${ }^{66}$ et celui découvert par M. Labrousse à saint-Bertrand-de-Comminges ${ }^{67}$. C.. Crispinus est un potier arrétin.

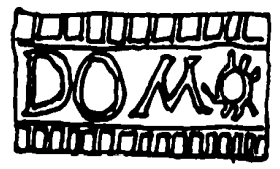

I) () $M($ itii)

Estampille de DOMITIVs sur un fond interne de vase de forme indélerminée. Elle est disposée dans un large rectangle. Ine sorte de couronne est placée dans le prolongement des lettres. Au-dessus et au-dessous de l'inscription sont des motifs composés de petits traits verticaux limités par un trait horizontal. DOM, suivi d'une couronne, semble être une signature classique du Domitius d'Arezzo68. A Arezzo, cette estampille s'accompagne également de palmettes. Plusieurs estampilles de Domitius ont été relevées a Pouzzoles ${ }^{69}$, avec un ornement composé de petits traits rappelant, l'encadrement de notre estampille, sans couronne mais avec des palmes ${ }^{70}$. (V. fig. $8 . n^{0} 1$ ).

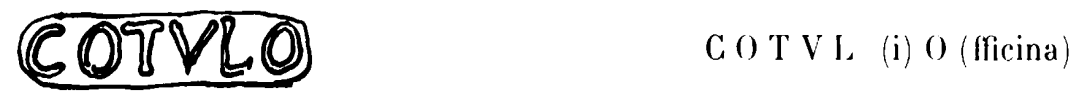

Estampille de COTVLO ou COTVI.VS, sur forme 18 Dragendorit. Ce potier aurait travaillé dans les ateliers de Ia (iraufesenque pendant la période Claude-Vespasien ${ }^{21}$. On relève dans l'Index d'Oswald COTVLVs a silchester; CoTVLo FEC a Autun, Nîmes, Aislingen, Amiens, Iaangres, Moulins, Paris, Trion ; CoTVI, a Vertault ; CoTTVI.O à Trion. (V. fig. $11, n^{0} 1$ ).

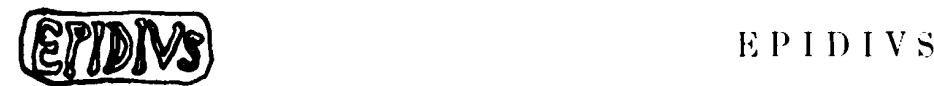

Estampille rectangulaire tris visible sur une forme Ritterling type 5. Oswald note EPIDIVS sur un mème type de vase ${ }^{72}$ et attribue cette signature à un potier du sud de la (iaule, en activité sous Claude. (V. fig. 10, no 1).

(65) C.I.L., XII, 5686, 281 et C.I.L., XIII, 10009,990 et 100.

(66) Bchlot, Fouilles du Mont-Beuvray (1894), dans les Mémoires de la sociéie Fiduenne, 1896, XXI1, p. 9.

67) M. Labrousse, lettre du 8-2-1961.

(68) C.I.I.., XI, 6700, $269 \mathrm{f}$.

(69) C.I.L., X, 8056, 126.

(70) Renseignement de .I. H. Comfort.

(71) I. Oswalb, Index of poller's' slamps on Terra Sigillala, 1931.

(72) Ibid., n. 71, p. 115 . 
ए०BbU

(i E L.(I)I(i)

Petile estampille rectangulaire sur fond interne de vase de forme Rilterling type 5. Il s'agit de I. SEMPRONIVS (iELLIVs, qui est un potier arrétin ${ }^{73}$. ()swald note celte signature sur

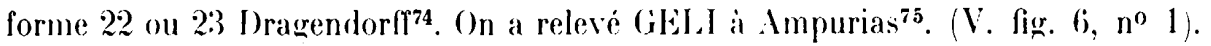

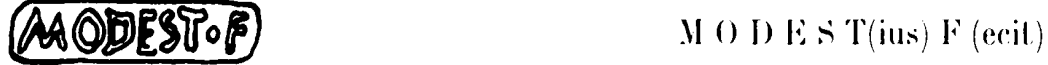

Estampille de MOINESTIVS sur une petite forme is Dragendorff. Ine estampille identique a été relevée sur une forme 18 a Poitiers ${ }^{76}$. Elle s'est rencontrée sous dilférentes formes a Vichy, Avallon (Musée). Jublains (Musée de Mayenne), Reims (Musée de Bar-le-Duc) ; elle est également. signalée dans les musées de Saint-Germain, Trèves, Wiesbaden, Leiden ${ }^{77}$. (V. fig. $\left.11, n^{0} 2\right)$.

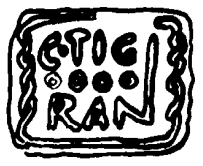

C. (aii) T I ( i / R I I TI

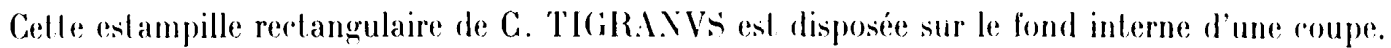
X el I sont liés. I.e nom est disposé sur deux liones séparées par une rangée de quatre petits cercles. Un encadrement. horizontalement rectiligne et, verticalement, composé d'un entrelac, orne l'estampille. Ine estampille tout a fait identique a été trouvée ì Haltern, où les marques de ce potier sont nombreuses ${ }^{78}$. Cetle signature s'est rencontrée sous la mème forme a Trion, Met\% (au Musée de Mayence, $\left.{ }^{79}\right)$; elle esl arrétine ${ }^{80}$. (V. fig. 5), no 6).
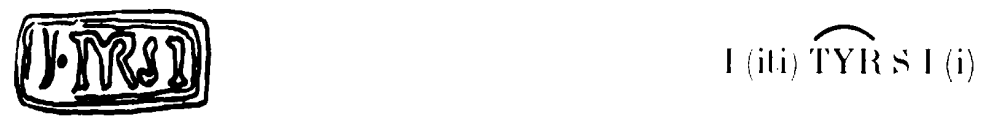

Marque du polier arrétin L. TITIVs TIIYKSIVS, dont l'époque semblerait se situer vers 10 avant J.-G. ${ }^{81}$. Elle est disposée au centre d'un fond de vase plat, dans un cadre rectangulaire orné d'un filet. Les lettres TYR sont liées. Celte estampille a été trouvée sous une forme identique a llaltern el sous des aspects différents au Mont-Beuvray a a Aulun ${ }^{84}$. saint-Bertrand-deComminges ${ }^{85}$. Trion. Mainz. Weisenau, Heddernheim, Veuss et Vechlen ${ }^{86}$. Roanne en a livré deux exemplaires ${ }^{87}$. (V. fig. $\left.8, n^{0} 2\right)$.

(73) C.I.L., XIII, 3c partie, 10009,132 a b.

(74) F. OiWal, et T. DAvils PRYCE, op. cil., $\mathrm{n}^{\circ} 27$, p. 188.

(7i) Caz rno, Terra sigillala, les rasos arelines y sus imilariones Galo-Romanas en Ampurias, dans Annuaire de l'Instilut d'eludes calalanes, $1909, \mathrm{p}$. 58.

(76) 1. (Oswa.r, op, cil., n. Z1.

(77) r.I.L., XIII, 10010, 1369.

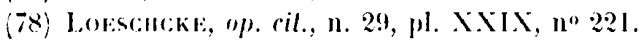

(79) C.I.L., XIII, $100099,255$.

(80) C.I.L., XV, 56.16.

(81) Renseignement de .I. .I. Labrousse.

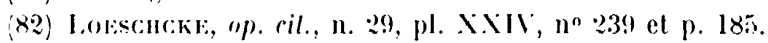

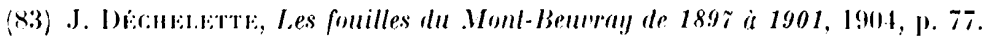

(81) Renseignement de .I. M. Labrousse.

(85) Renseignement de .I. M. Labrousse.

(86) (..I.L., . XIII, 100009, :273.

(87) J. Cisorss, op. cil., n. $x$ et J. Déchlitetre, op. cit., n. 6.4. 


\section{"W(Le)ISII)}

Celte estampille se trouve sur un petit fond de vase fragmenté. Elle est elle-mème incomplète ; seule la base des lettres est visible, avec ligature AX. Il s'agit sans doute de X.YTHYS, qui fut esclave d'Atéius ${ }^{88}$. Décheletle pense que les productions de X'anlhus sont caractéristiques de la période de transition entre la lin des productions des oflicines italiques et le début de celles du sud de la ciaule ${ }^{89}$.

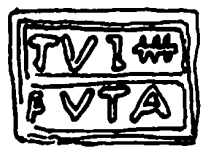

F V T $\mathrm{A} / \mathrm{T}$ VI (?)

Cetle estampille se présente dans un cadre rectangulaire. sur un fond interne de vase de forme indéterminée. La lettre $\mathrm{F}$, au début de la deuxième ligne, est douteuse. In motif se situe dans le prolongement de l'inscription de la premiere ligne : il semble donc qu'il faille inverser les deux lignes.

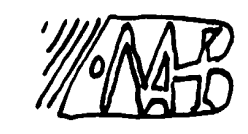

... $\widehat{\Pi \lambda} \ldots$

Fragment d'estampille sur un tesson appartenant is un vase de forme indéterminée. Peut-être C.M $\triangle \mathrm{R}^{90}$ ? Dans le cas ou le motif terminal appartiendrait exclusivement a l'encadrement ${ }^{91}$, nous serions en presence de l'estampiile de A. Mamn(eins).

\section{(aVIIII/ $\quad$ i ou $\mathrm{N} \ldots$}

Estampille sur fond de vase de forme indéterminée, probablement in planla pedis. Une seule lettre est visible, $\mathrm{I}$ ou $\mathrm{M}$.

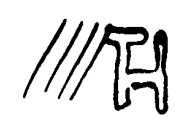

Xan $]$ T H $[\mathrm{i}]$ ?

Lstampille en relief à l'extérieur d'une lasse ansée d'origine arréline. Probablement Xanlhus ${ }^{92}$. (V. fig. $\left.5, \mathrm{n}^{0} 1\right)$.

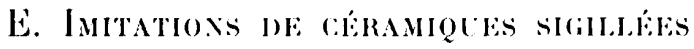

Nous avons attribue aux productions précoces de Lezoux le petit fond de vase portant une estampille ou, plus exactement, une imitation d'estampille ARA ${ }^{93}$. si co fragment mérite l'appellation de céramique sigillée, il en va différemment de rertaines imitations, dont quelques fragments ont été recueillis sur le site.

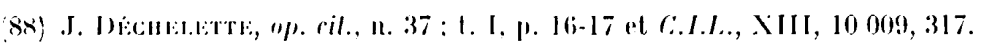

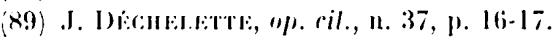

(90) (:.I.I.., XI, 372 h, $\mathrm{d}$.

(91) (:I.I.., XV, 2, p. 703, encadrement type jis.

(92) Renseignement de II. le professeur stenico.

(93) II. Virter, op. cil., n. 60. 

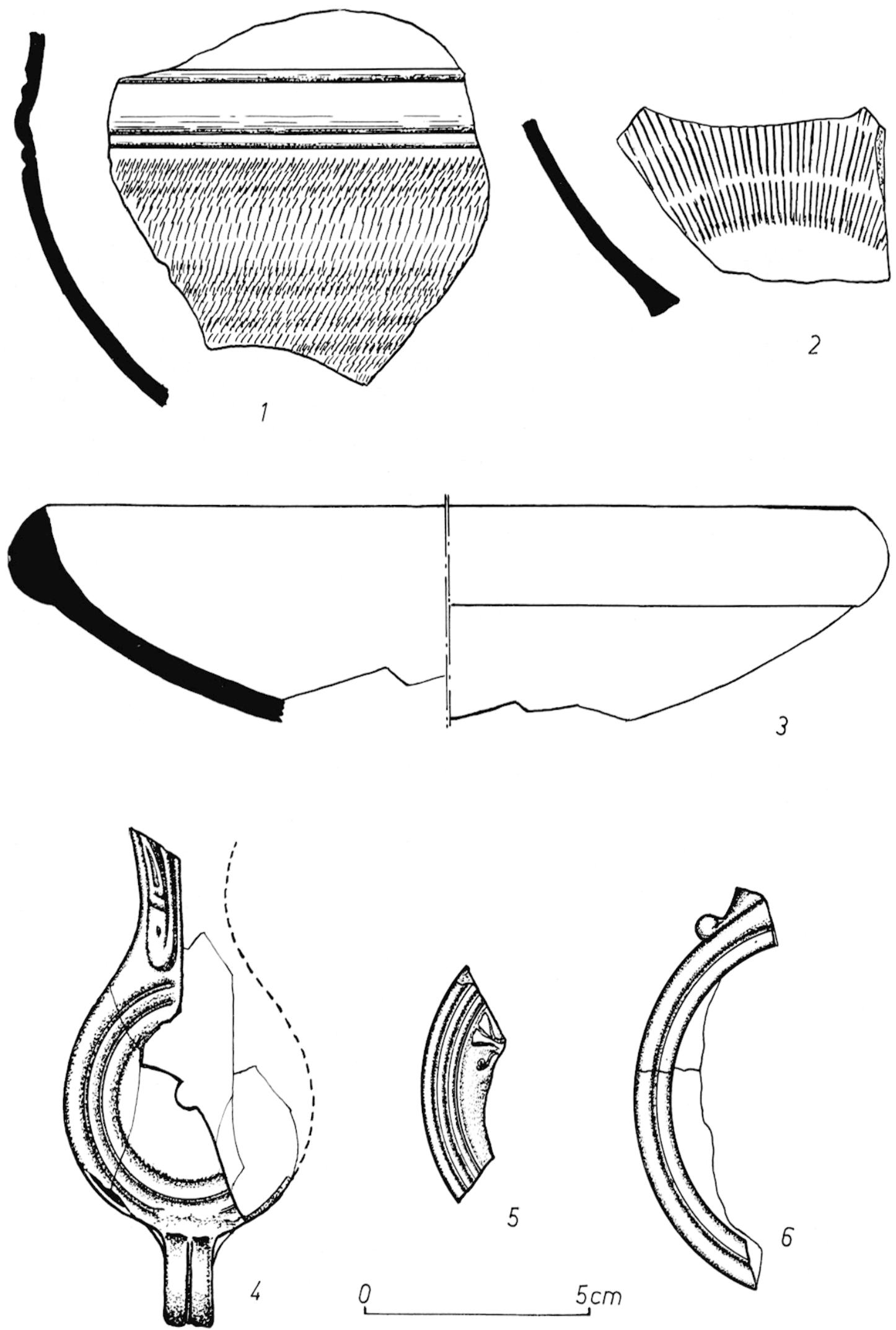

13. Nos 1 à 3 , imitations de céramique sigillée; nos 4 à 6 , lampes. 
Fig. 13. nos 1-2 : il s'agit. de deux fragments appartenant a deux vases différents mais dont la forme est une copie des vases caliciformes de type 11 Dragendorff. Le vernis est mat, dégradé. La pièce $n^{0}$ ? ne possédait pas de couleur sur toute la surface interne. où l'écru de la pâte reste visible, portant quelques traces de coulées rouges et de projections d'enduit. La pâte des deux fragments est grisâtre. Ln vase de cette catégorie a été trouvé à (iergovie ${ }^{94}$.

Fig. $13, n^{0} 3$ : frag̣ment de coupe dont le fond manque. La couverte rouge est dégradéc, la pàte est grossière el grisàtre. Ce fragment semble appartenir ì un vase exceptionnel.

Considérons attentivement les deux lots de céramiques provenant, l'un, d'Italie et l'autre, du Surl de la Gaule. Ce sont ces deux lots qui nous donnent la date de l'occupation du site en raison de leur densité par rapport à la quantité relativement peu élevée de céramiques de la (iaule centrale, que nous savons beaucoup plus tardive et trouvée dans des niveaux parfois différents. Ce fait n'est pas nouveau à Roanne, où I)échiclette avait déjà observé, dans la nécropole gallo-romaine de la rue Saint-Jean et au lieu-dit La Livatte ${ }^{95}$, la présence en petit nombre de céramiques du $\mathrm{II}^{\mathrm{e}}$ siècle après .J.-(:. Ionc, sans oublier que nous avons des éléments de datation antérieurs a l'apparition de la céramique sigillée, on peut inférer que, depuis une dizaine d'années avant notre ère, jusqu'aux environs de 7) après .J.-C., l'emplacement de la Nouvelle Poste a subi une occupation dense et que la population utilisait de la céramique d'importation.

Considérant plus particulièrement la série de vases d'origine italique, on constate le petit nombre de vases ornés recueillis relativement au nombre important de formes lisses de même origine. Ce fait a été observé par M. Nichel Labrousse à Saint-Bertrand-de Comminges ${ }^{96}$ et il semble que ce soit une règle générale en Gaule. Si, pour les vases originaires du Sud de la Gaule, on compare le nombre de vases ornés par rapport aux formes lisses de même origine, on constate une augmentation importante de la céramique ornée. les vases en provenance du Centre de la Gaule sont presque tous ornés.

\section{II. - LES LAMPES}

Les découvertes de lampes furent rares. I)'importants fragments permettant cependant la reconstitution l'une lampe dite "à tête d'oiseaux" ont été recueillis (fig. 13, no 4). Ce type est le plus ancien que nous ayons rencontré : sa présence a été signalée dans les ramps augustéens de Haltern ${ }^{97}$ et Oberaden. Il n'apparait plus dans le camp claudien de Ilofheim ${ }^{98}$. On a tendance à faire remonter la datation de cette lampe à la période républicaine ${ }^{99}$.

(91) Musée de cilermont-ferrand, dipòt des fouilles de Gerrovie.

(95) J. DÉ:CHEJETTE, op. ril., n. 6, p. 39.

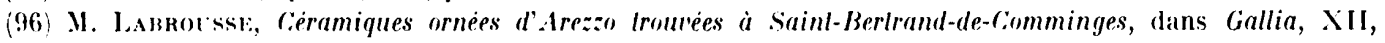
195. p. 301 et suiv.

(97) Josschckl, "p. cil., n. 29, p. 203, type 31.

(98) Ritrensixi, op. cil., n. 35.

(99) L. I.rat, Calalogue des collections archeologiques de Besanģon..., Les lampes anliques, dans .Innales de l' Lniversilè de Besançn, 1954, p. 5. 
Les fragments nos 5 et 6 (fig. 13) appartiennent au type qui a succédé à celui que nous venons de décrire. Il s'agit de lampes à volutes mais leur fragmentation est trop grande pour que nous puissions établir une détermination précise. Ce type de lampe a été utilisé depuis la période augustéenne.

\section{III. -.. OBJETS METALLIQUES}

\section{A. Brovze}

1. Monnaie (fig. 14). - Lne seule monnaie a été trouvée localisée dans la poche $\mathrm{G}$, qui a livré une série de céramiques un peu antérieures à la conquête ou contemporaines. $\mathrm{Au}$ droit, tête de style romain à droite, dans un cercle au pourtour; au revers, taureau à gauche. Au-dessus, (EERIANIS. Au-dessous, ININTILLI. I)'apres J.-B. Colbert de Beaulieu ${ }^{100}$, il s'agit d'une monnaie gauloise fortement romanisée, qui aurait été émise longtemps après la défaite d'Alésia.
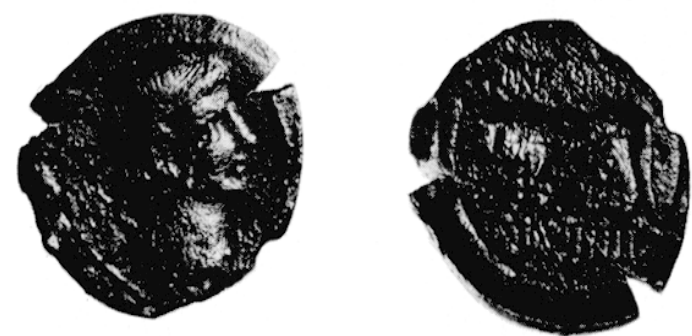

11. Monnaie, face et revers.

2. Fibules (fig. 15, nos 1 et 2 ). - I)eux fibules en bronze, incomplètes, ont été recueillies. No 1 : romposée de deux pièces soudées. L'are est une mince plaque de bronze ornée de trois rainures longiturlinales - l'une est médiane et les deux autres suivent la bordure de la pièce - et soudée sur la corde extéricure. Le ressort est à huit spires. L'ardillon manque. Nous relevons une fibule semblable à Iofheim101. On peut également la rapprocher du no 42:20 de Saint-Bertrand-de-Comminges ${ }^{102}$ ainsi que du $n^{0} 2441$ de Gergovie ${ }^{103}$. - No 2 : possède un ressort à quatre spires. L'extrémité de l'ardillon manque ainsi que la majeure partie de l'arc. La corde est extérieure, elle est retenue à l'are par une petite pièce soudér. Ces fibules sont de types courants en usage pendant le dernier siècle avant of le premier après J.-C.. ${ }^{104}$.

\section{B. FER}

A part quelques éléments informes, seule une remarquable lame de couteau mérite de retenir l'attention (ig. 15, no 3). Elle est longue de $0,170 \mathrm{~m}$. La section de la lame est triangulaire; celle de la soie est rectangulaire. La partie supérieure de l'outil est courbe.

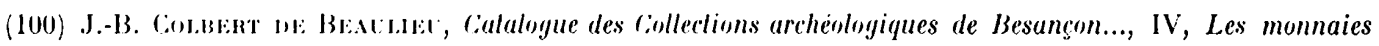
gauloises, 1959, p. 54, $n^{\circ \mathrm{s}} 164$ et 165 .

(101) Ritterdivi, op. cil., n. 35, p. 41, fig. 8.

(102) Robert Gavi:LLE, Nole sur les fibules gallo-romaines recueillies ì Jugdunum Convenarum (Saint-Bertrandde-Comminges, Ilaule-Grarmne), dans Celtirum, Acles du second Colloque inlernal. d'éludes ganloises, celtiques el protocelliques, 1962, p. 229 , figr. 9.

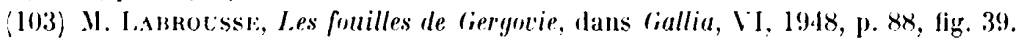

(104) Renseignement de .I. R. Joffroy. 

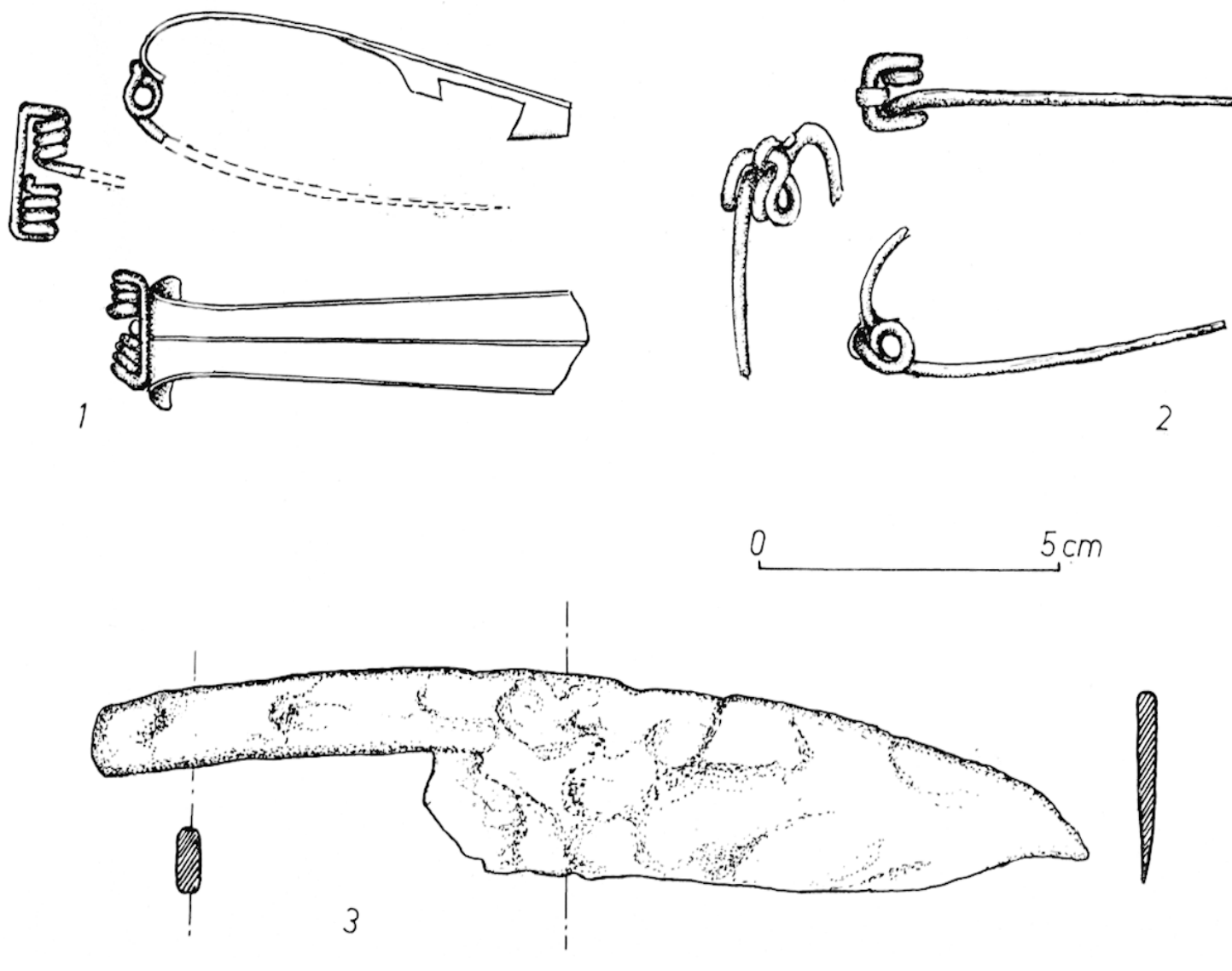

15. Ubjets métalliques.

Cette particularité se rencontre sur un certain nombre de lames, soit plus anciennes, soit contemporaines de la période gallo-romaine ${ }^{105}$. Nous ne savons pas s'il s'agit d'un usage ou d'une tradition.

\section{IV. . LES AMPHORES}

Ce matériel, qui se présente sous un aspect très fragmenté, est, compte tenu de l'ensemble de la céramique recueillie, relativement rare sur le site puisque l'examen des cols ne laisse apparaitre que douze modèles de formes différentes (fig. 16).

\section{Le's pâles}

Leur aspect permet de diviser ce lot en trois parties distinctes :

a) Imphores revètues d'un engobe:

No 1 : pàte rouge assez fine. très léger engobe blanc sur la face externe laissant apparaitre la couleur sous-jacente.

No 3 : pite ocre jaune, assez grossiire, engobée intérieurement et extérieurement en beige clair.

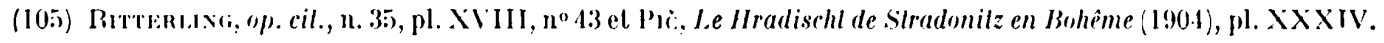


No 2 : pàte rouge grossière ì engobe blane rosé.

No 5) : pate rouge grossiere is engobe blanc.

No 4 : pàte semblable au $\mathrm{n}^{0}$ ).

vo 6 : pàte rose, fine, engobe blanc ocre.

b) Imphores non revêtues d'un engobe:

So 13) : paite légèrement rosée. surtout vers le corur, texture fine el homogène.

lo 7 : pàte beige rosé fine el compacte.

No 8 : pàte asse\% fine, rouge brique.

No 11 : paite line, rouge.

c) Amphores ì pâle blanche:

lo 9 : pâte blanche légèrement verdàtre, de texture très fine sans grains de dégraissant apparents.

No 10 : pàte très dure, blanche sur une épaisseur de 0,007 ì $0,010 \mathrm{~m}$ tandis que le coxur a gardé une teinte légèrement rosée.

No 12 : paite blanc gris, fine.

\section{Les formes}

Less amphoress à pâle de lype a ol b.

La présence ou l'absence de l'engobe ne semble pas constiluer un critère propre a sérier des formes différentes dans ce groupe car dans des formes semblables les deux types de présentation se trouvent souvent mêlés ${ }^{106}$. La plus grande partie de ce matériel possede des cols se rapprochant de la forme I)ressel 1, Lamboglia 107, Républicaine III. d'un type courant à l'époque C'ésar-Auguste ${ }^{108}$ et qui s'apparente aux amphores importées d'Italir ou de la Narbonnaise trouvées au Mont-Beuvray ${ }^{109}$. Il faut cependant remarquer que les levres sont toujours courtess (longueur moyenne de $0,05 \mathrm{~m}$ ). Les quelques fonds recucillis présentent un pied effilé, raccordé à la panse sans cassure et le point d'attache des anses est distant de la tranche inférieure de la levre (figr. $16, \mathrm{n}^{0} 3$ ) : il convient de rapprocher (e matériel des amphores d'Entremont et des sites gaulois antérieurs a la guerre des Gaules, donce, des types d'amphores Républicaine III A et A" de la classification de F. Benoit ${ }^{111}$ (Lamboglia : Dressel 1 A et A"). La plupart des rebords de lèvre se retrouvent dans les strates VI A2-VI Al d'Albintimilium ${ }^{112}$, soit pendant la période de 50 à 30 avant J.-(C., ainsi que dans le matériel de l'usine à gaz de Bâle ${ }^{113}$ (en particulier le col no 3 ).

Les amphores à pâle de lype c.

Dans cette catégorie qui ne représente que le quart de l'ensemble de ce matériel, nous distinguons deux lypes différents de cols, dont l'élat très fragmenté ne facilite pas la déter-

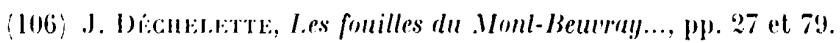

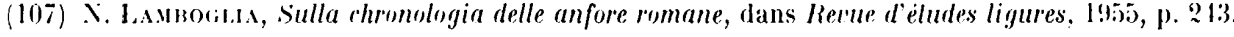

(108) F. Br:vort, Typulogie el épigraphie amphorique, dans Revue d'éludes ligures, 1957, p. 2633.

(109) J. J):cher.eTte, op. cil., n. 106, ibid.

(110) A ce propos, on rapprochera ce matériel de différentes trouvailles faites sur l'oppidum d'Essalois (Loire);

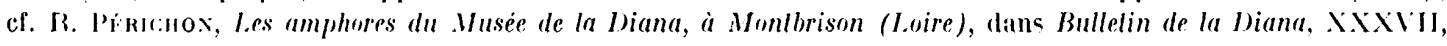
1961 .

(111) F. B1:NonT, "p. cil., n. 108, p. 263.

(112) N. I.AMBOtil. op. cil., n. 107, pp. 259 et 260.

113: 1: Mason, Gallische Ansiedeluag mit Gräberfeld bei Busel, n. 16, pl. IV. 
mination : le col no 9, à lèvre concave nettement détachée du goulot, diffère des amphores italiques, républicaines et semble appartenir à une amphore du type 7 de Lamboglia ${ }^{114}$ (Dressel 10), dont un exemplaire est signalé au Vont-Beuvray ${ }^{115}$; - le tesson $n^{0} 10$ provient d'une amphore à col évasé, que l'on peut apparenter à la forme 9 de Iressel, type 7 de Lamboglia.

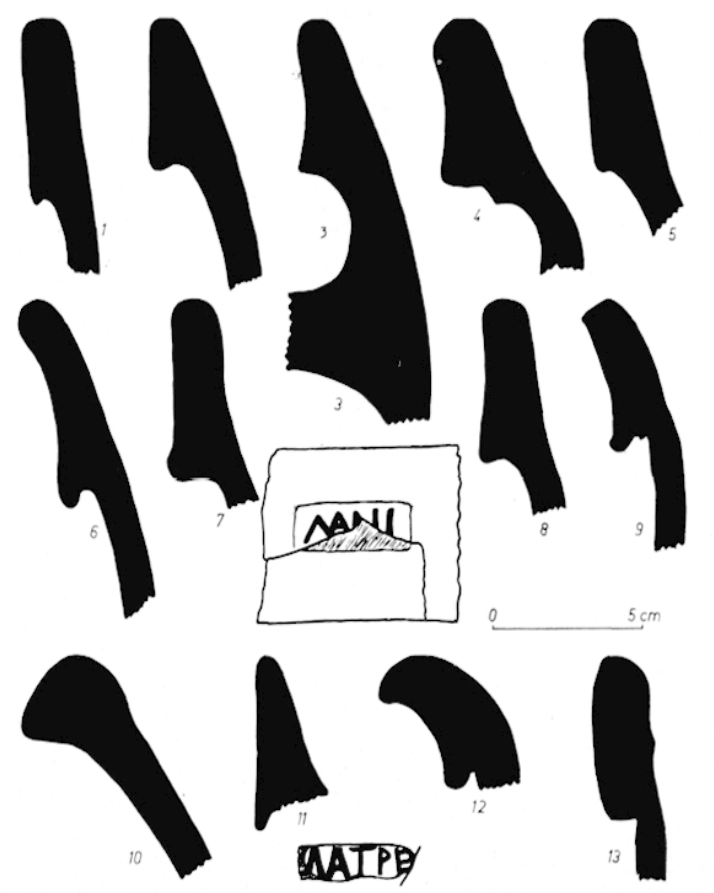

16. Amphores.

\section{Les marrues}

a) A mi-hauteur sur le col de l'amphore no 11 : MANI, le A étant formé dans le jambage du . II (fig. 16).

b) Sur le dessus de l'anse d'une amphore à pâte rouge à engobe blanc: VATP[E ?], la derniere lettre pouvant ètre un $\mathrm{E}$ ou un P (fig. 16).

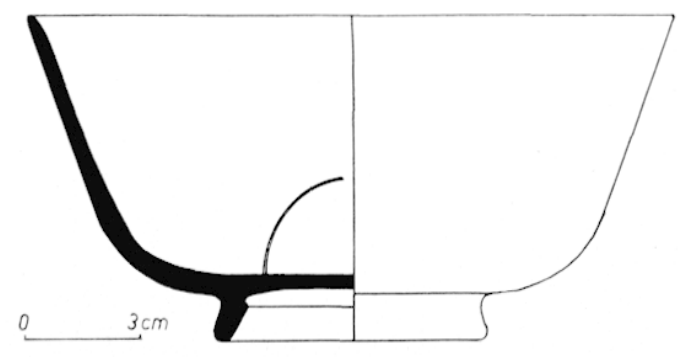

17. Imitation de céramiques campaniennes.

\section{V. - LA CERAMIQUE CAMPANIENNE}

Cous devons signaler plusicurs fragments d'un vase dont la facture laisse supposer une imitation plutôt qu'une production originale de céramique campanienne ( fig. 17). Sa forme est très proche de la coupe évasée (':21 du Grand Conglouén ${ }^{116}$, bien que sur notre vase le rebord de la lèvre ne soit pas ourlé. I)'après $\mathrm{F}$. Benoit, cette forme aurait constitué un prototype de céramique sigillée ( 29 I Jragendorff) du Sud de la (iaule ${ }^{117}$. La pâte est rosée et s'apparente à la pâte $\mathrm{B}$ des céramiques campaniennes ${ }^{118}$. Le vernis est brun foncé à l'intérieur du récipient mais la teinte extérieure, qui manque d'uniformilé, n'a reçu qu'un enduit partiel.

(114) F. Bexolt, op. cil., n. 108, p. 257.

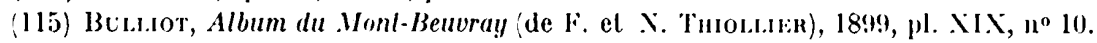

(116) F. B exort, L'épave du Grand Conglonè à Marseille, XIV'e suppl. à Gallia, 1961, pl. XII, fig. 3.

(117) F. Bwort, op. cit., n. 116, p. 94.

(118) N. LavBogin, Per une classificazime preliminare della ceramica campana, I. Comgresso internaz. di sludi liguri, 1952, p. 139 à 206. 

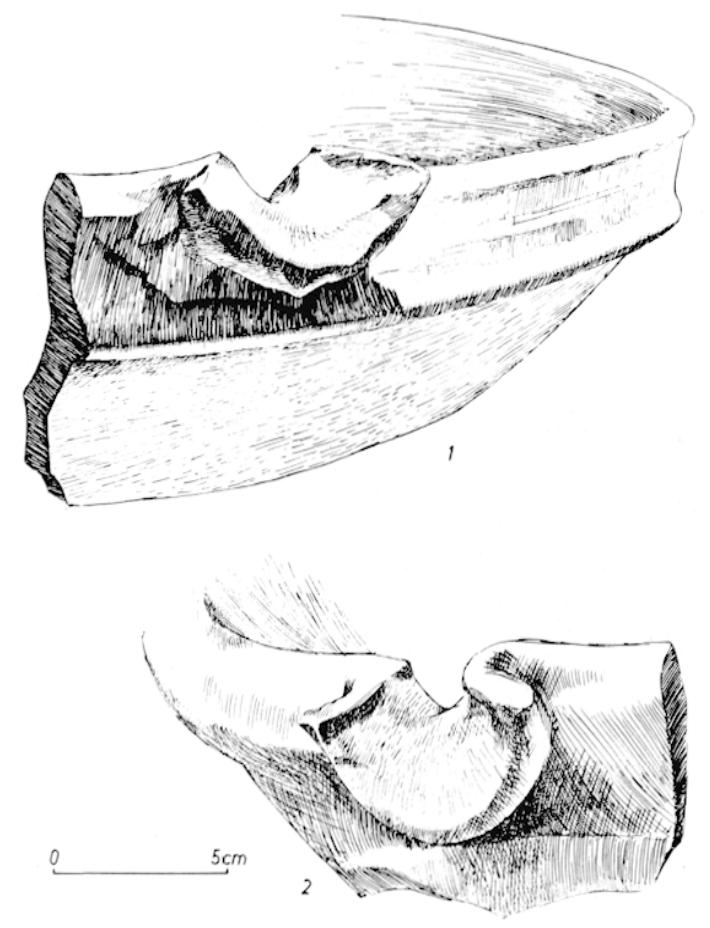

18. Mortiers.

\section{VI. -- LES MORTIERS}

Les mortiers sont très raressur ce chantier dont l'ensemble céramique ne laisse apparaître que deux tessons munis de leur bec (fig. 18, nos 1 et 2). Ils sont montés à l'aide d'une pâte fine et assez homogène, de couleur ocre tres 'lair ${ }^{119}$. Contrairement à l'habitude ${ }^{120}$. ils ne semblent pas disposer à l'intérieur d'un revêtement de quartz. La forme de leur col, dont le diametre est d'environ $0,035 \mathrm{~m}$, est plus sobre et moins moulurée que celle de l'ensemble des mortiers de la période gallo-romaine du $i^{\text {er }}$ au me $^{\mathrm{e}}$ siecles ${ }^{121}$. On peut néanmoins les apparenter aux mortiers de la période Claudr-I)omitien ${ }^{122}$. Le bec 123, à lèvre épaisse et retombante, est monté d'une manière grossière et irrégulière, qui contraste avec le fini de l'ensemble du récipient.

\section{VII. - LA CERAMIQUE PEINTE}

La céramique peinte est abondante et variée. Cette abondance permet d'envisager l'évolution de sa production entre la fin de l'Indépendance et le $\mathrm{I}^{\mathrm{er}}$ siècle de notre ère. Elle se présente sous des aspects très divers. Certains vases semblent importés, d'autres sont des productions locales ou régionales. Nous analyserons chaque type séparément et, pour rhacun d'entre eux. nous préciserons son ornementation. Ce procédé permet de ronstater l'civolution de cette ornementation et d'étahlir ainsi une chronologie, pour le moment relative, de l'ensemble de ces vases que l'on peut diviser en quatre groupes distincts : le premier comprendl les formes tronconiques ou ovoïdes; le deuxième, les gobolets ; le troisième est constitué par les jattes carénées; le quatrième comprend la grande masse de vases en forme de bol que nous considérons comme une production locale et que nous appelons "vases de type Roanne".

(119) Ce tape de pate, que l'on peut comparer à celui de certaines amphores, n'est pas habituel dans la coramique de ce site.

(120) II. Laвno1-ssi:, Les fouilles de Gergocie (1945-1946), dans Gallia, VI, 1994, p. 82. I.I, 19.19 .

121 J.-J. HATT, Apercu sur lévolulion de la ceramique commune gallo-rrimaine, dans Rerue des éludes anriennes,

(122) J.-J. H.TT, ilid., pl. X, no 17 .

(123) I.e col et te bec de nos mortiers sont tris comparables ia ceux trouvis sur le site de ciambodunum el dissis

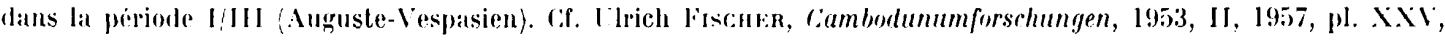
$n^{\circ} 1$. 

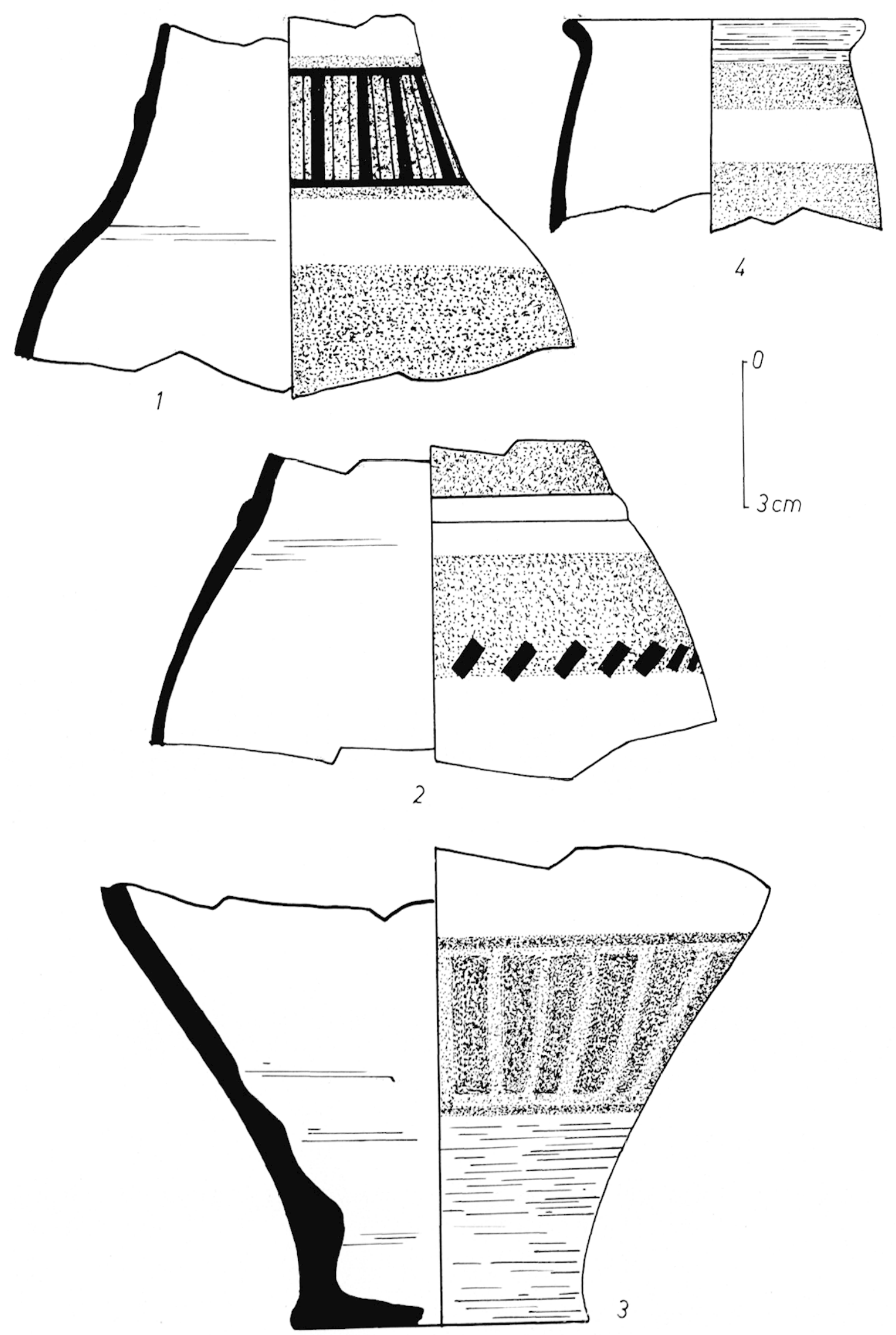

19. Céramiques peintes de forme haute. 


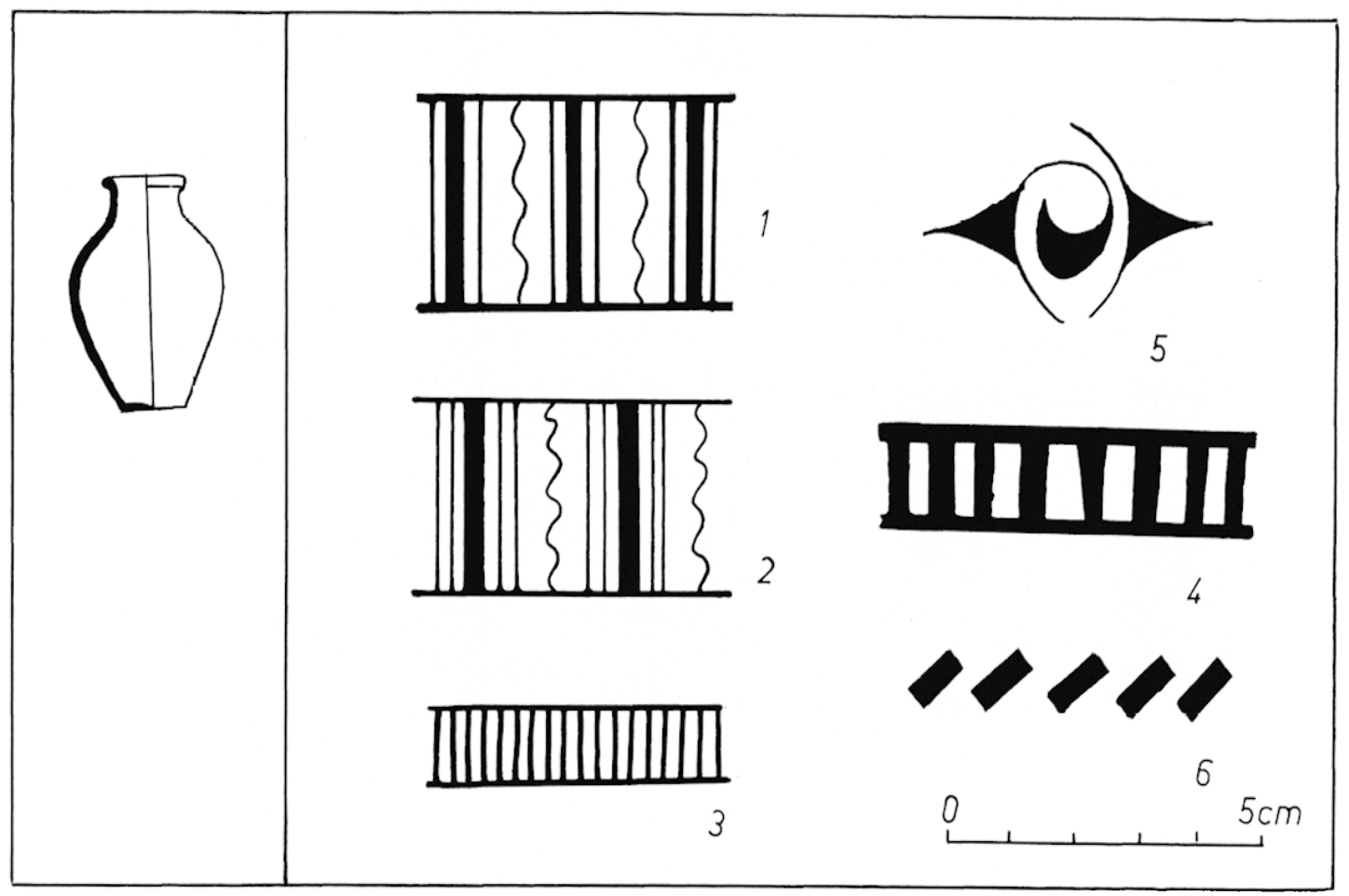

20. Motifs giométriques peints sur vases de forme haute.

Io Vases tronconiques ou noroïdes (fig. 19, nos 1, 2, 3).

Leur forme est variable. Ils ont généralement une panse ovoüde prolongée par un pied et un col étroits. Le col est parfois relié à la panse par un angle vif. Les épaisseurs des parois sont de l'ordre de 0,0046 m et varient de quelques dixièmes. La pâte est marron foncé, relativement chargée en oxyde de fer si on la compare à celle des vases du quatrième groupe. De plus, assez peu travaillée, elle montre à la cassure des dégraissants grossiers ainsi que des particules de mica.

L'ornementation est composée de larges bandes horizontales rouges et blanches alternées. Des motifs géométriques peints en surcharge sont encore visibles sur les bandes rouges. Les thèmes sont assez simples. Nous avons relevé : des traits verticaux parallèles fins, épais ou ondés, disposés dans un ordre précis, limités en haut et en bas par une ligne horizontale (fig. 20, motifs 1 et 2 ) ; des traits verticaux réguliers qui, limités par deux lignes parallèles, déterminent une sorte de motif fin en "échelle" (fig. 20, motif 3) ou grossier (fig. 20, motif 4) ; une volute arcompagnée de motifs triangulaires pleins (fig. 20, motif 5) ; des rectangles pleins, penchés à droite et parallèles (fig. 20, motif 6).

Ce type de vase, par sa forme et son ornementation, se rattache aux formes de céramiques peintes de la période de l'Indépendance, dont différents sites ont livé de nombreux exemplaires : le Mont-Beuvrạ ${ }^{124}$, l'usine à gaz de Bâle ${ }^{125}$, Aulnat-Sud, près de Clermont- 

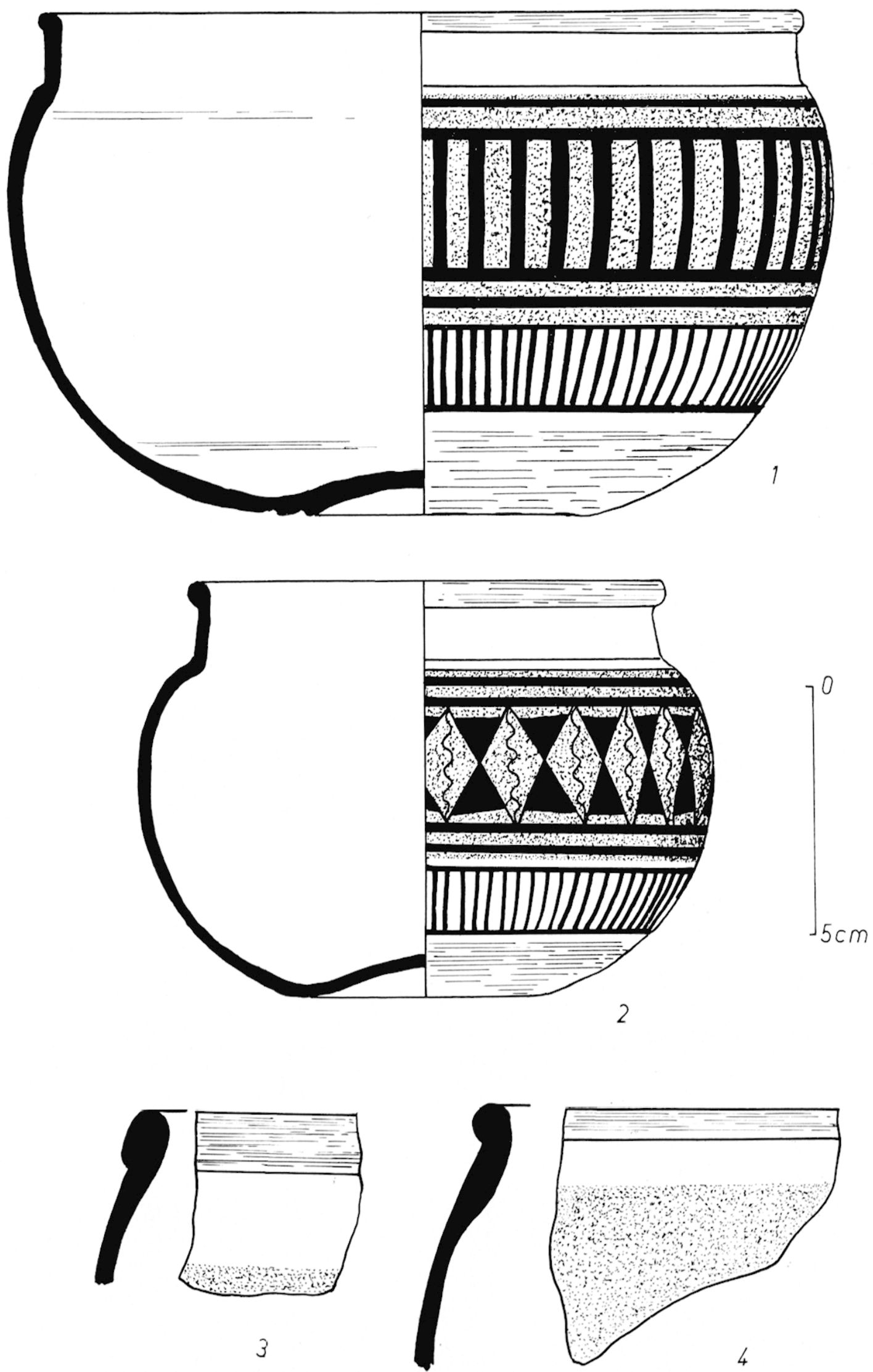

21. Céramiques peintes : nos 1 et 2 , jattes; nos 3 et 1 , fragments de bols, type Roanne de transition. 
Ferrand ${ }^{126}$, l'oppidum de Manchingre ${ }^{127}$, le T'errail, à Amplepuis (Rhòne) ${ }^{128}$, le Crêt-Châtelard, à Saint-Varcel-de-Féline (Loire) ${ }^{129}$. On ne peut éviter de prolonger la comparaison jusqu'aux céramiques peintes de la .1 arne $e^{130}$, dont ces vases sont des descendants dégénérés. La proportion des vases de ce type par rapport à l'ensemble de la céramique peinte de la Nouvelle Poste est faible: quelques fragments contre des milliers de tessons du quatrième groupe.

I Io Vase preinl en forme de gobelet (fig. 19, no 4).

ln seul fragment appartenant à ce type de vase a été trouvé. Sa fabrication semble plus soignée que celle des vases du groupe 1, la pâte mieux dégraissée et mieux cuite apparaît d'un jaune-rose clair; quelques traces de mica se distinguent en surface et dans la texture. L'ornementation est composée de bandes horizontales rouges et blanches alternées. Aucun motif n'est visible en surcharge.

III Jalles carénées (fig. 21, no 1 et 2 ).

Ce type de vase en forme de sphère aplatie à la base est muni d'un col à peu près cylindrique. Le raccordement du col et de la panse est à angle vif. La jatte $\mathrm{n}^{0} 1$ mesure $0,09: 3 \mathrm{~m}$ de hauteur environ, son diamètre maximum est de $0,168 \mathrm{~m}$. Le $\mathrm{n}^{0} 2$ mesure approximativement 0,086 $\mathrm{m}$ de hauteur et possède un diamètre de $0,136 \mathrm{~m}$. Ces vases présentent à la cassure une pâte marron foncé, chargée en oxyde de fer, peu travaillée et grenue; de gros grains de quartz utilisés comme dégraissants sont visibles ${ }^{131}$.

Ces jattes carénées sont habillées d'une large bande d'ocre rouge limitée au col et à la base par une bande l'engobe blanc. Lne décoration composée de motifs géométriques en surcharge orne rertaines parties colorées des récipients. Sur ces deux vases, la bande inféricure blanche est ornée, en brun, d'un motif composé de traits horizontaux espacés et reliés par des petits traits parallèles réguliers formant un motif "en échelle ». La jatte no 1 possède un grand motif "en échelle " composé de traits épais (fig. 22), nº 2 ), disposé sur la partie de la panse colorée en rouge. La large bande rouge de la jatte no 2 est ornée de bandes parallèles, disposées par deux, près des bords inférieurs et supérieurs de la coloration. Entre ces handes, on distingue un motif en forme d'X dont les angles opposés, dans le sens vertical, ont été garnis de peinture brune. Une ligne ondée verticale sépare chacun des motifs en X. Le col et la hase des vases ne sont pas peints.

Nous avons présenté, sur la même figure 21 nos 3 et 4 , deux tessons dont la parenté avec les vases carénés réside dans le fait que leur ornementation est composée d'une large

(126) J.-J. HATt, Essai d'une comparaison entre la céramique cellique d'Aulnal-Sud el la céramique gallr-romaine précoce de fiergmie, dans le Bullelin historique el scienlifique de l'Auvergne, I.XV, 1945, p. 169, fig. XV, nos 1, 2, 3 et i) i 11 .

(127) V. Manir, Zur hemallen Spällatènekeramik aus dem Oppidum von Manching, dans Neue fiunde ans dem Oppidum von Manching, Germania, 39, 1961, p. 299-383, v. p. 364, nos 1 et 6 .

(12x) R. PÉncios, Apercu sur le sile du Terrail, à Amplepuis (Rhìne), dans Ogam, XIV, 1962, pl. XXVII, $n^{\circ} 6,7$ et $x$.

129) Collections du . Vusée de la Diana, à Montbrison (Loire), fouilles de $\mathrm{V}$. I)urand et A. Chaverondier.

(130) J. Dichlistre, Manuel, Second Age du Fer ou époque de la Tène, fig. 660 et 661.

(131) J. Canots: et R. Piricnox, Observalions sur quelques jalles carénees peinles decouverles en torez, dans Cellicum $I V, 1953$. 
bande d'ocre rouge limitée par une bande blanche étroite. Par la forme, ces tessons s'apparenteraient plutôt aux vases du quatrième groupe qui comporte exclusivement des bols "type Roanne". Dans une étude antérieure, nous avons émis l'idée que les jattes carénées pouvaient être à l'origine des vases de "type Roanne". Il est possible que nous soyons en présence de fragments appartenant à des vases de transition, qui prolongent le mode d'ornementation des jattes sur des formes plus évoluées. Aucun motif brun peint en surcharge n'est visible sur ces tessons. Il n'est cependant pas exclu qu'ils aient possédé une ornementation géométrique.

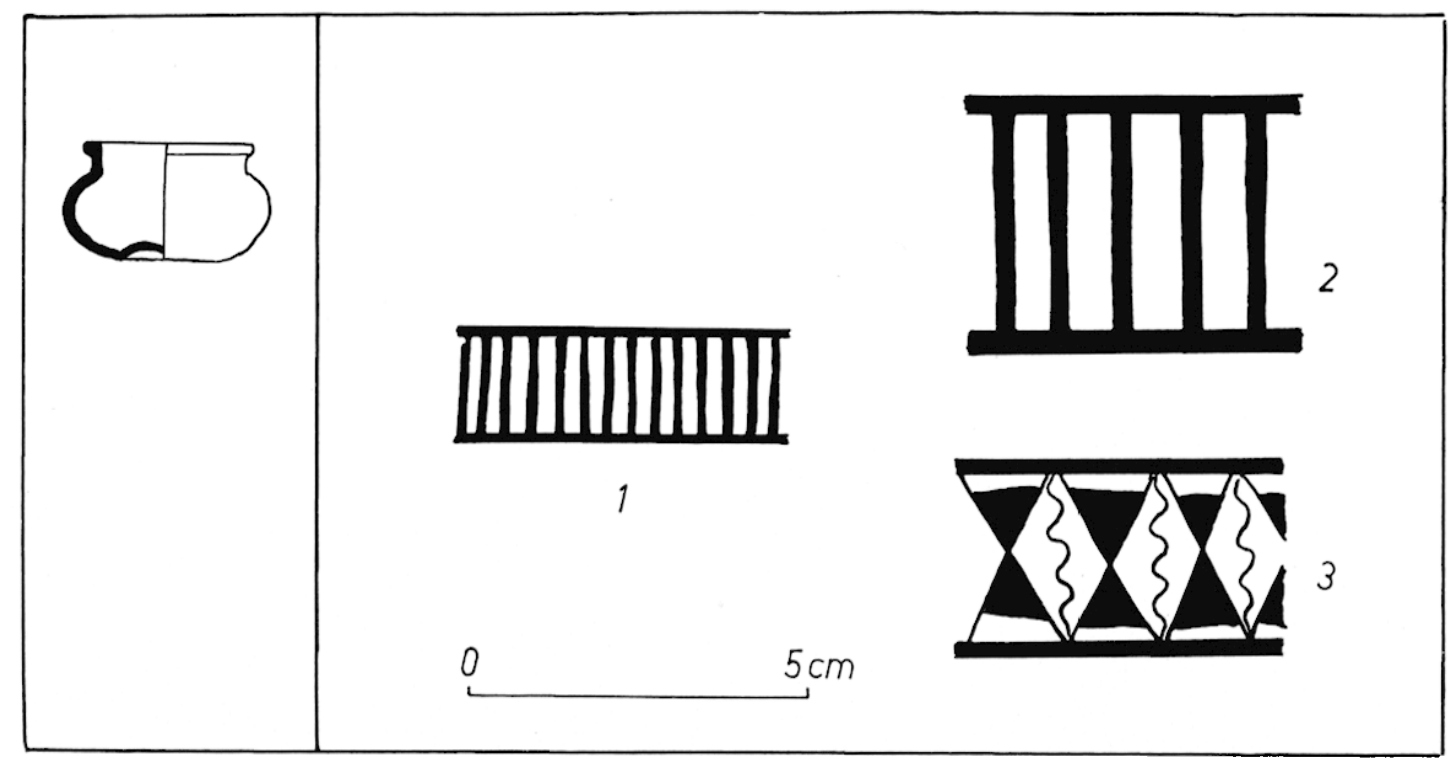

22. Motil's géométriques peints sur jalles.

IVo Bols de "lype Roanne" (fig. 23).

Il s'agit de vases globulaires de dimensions très variables ${ }^{132}$ mais dont les formes sont constantes. Les seuls éléments variables de la forme résident dans le diamètre de l'ouverture du col - comparer les vases $n^{0}$ 2 2 et 3 de la fig. 23. Le fond accuse une concavité assez marquée. Le rebord du col comporte une lèvre formant un bourrelet à l'extérieur. La pâte est fine, très épurée, à basse teneur en fer ${ }^{133}$ et apparaît de couleur beige rosé. Elle est peu dégraissée par du quartz en grains, dont certains éléments sont visibles dans les cassures.

Le décor est composé d'une large bande blanche disposée sur la partie la plus renflée de la panse. Cette bande est limitée, près du col et à quelques centimètres du fond, par deux bandes étroites d'ocre rouge. Ces vases ont subi un polissage très soigné, après cuisson. L'ornementation est composée de motifs géométriques peints en surcharge, exclusivement

(132) Le plus grand diamètre relevé sur la panse est de $\varnothing 0,250 \mathrm{~m}$ environ et le plus petit de $\varnothing 0,095$.

(133) J. CAвотSE, Introduclion à l'élude des vases peints de "Type Roanne ", dans Revue archéologique du Cientre, 1962 , p. 246 et suiv. 

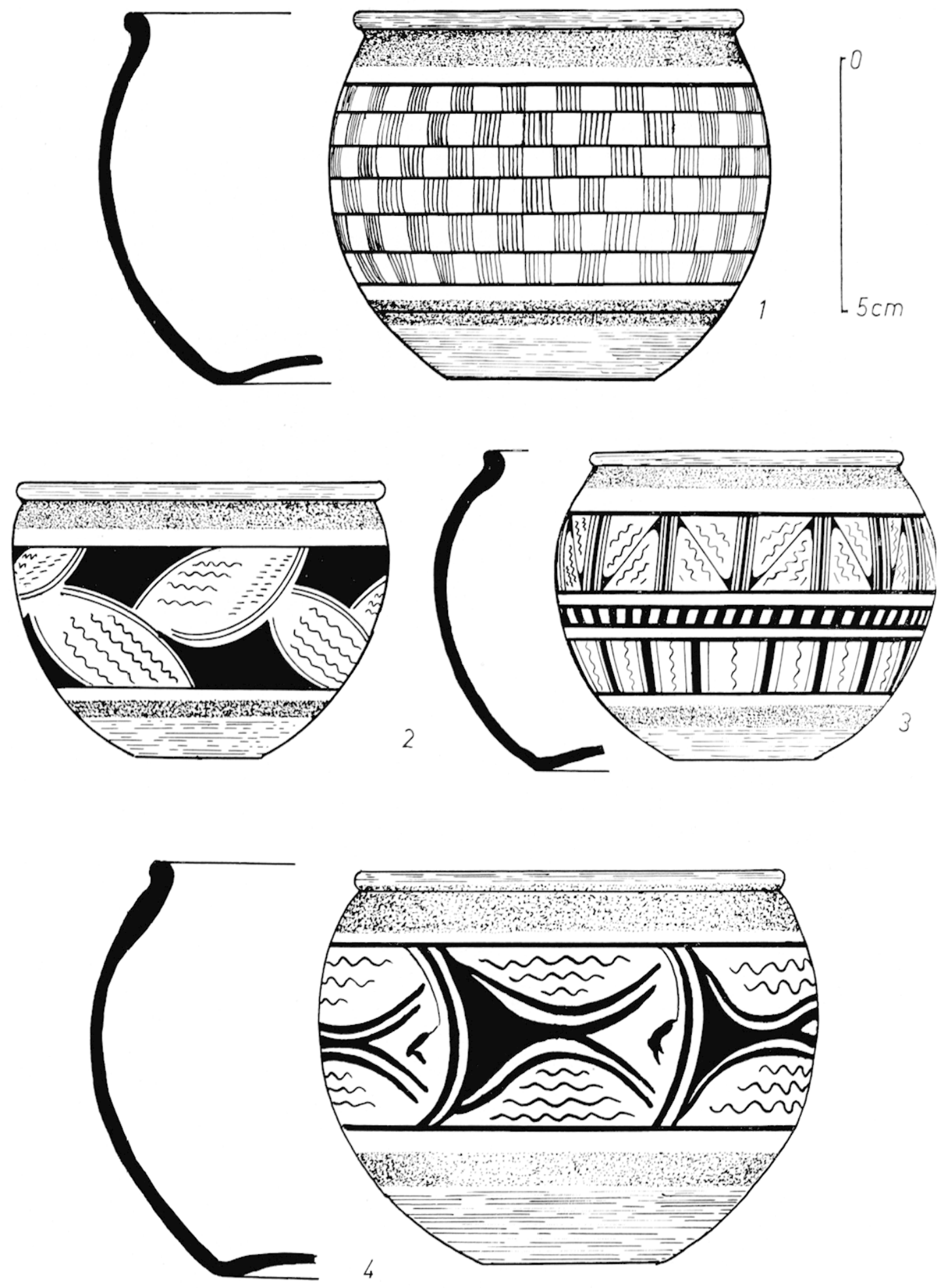

23. Ceramiques peintes : hols "type Roanne". 


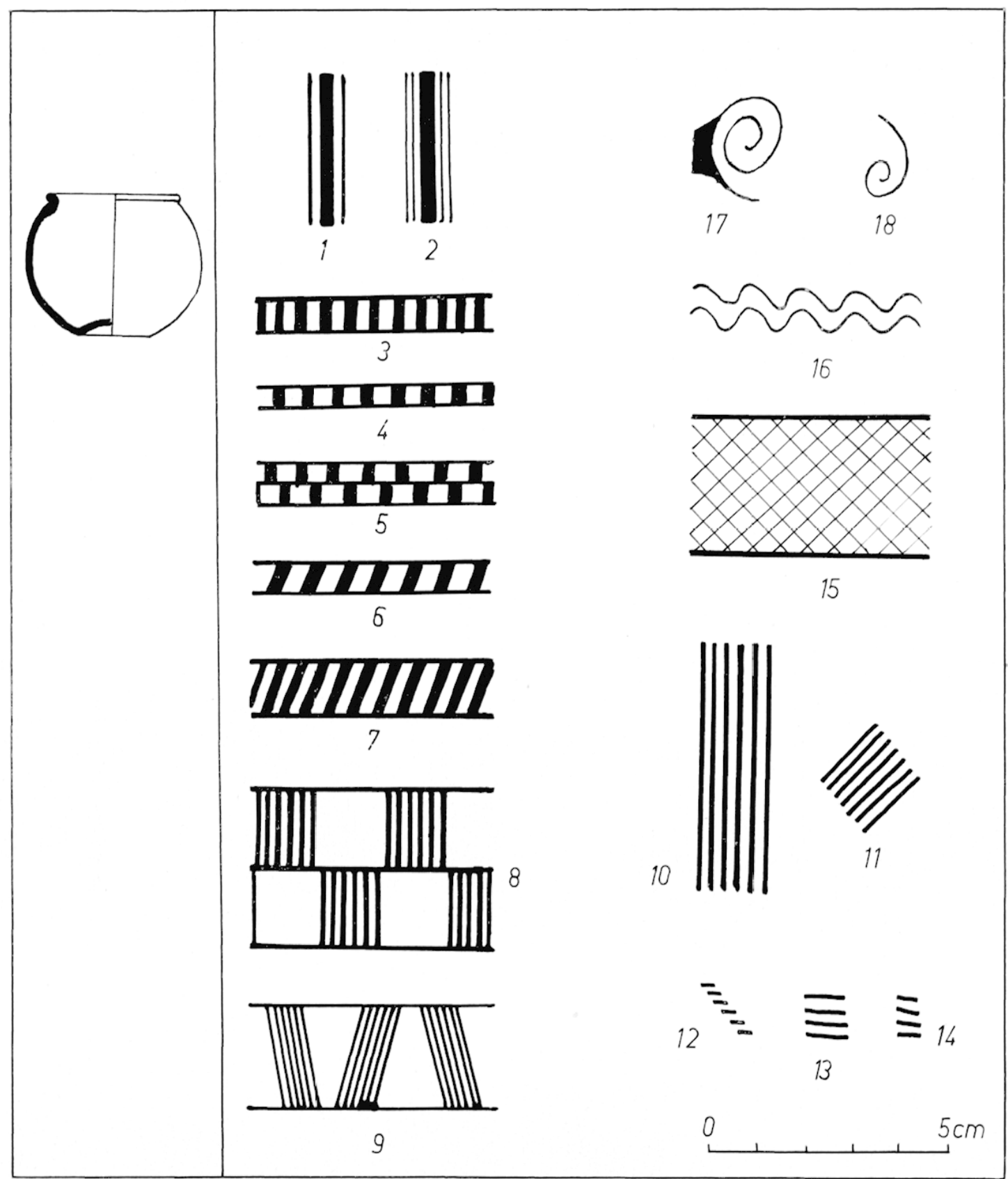

24. Motifs gómetriques peints sur bols "lype Roanne".

sur la partie engobée de blanc. Seule la bande rouge inférieure s'orne parfois d'un mince filet médian. La peinture utilisée est un colorant à base de jus végétal ${ }^{134}$.

Nous avons classé ces motifs en trois catégories :

a) Les motifs linéaires: la gamme en est étendue. On relève, de mème que sur les vases tronconiques du groupe 1 , des traits verticaux parallèles, fins et épais (fig. $24, n^{\text {os }} 1$ et 2 ) ainsi que loute une

(134) J. Ciaborse, op. cil., n. 133, p. 247. 


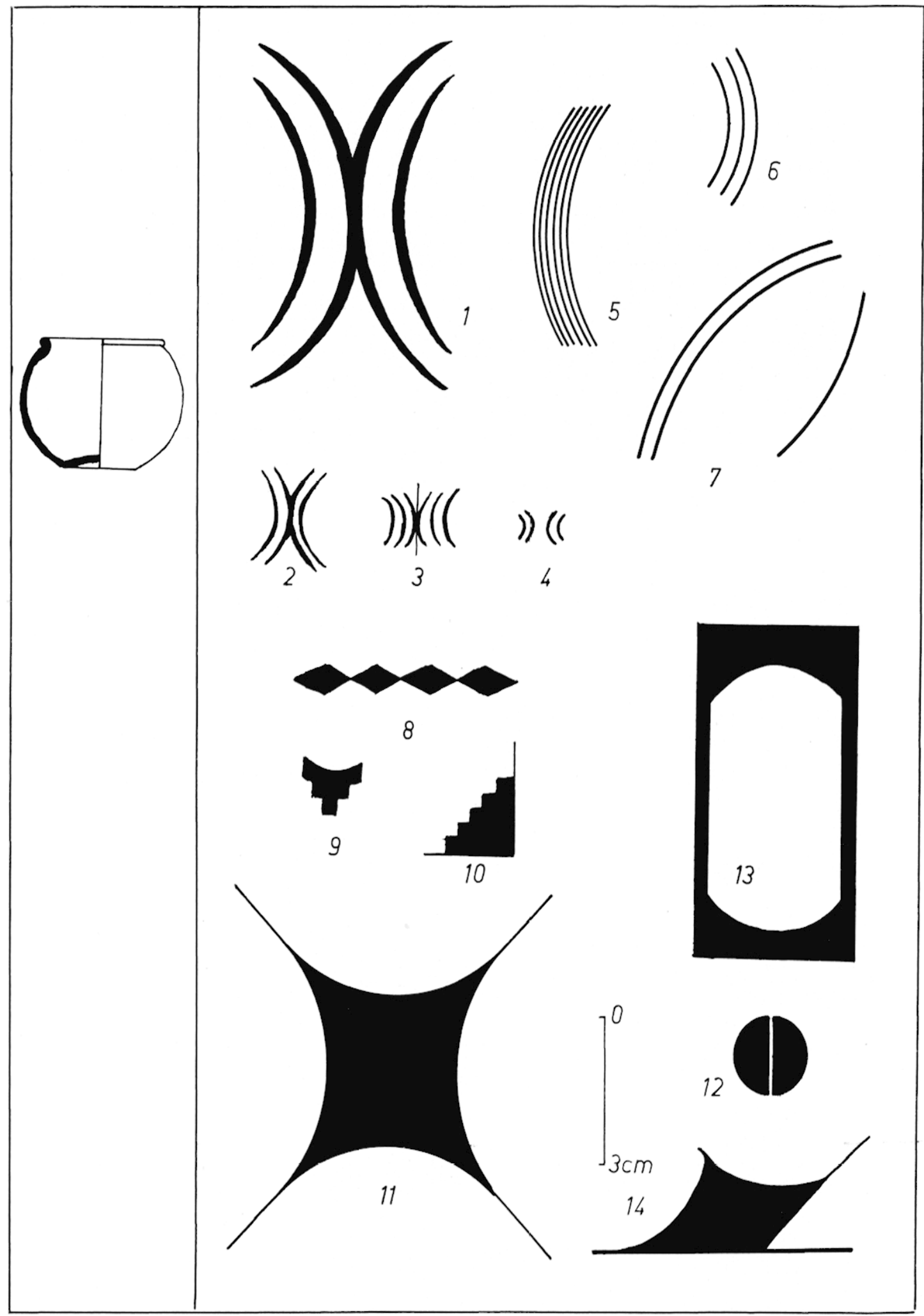

25. Notifs géométriques peints sur bols "type Roanne". 
série de lignes minces horizontales reliées entre elles par des traits généralement réguliers, fins ou épais, parfois disposés obliquement, parfois groupés par cinq ou six (fig. 24, nos 3) à 9). Des groupes de traits parallẹles isolés sont observés sur différents vases (figr. 24, nos 10 a 14). I ne sorte de grille losangrée est déterminée par de fins traits obliques s'entrecroisant (fig. 24, no 15)). Les liọnes ondées (figr. 24, $n^{0} 16$ ) sont utilisées dans de nombreuses combinaisons (voir fig. 23, les vases nos 2.3 et 4).

Plus rares sont les molifs en forme de volutes ou de spires (fig. 24, nos 17 et 18). Par contre, nous devons noter la fréquence de molifs linéaires courbes déterminant des ares (figr. 25), nos 1 ia 7 ). Certains de res arcs, accolés, sont exécutés avec un effet de pleins et de déliés (figr. 25), nos 1 ia 3 ). Lorsque ces courbes sont parallịles ou déterminent des segments de cercles concentriq̧ues. le trait est généralement fin et régulier

b) Les motifs géométriques pleins: ils sont de plusieurs sortes, soit qu'ils représentent un molif ornemental (fig. 25), nos 8 à 12), soit qu'il s'agisse d'espaces peints, déterminés par des droites ou des courbes et ne se rattachant i aucune forme ornementale classique (fig. 25) nos 13 et 14). La première série comporte des losanges (fig. 25), no 8 ). des pyramides ì degrés (fig. 25), nos 9 et 10), des motifs " cruciformes" (fig. 25). no 11), des demi-sphères (fig. 25. no 12).

c) Les remplissages d'angles: celte désignation correspond ì un procédé qui consiste ì garnir de peinture l'angle formé par deux lignes droites ou courbes. La figure 26 illustre cette technique. En plus des comparaisons que l'on peut effectuer entre chaque groupe de vases nous montrant des types netlement différenciés, une confrontation des motifs relevés sur les vases de chacun des

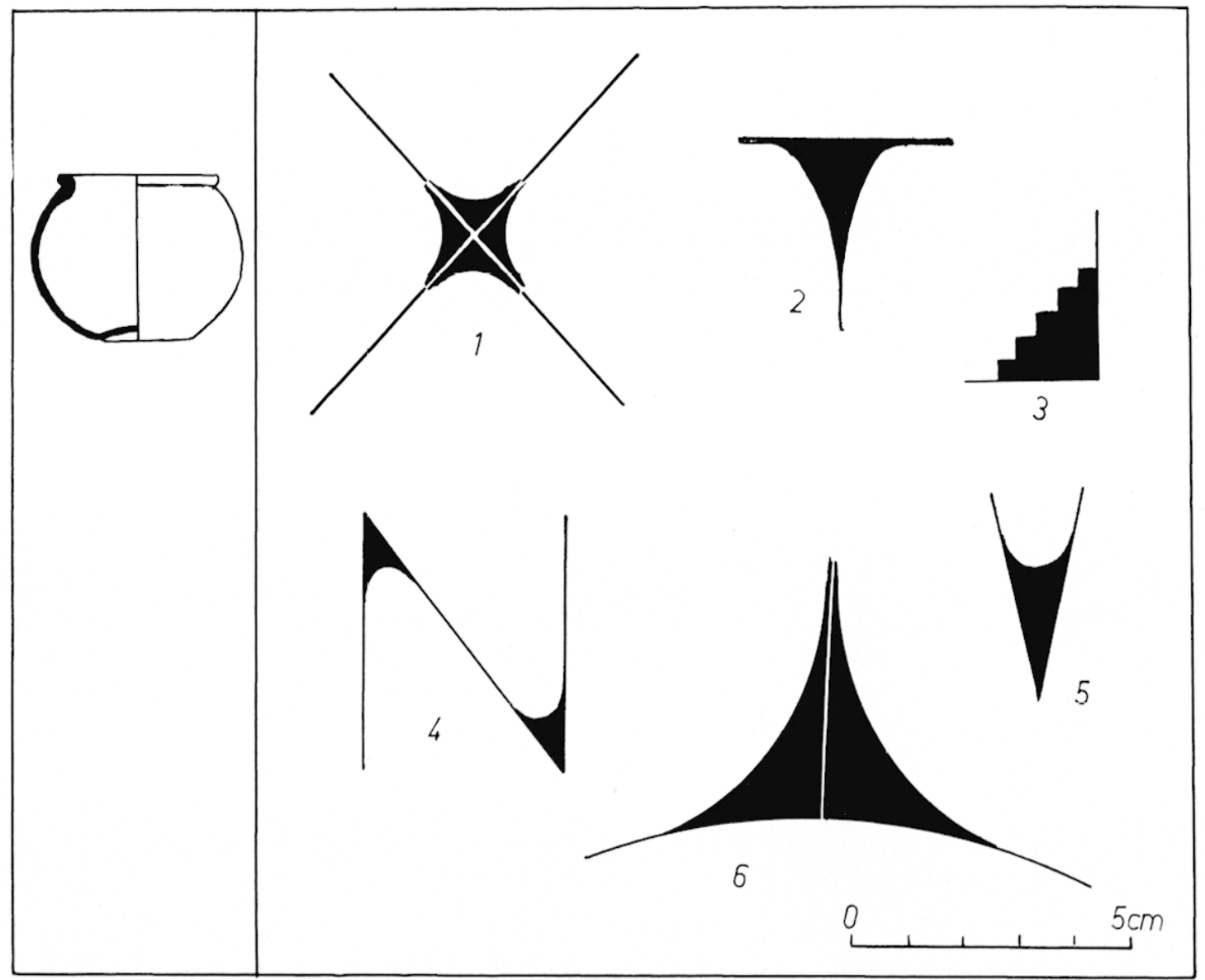

26. Motifs géométriques peints sur bols "lype Roanne". 
groupes s'impose. Il en ressort qu'un certain nombre de motifs de notre quatrième groupe se rencontre sur des vases des groupes 1 et III. Par exemple, les motifs nos 1.2 et 5, de notre ler groupe (fig. 19), qui subsistent sur des vases de notre IVe groupe (fig. 23), molifs 1, 2, 7 et 8 . Le motif dit "en échelle » de notre premier groupe (fig. 19) se retrouve sur les vases des IIe et IVe groupes (fig. 19, no 4 et figr. 23) ; sur ce dernier, son aspect est différent, sa facture plus soignée.

Il apparaît que les motifs en forme d'arc ainsi que certains motifs pleins ne se rencontrent que sur des vases du quatrième groupe, de même que les remplissages d'angles.

Au point de vue de l'ornementation générale, il apparaît également de façon évidente que la coloration a subi une transformation importante puisque la peinture géométrique brune qui, sur les vases appartenant aux types qui nous semblent les plus anciens, était. appliquée fréquemment sur des fonds rouges, se rencontre presque exclusivement sur fond blanc sur les vases de "type Roanne». Il semblerait cependant qu'une certaine contemporanéité existe entre les vases des quatre groupes mais les types de transition sont abandonnés pour le bol de "type Roanne", sur lequel nous voyons apparaître de nouveaux procédés de décoration ainsi qu'une floraison de motifs et thèmes ornementaux.

\section{VII. - L LA CERAMIQUE COMMUNE}

Nous entendons par ce terme l'ensemble de la poterie trouvée sur le site, à l'exclusion de la céramique sigillée, des amphores et des vases peints. Nous avons adopté pour les poteries ne possédant ni engobe, ni couverte, un classement fondé sur les définitions techniques des pâtes ${ }^{135}$, en divisant celles-ci en deux catégories : les pâtes cuites à feu réducteur, caractérisées par une coloration allant du gris au noir (céramiques carbonifères); les pâtes cuites à feu oxydant, caractérisées par des colorations ocres ou rouges (céramiques oxydées). Dans chacune de ces catégories, nous avons considéré la nature des pâtés en distinguant les pâtes fines et les pâtes grossières.

a) La céramique fine ardoisée: cuite à feu réducteur et dont la pâte, de teinte gris clair, est recouverte d'un lustre de couleur gris ardoise. La majeure partic des céramiques de ce groupe est composée d'une série très définie de plats et d'assiettes, qui ne se retrouvent dans aucun autre type. Ce matériel, de tradition celtique, est encore important dans cette zone $^{136}$ alors que, dans des sites plus récents, il a totalement disparu ${ }^{137}$. (Fig. 27. 28, 29).

Io Plals et assieltes: A) Les pièces de ce type sont constiluées par des séries de plats et d'assieltes a fond plat aux formes pures, toujours exemptes de décoration. Les rebords aux lignes arrondies et aux parois obliques ne présentent pas de moulures (fig. 27 nos 1 a 9), sauf les plats creux dont les rebords amincis sont renforcés à leur sommet par un bourrelet circulaire retombant à l'extérieur (fig. $27, \mathrm{n}^{0 \mathrm{~s}} 10$ et 11). Dans ce dernier type, il convient de noter quelques rares exem-

(135) J. Cabors:, Essai de classificalion de la céramique "commune" gallo-romaine de la "Vinvelle Posle ", Roanne, dans Cellicum $I I I, 1961$.

(136) ce type de rebord se retrouve aussi bien à Aulnat-Sud qu’à Gergovie. C.f. J.-J. Hatr, op. cil., n. 126, p. 159.

(137) Nous citerons en comparaison le chantier de fouilles de "Roanne-cadore ", situé à quelques centaines de metres de la Nouvelle Poste et dont le matíriel, datant de la période claude-Neron, ne comporte pas ce type de ceraminue. 
plaires dont le fond est orné sur sa face externe de spires hélicoïdales exécutées au peigne. Ces plats présentent un fond rectiligne portant sur toute la surface ou reposant sur un pied circulaire ${ }^{138}$ (fig. 27, nos 12 a 15). Parmi ces fonds à pied, nous remarquons l'existence de "plateaux" constitués uniquement d'un disque circulaire monté sur bourrelet; ces plateaux ont été soit obtenus par moulage d'un plat privé de son rebord (fig. 27, $\mathrm{n}^{0} 14$ ), soit fabriqués spécialement. sur un exemplaire de ce dernier type, nous observons la présence d'un graffite (fig. $27, \mathrm{n}^{0} 15$ et au-dessous).

B) Il existe. bien qu'en moindre quantité, plusieurs exemplaires de coupes à fond conique. Certains rebords de ces coupes s'apparentent a ceux du lype précédent (fig. 28, nos 4 et 5) mais la plupart sont beaucoup plus arrondis ì leur sommet et s'infléchissent sur l'intérieur du vase (fig. 28, nos 2 et 3). Dans cette dernière forme de coupe, nous relevons parfois sur la face interne un décor yrossier exécuté au lissoir ${ }^{139}$.

I Io Les cruches ansées: de forme grobulaire a parois fines et non moulurées, elles sont entièrement décorées de molifs linéaires exécutés au lissoir. Des bandes lissées horizontales, renforcées d'une légère incision, délimilent les différents registres. Le décor est exécuté sommairement et de manière irrégulière (fig. $28, n^{\text {os }} 6$ et 7 ).

II ${ }^{\circ}$ Les vases à large ouverlure: c'est dans ce dernier type que nous trouvons le plus de fantaisie dans l'exécution des formes. Ces vases possèdent des cols très dégagés et largement ouverts. IIs sont presque toujours décorés de traits au lissoir assez irréguliers (fig. 40, no 8). Comme dans le cas des cruches, les motifs décoratifs se bornent à un enchaînement de traits verlicaux, horizontaux et chevronnés. Un vase nous a fourni un décor composé de losanges exécutés à la molette. Là encore, le travail est grossier. Bien que de forme conique, les fonds sont toujours mal exécutés, soit que le potier ait renforcé exagérément la jointure du corps du vase avec le fond (fig. $29, \mathrm{n}^{0} 3$ ), soit que, dans l'exécution du còne, ayant trop aminci le centre, il ait été obligé de le terminer par une sorte de "bouton" servant de renforcement (fig. 29, no 2).

Il semble cependant que l'évolution des techniques soit inégale et certains exemplaires, par ailleurs mieux travaillés et mieux lissés, présentent des fonds coniques d'une évolution certaine (fig. 29, no 4). Ce type de vase semble donc marquer la transition entre le fond plat traditionnel, iourd et fragile (fig. 29, no 1 ) et le fond conique, qui, alliant la résistance au choc et à la pression, permet de donner plus de légèreté a l'ensemble de la pièce en affinant les parois depuis la base (fig. 29, $\mathrm{n}^{\circ}$ ) $)$.

Notons encore la présence de quelques tessons de gobelets à parois fines, décorés à la molette (fig. 29, no 6).

b) La céramique fine noire: procédant d'une technique de fabrication identique à celle de la céramique ardoisée, ce type de poterie se caractérise par une fumigation intense de la pâte, qui a pour effet de recouvrir les vases d'une pellicule d'un noir brillant que le lissage rend particulièrement profond. D'une manière générale, outre sa teinte caractéristique, ce groupe diffère du précédent par la fantaisie de ses formes et par l'importance de son décor ${ }^{140}$ (fig. 41, nos 4,6,8,9). Il semble que, contrairement à la céramique ardoisée, qui procède directement du type traditionnel, celle-ci ait ressenti plus profondément l'influence italique. (Fig. 29, no 7 , fig. 30 et 31 ).

(138) Ces deux tỵpes de fond se retrowvent semblablement et dans la mème proportion à Bibracte : "... les assiettes se divisent en plusieurs catégories. Les unes sont entièrement plates avec un rebord de deux centimètres de haut ou légerement incliné en dehors; d'autres au contraire, en nombre au moins égal, reposent sur une hase circulaire en saillie évidé..." (Brtı.tor, Fouilles du .Mont-Beutray, 1899, I, p. 18.3). pl. XIIl.

(139) Cette décoration est fréquente sur les céramiques de l'usine à gaz de Băle. C.f. E. I AJor, op. cil., n. 16,

(140) On note souvent l'utilisation d'un decor au peigne traditionnel exécuté avec finesse. Voir fig. $41, n^{\circ} 4$ en comparaison avec les décors de Stradonitz, cf. Pı́c, "p. cil., n. 105, pl. L.II. 


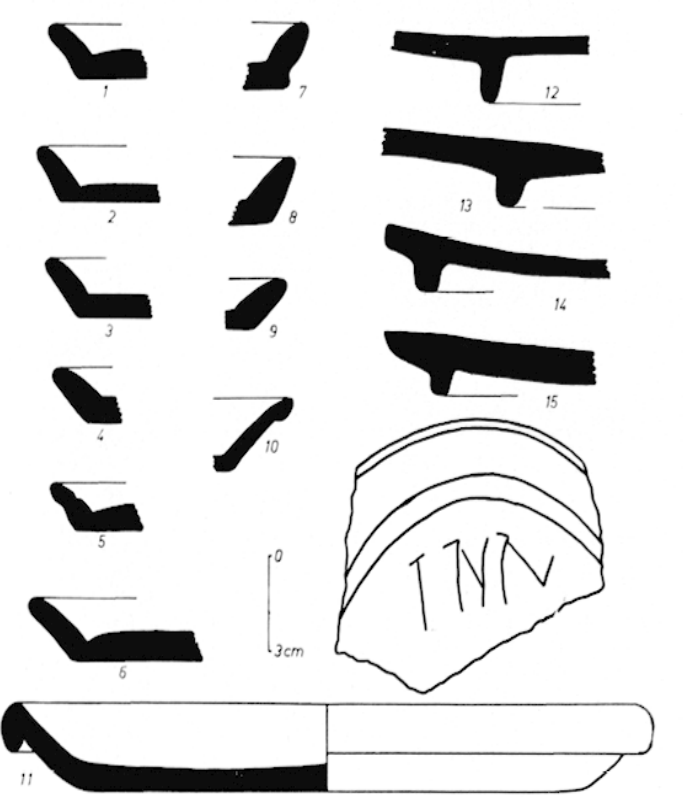

27. Plats el assiettes en céramique fine ardoisée.
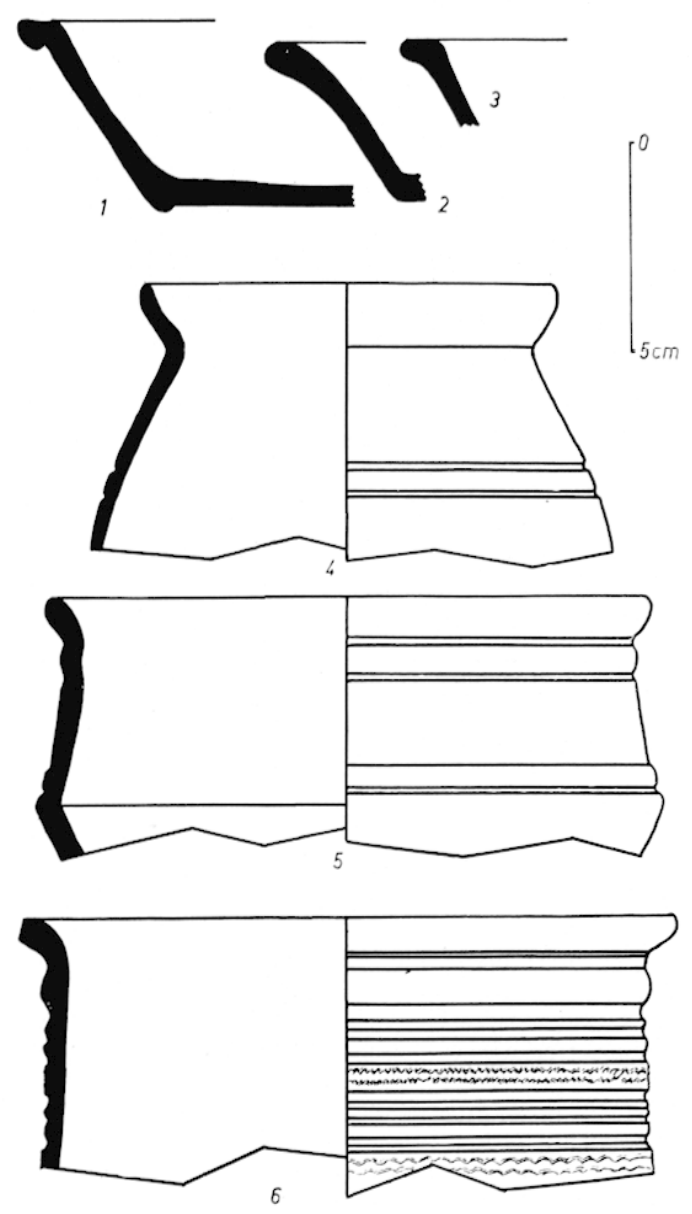

30. Céramique fine noire.

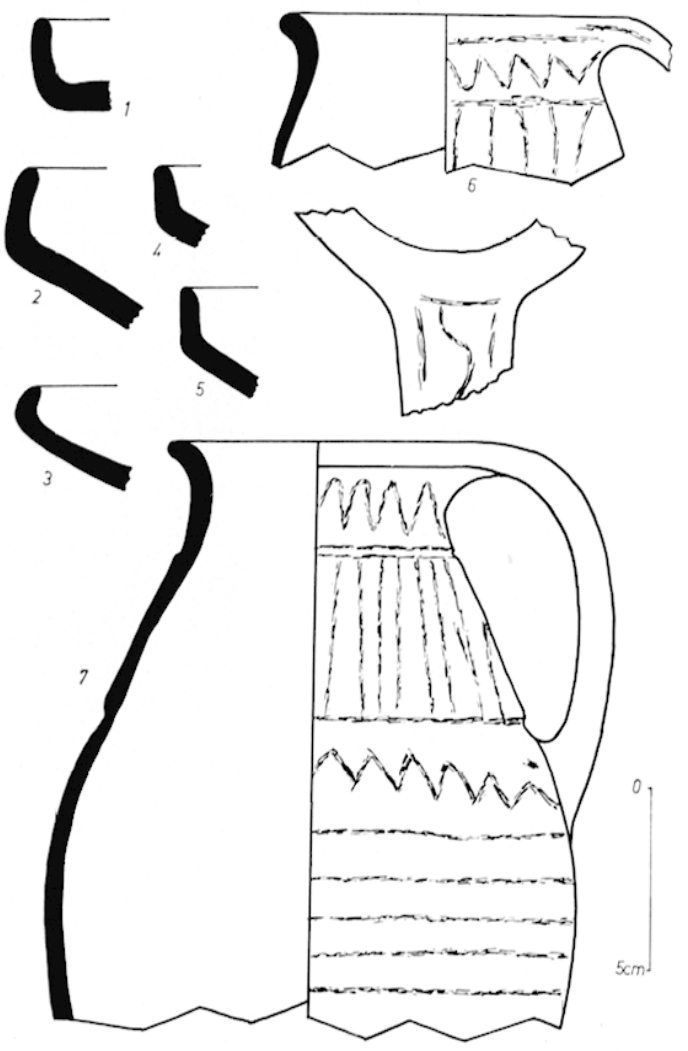

28. Rebords de plats et cruches en ciramique fine ardoisée.
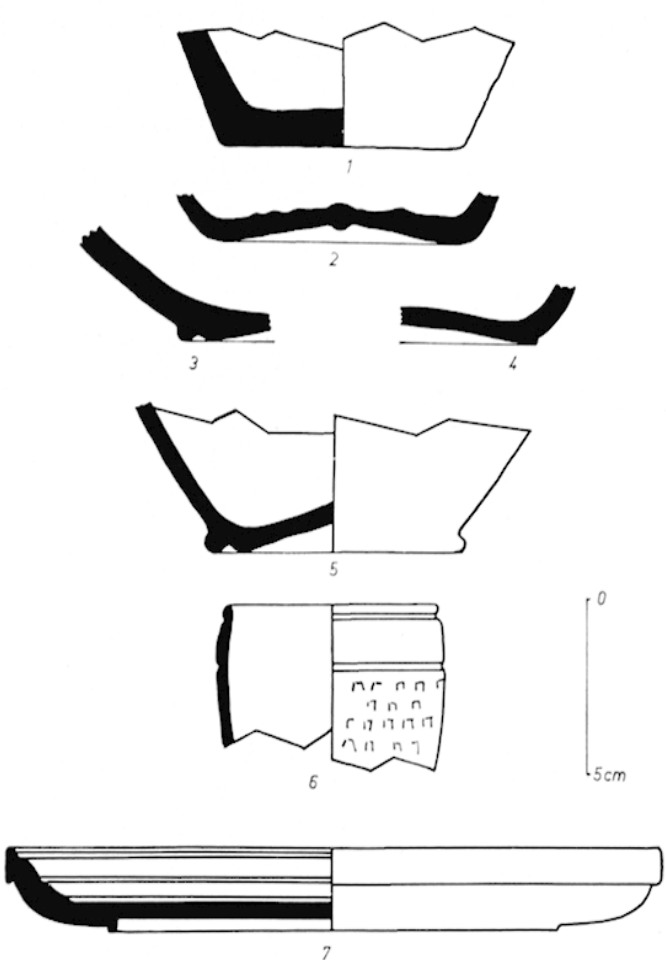

29. Céramique fine ardoisće, et noire $\left(n^{\circ} 7\right)$. 
I0 Plals el assielles: plus élancés de formes et d'allure plus légère, ces plats présentent des parois galbées presque toujours renforcées en leur sommet par une surépaisseur ou un rebord (fig.. 30, $\left.\mathrm{n}^{\mathrm{os}} 1,2,3\right)$. D'autres, inspirés directement de l'art italique, reproduisent des formes de céramique sigillée (fig. 29, $\mathrm{n}^{0} 7$ ).

I Io Les rases à large ouverture: traités plus soigneusement que les vases ardoisés, les rases globulaires de ce type voient disparaitre de leur panse les traits de lissoir grossiers et asymétriques pour ne laisser subsister que des incisions fines et régulières (fig. 30, $\mathrm{n}^{0}$ 4). I' autres vases carénés ou à parois cylindriques utilisent, parfois avec outrance, les décors moulurés (fig. 30, nos 5 et 6).

Il convient de remarquer la courbure de la plupart des lèvres des cols de ces vases (fig. $31, \mathrm{n}^{\mathrm{os}} \mathbf{1}$ à a) et de noter la présence de quelques gobelets à parois fines en pàte non lissée mais dont les saignées concentriques sont mises en valeur par un trait de lissoir (fig. $31, \mathrm{n}^{\circ}$ 6). Les cruches ansées sont toujours absentes dans ce genre de céramique.

c) La céramique grossière carbonifère: elle représente la part la plus importante dans l'ensemble de la poterie carbonifère recueillie sur le site. Constituée à partir d'une pâte siliceuse à gros grains apparents, elle est généralement mal travaillée. La polerie est montée sans l'aide du tour et seul le col a subi parfois un début de lissage. (Fig. 32 et 33).

Le décor est exceptionnel : quelques rares exemplaires ont la base du col soulignée de lignes incisées et de décors poinçonnés; ces derniers sont la plupart du temps illisibles (fig. $40, n^{0 s} 4,5,6,7$; fig. $41, n^{0 s} 3,5$ et $5 \mathrm{~A}$ ). Très souvent, la base des cols est recouverte d'un enduit de mica sur une largeur de un ou deux centimètres.

La plus grande partie de ce lot, soil environ $70 \%$, est composée de vases ovoïdes à fonds plats dans lesquels nous distinguons deux techniques différentes:

$1^{0}$ une série de vases de tradition purement celtique dont le col est constitué par un renflement léger de la panse qui s'infléchit en courbe régulière et généralement peu prononcée vers l'extérieur (fig. 33), nos 1 a 7 ). Quelques panses sont agrémentées d'un décor balayé très grossier. De rares exemplaires, dont le col possède à sa base un décor ondé, sont à classer dans la catégorie des "poteries charbonneuses", le carbone ì l'état granulaire ayant été employé comme dégraissant;

$2^{0}$ une deuxième série, de loin la plus importante, représente une technique plus évoluée où le rebord du col, généralement plus épais que dans la catégorie précédente, est nettement évasé vers l'extérieur, formant ainsi un angle important avec la panse (fig. 33, nos 8 à 13). Bien que ces vases soient toujours très grossiers, le col, sur la face externe, a subi un lissage plus soigné. La face interne est toujours moulurée par une ou, plus souvent, deux saignées concentriques. La jointure du col et de la panse est habituellement soulignée par un léger épaulement. Bien que de dimensions et d'exécution différentes, ces vases présentent entre cux une parenté indéniable. Il semble que nous trouvions lí les effets de l'influence romaine sur la céramique traditionnelle.

I'après la statistique de densité que nous avons faite sur l'ensemble de la céramique carbonifère grossière (fig. 32), nous constatons que les vases globulaires y entrent pour $69 \%$ et que, dans ce pourcentage. les vases purement celtiques ne représentent que $11 \%$. Les $31 \%$ restants renferment des types divers que nous décrivons ci-après :

1) les jattes carénées (fig. 34, nos 1 et 2), de tradition celtique ${ }^{141}$, dont le col plus ou moins rabaltu présente parfois, sur le dessus et il la base. des saignées excentriques:

(141) Tỵpes semblables à ceux d'Aulnat-Sud, cf. J.-J. Hatr, op. cit., n. 126, fị̣. 8, p. 161. 

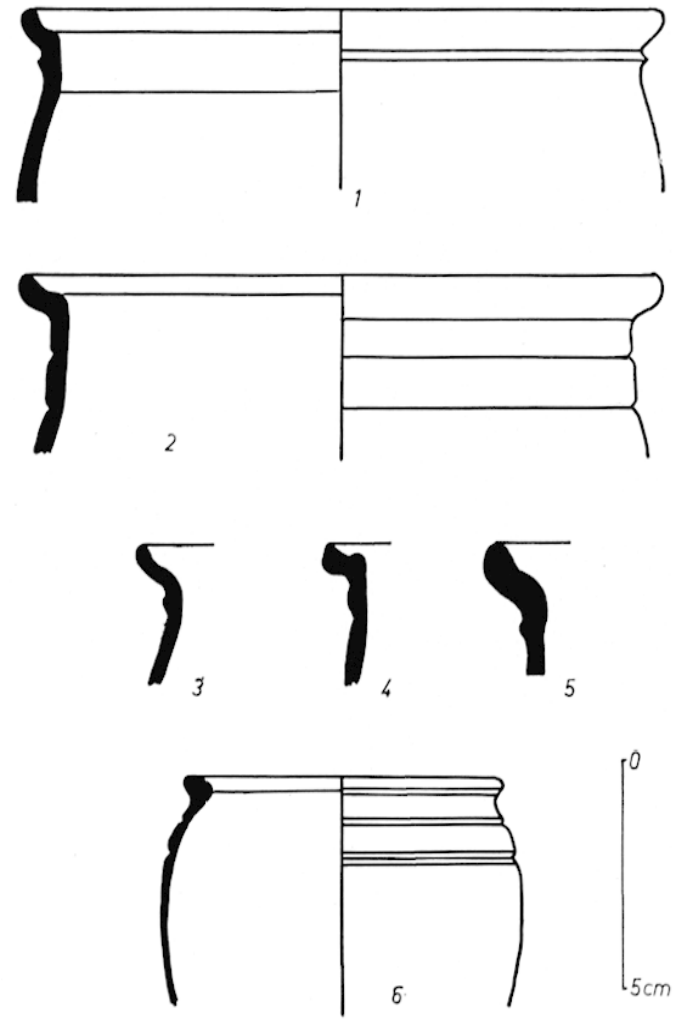

31. Rebords de vases en céramique fine noire.

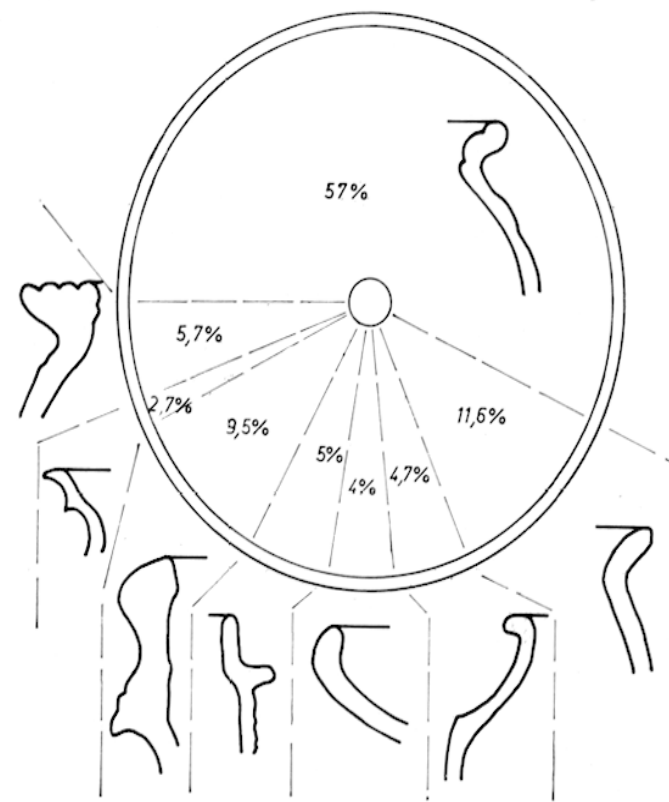

32. Répartition de la céramique grossière carlonifere.
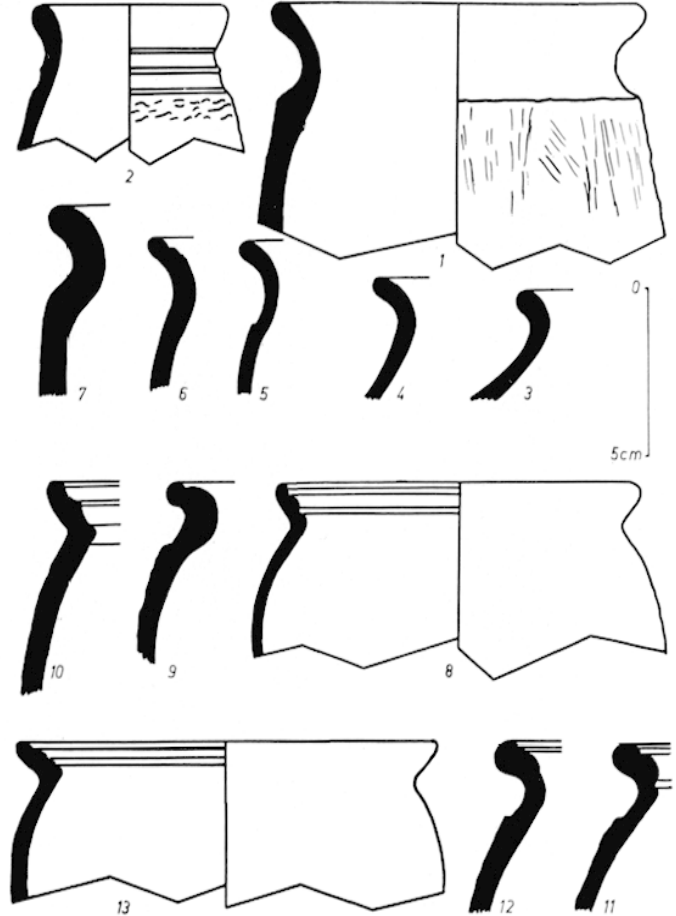

33. Céramique grossière carhonifere.
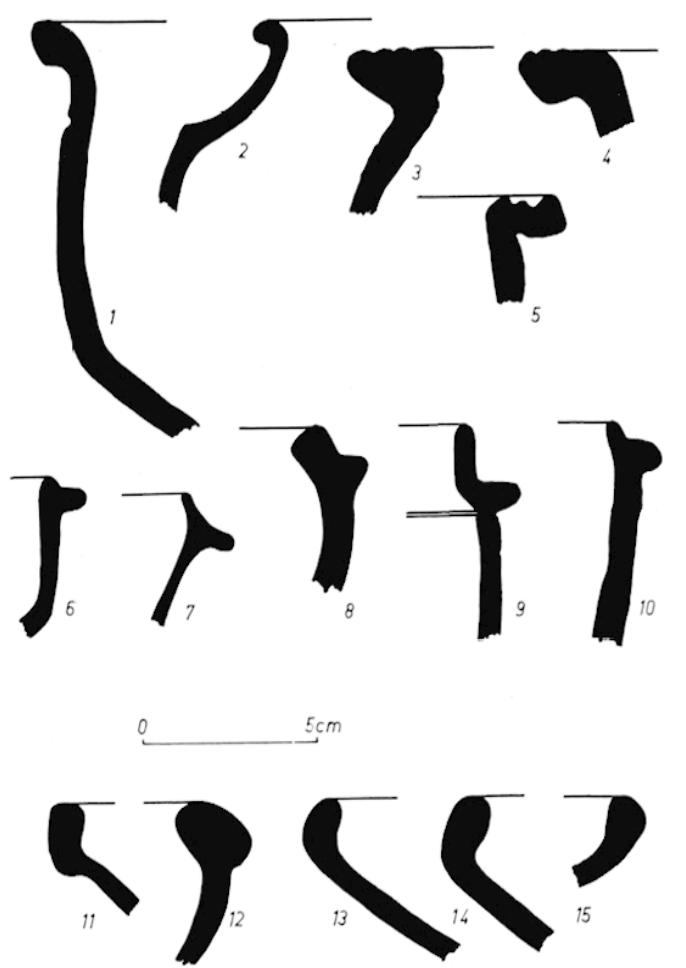

34. Cèramiqque grossière carbonifère. 
2) les dolia, dont le col large, épais, à rebord horizontal est orné de deux ou trois cercles concentriques (figr. 34, $\mathrm{n}^{\text {os }} 3$ a a 5 );

3) les écuelles creuses à rebord rentrant (fig. 34, nos 11 i 15 ), de facture typiquement traditionnelle ${ }^{142}$, dont certains types se retrouvent dans la céramique fine carbonifère;

4) les marmites, dont le col, parfois à peine marqué, est dans le prolongement du départ de la panse : souvent déporté vers l'intérieur, il en est séparé par une épaisse moulure extérieure (figr. 34, nos 6 a i 10 );

5) les grands cuviers, dont la base du col est ceinturée d'un boudin d'argile écrasé i espacements réguliers à l'aide du pouce. Le rebord extérieur de l'une de ces pièces porte un estampage circulaire dans lequel est inscrite une croix en relief (fig. 40, $\mathrm{n}^{\circ} 3$ ) :

6) un type de rase de facture relativement plus fine, dont le rebord du col, mince et peu accentué, est amené par une suite de moulurations successives. Bien que mal lissés, ces rases sont très réguliers et dénotent par leur forme, comme dans leur exécution, une certaine recherche (fig. 38 , $\mathrm{n}^{03} \quad 5$ is 9 ).

d) La céramique fine oxydée ( fig. 35 et 36) : poteries cuites à feu oxỹdant ; la coloration de la pâte peut varier du jaune clair au rouge brique. En fait, l'ensemble du matériel est fabriqué à partir d'une argile fine, à basse teneur en fer, de qualité toujours égale qui donne une coloration homogène jaune rosée habituelle aux céramiques locales. Cependant, certains vases, enduits extéricurement d'un revêtement de couleur marron, sont faits d'une pâte à forte teneur en oxyde de fer et présentent à la cassure une coloration rouge foncé, ce qui laisse supposer une production extra-régionale. Ces poteries comportent rarement une décoration. Celle-ci se rencontre principalement sur des gobelets à parois fines agrémentées à la molette d'un décor en palmettes. Ces gobelets, communs à la Tène III, sont assez rares dans ce type de céramique car, dans la majorité des cas, ils sont cuits en feu réducteur et présentent une coloration gris foncé. Ces palmettes sont parfois employées conjointement avec une décoration composée de traits parallèles exécutés à la barbotine (fig. $41, \mathrm{n}^{\text {os }} 7$, $12,12 \mathrm{~A}$ et 13$)$.

La plus grande partie du matériel est constiluée par des flacons à liquide, à goulot mouluré munis d'une anse trifide (fig. 35), nos 1 ia 6). La forme de ces flacons est constante et leur volume sensiblement semblable; seules, apparaissent nettement les différences de décoration des cols (notons que le goulot était fabriqué à part, puis raltaché au vase et à l'anse au dernier stade de montage). En dehors de ces flacons, le reste du matériel ne représente que quelques vases de formes diverses (fig. 35, nos 1 a j)). aux rebords bien accentués, soigneusement tournés et lissés; la plupart se ressentent de l'influence italique.

Cette influence marque aussi les fonds qui se présentent toujours, soit avec l'intérieur horizontal et l'extérieur concave et, dans ce cas, la liaison de la panse et du fond est souvent soulignée par un bourrelet de renforcement (fig. 35, nos 6 et 7), soit avec l'intérieur et l'extérieur formant une voûte dont la périphérie vient se perdre dans le départ de la panse (figr. 35), no 8). La plupart du temps, le fond conserve une épaisseur égale à celle des parois.

e) La céramique grossiere oxydée: elle représente une part importante de la récolte. La pâte hétérogène contenant de gros grains de quartz est très semblable comme texture à celle de la céramique "grossière fumigée ». Cependant, outre les différences techniques qui

(142) J.-J. HatT, ibidem, p. I59, fig. 6 et Pıč, op. cil., n. 105, pl. LI, no 11. 

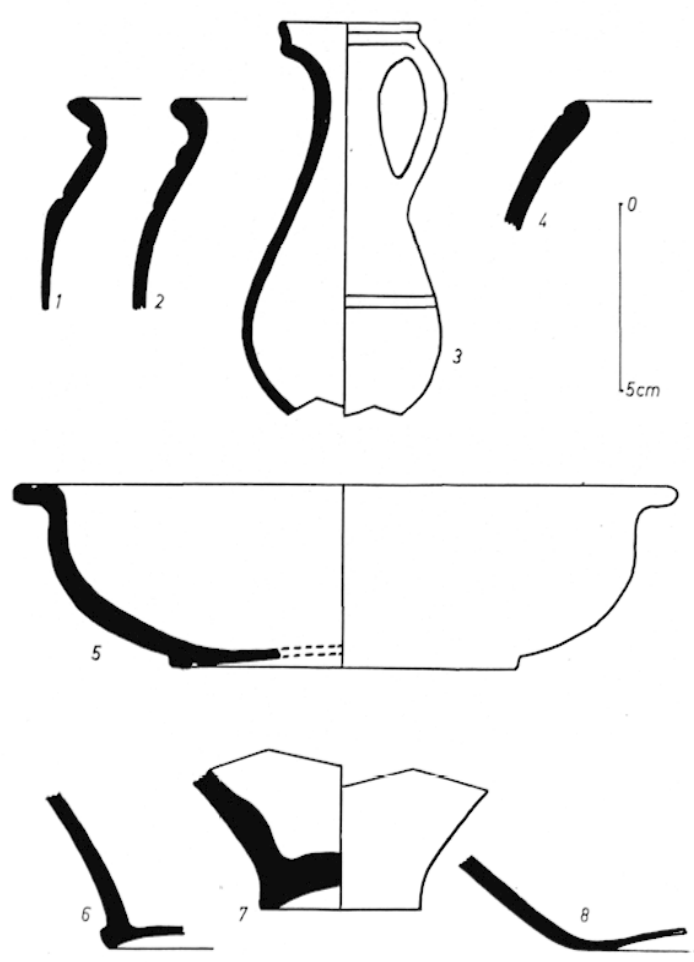

35. Céramique fine oxydée.

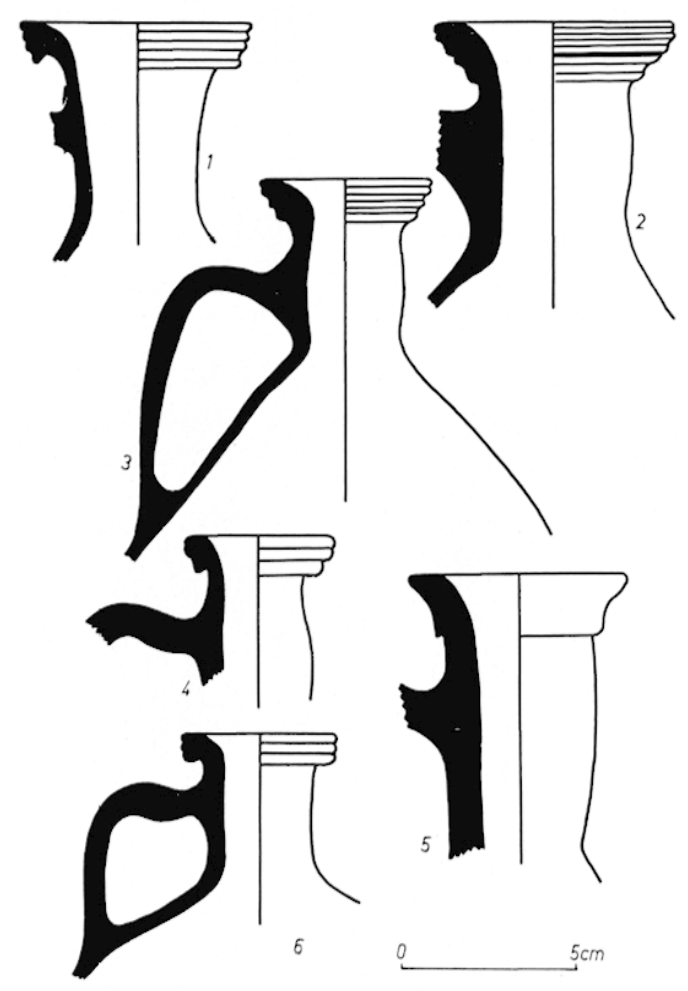

36. Flacons à liquide en céramique fine oxydèe.

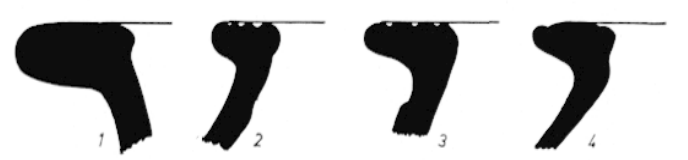

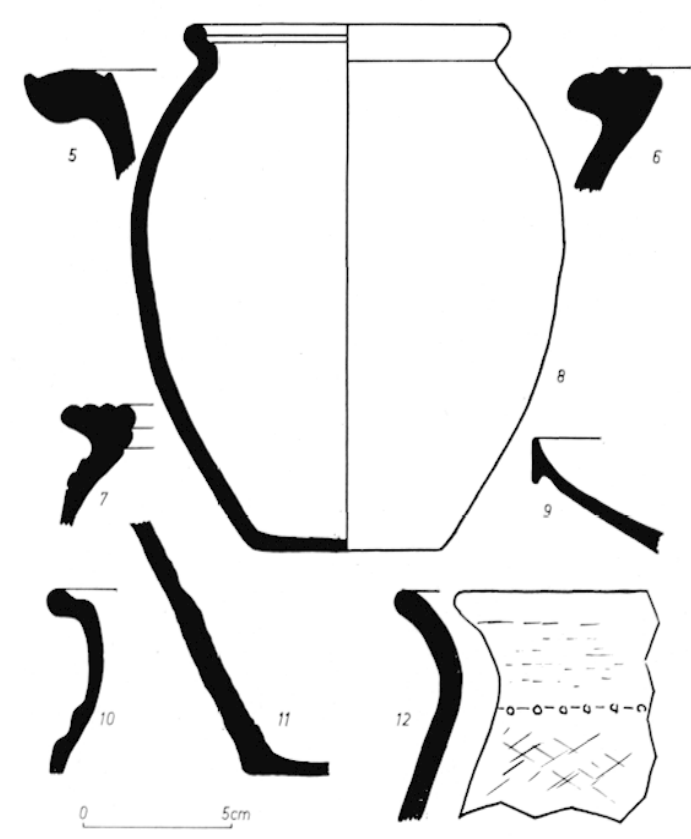

37. Ceramique ğrossière oxydée.

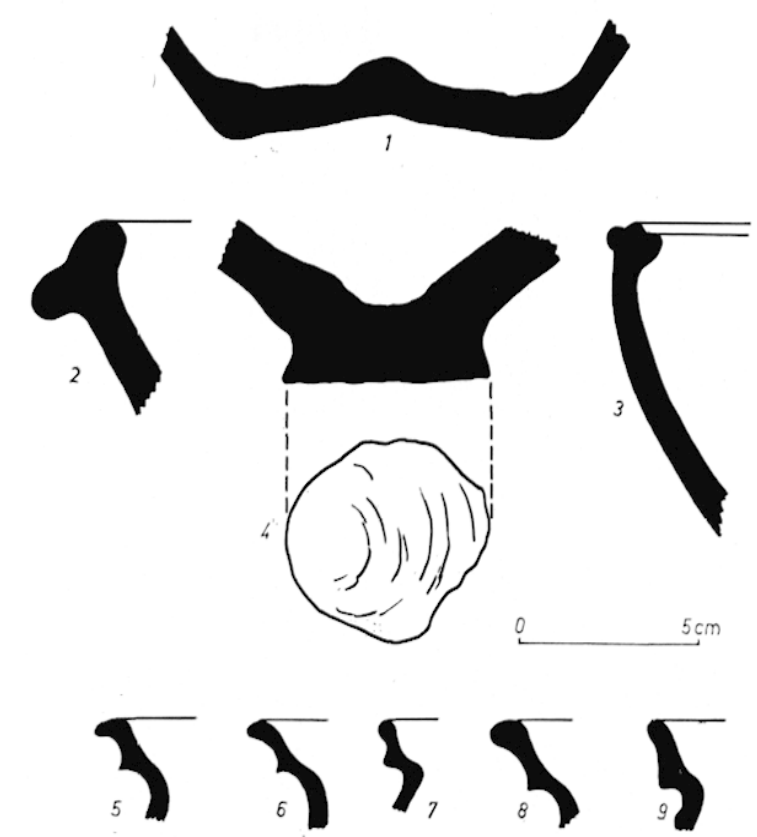

38. Céramique grossière oxydée. 
séparent ces deux pâtes, l'étude des formes fait apparaître pour l'ensemble un pourcentage de céramique plus évoluée, très empreinte de l'influence romaine. Les types sont peu nombreux et la majorité du matériel est constitué, d'une part, de dolia à rebords épais et horizontaux (flg. 37 nos 1 à 7 ), d'autre part, de vases ovoïdes à col épais et évasé sur l'extérieur (fig. $37, n^{\circ} 8$ ). Ces dernicrs, scmblables aux vases décrits comme "céramique grossière carbonifère", possèdent toujours deux moulures à l'intéricur du col; celui-ci, lissé ou non, a parfois été enduit de mica. (Fig. 37 et 38 ).

Ce genre de poterie ne possède pas de décors.

Les types particuliers sont représentés par un très faible pourcentage de vases de formes diverses (fig. 37, nos 9 et 10 ; fig. 38, nos $^{\text {os }} 2$ et 3 ), dont certains, de tradition celtique ${ }^{143}$. possèdent à la base du col un décor poinçonné (fig. $37, \mathrm{n}^{\circ} 12$ ).

Les fonds sont toujours grossiers et mal exécutés. On distingue cependant une évolution depuis le fond plat, généralement de faible épaisseur par rapport aux parois (fig. 37, $\mathrm{n}^{0} 11$ ), jusqu'à quelques timides essais tendant à donner une certaine conicité à la face externe du fond, afin de le rendre moins fragile et permettant un allégement de l'ensemble du vase. L'intérieur du fond restant rectiligne, l'artisan a été obligé, la plupart du temps, d'en rehausser le centre par un "boulon 》 de renforcement pour pallier un amincissement excessif (fig. 38, $\mathrm{n}^{0} 1$ ). Une autre technique, propre ì la céramique grossière, consiste à exécuter un fond de diamètre étroit mais de forte épaisseur. La face externe des fonds de ce type porte toujours des traces de découpage exécuté avec un fil souple (fig. 38, no 4). Cette technique laisse supposer que, le vase une fois terminé et encore en place sur le plateau du tour, l'ouvrier sectionnait le pied (à l'aide d'une ficelle par exemple) dans sa partie la plus étroite, ce qui lui permettait d'obtenir des vases à pied étroit tout en opérant le montage sur une base large et mieux assise.

f) La céramique de type parliculier: n'entrant dans aucune des catégories précédemment décrites, ces poteries, fabriquées à partir de pâtes fines, sont d'une exécution soignée et possèdent presque toujours un revêtement coloré sur leur surface.

Un type bien défini affecte la forme de gobelets coniques (fig. 39), à parois fines, en pâte ocre clair. La face interne est revêtue d'une couche d'enduit rouge-marron tandis que la face externe est colorée en beige foncé : cette de rnière face est décorée de motifs géométriques (bâtonnets, triangles effilés, chevrons) exécutés en creux ou en relief à l'aide d'une molctte. Les différents registres moletés sont séparés par des moulures circulaires lissées. Ln autre type, dont nous possédons peu de fragments, comprend des vases à parois fines, sans revêtement, dont la pâte, à forte teneur en fer, est de couleur rouge-mat.

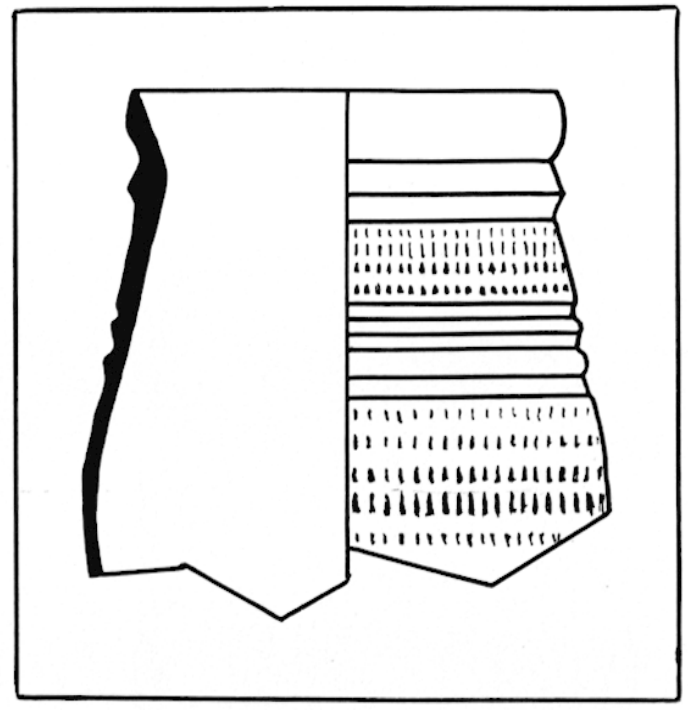

39. Vase à revêtement coloré.

(143) Types semblables à ceux de l'usine à gaz de Bàle, cf. E. Major, op. cil., n. 16, pl. VIII. 


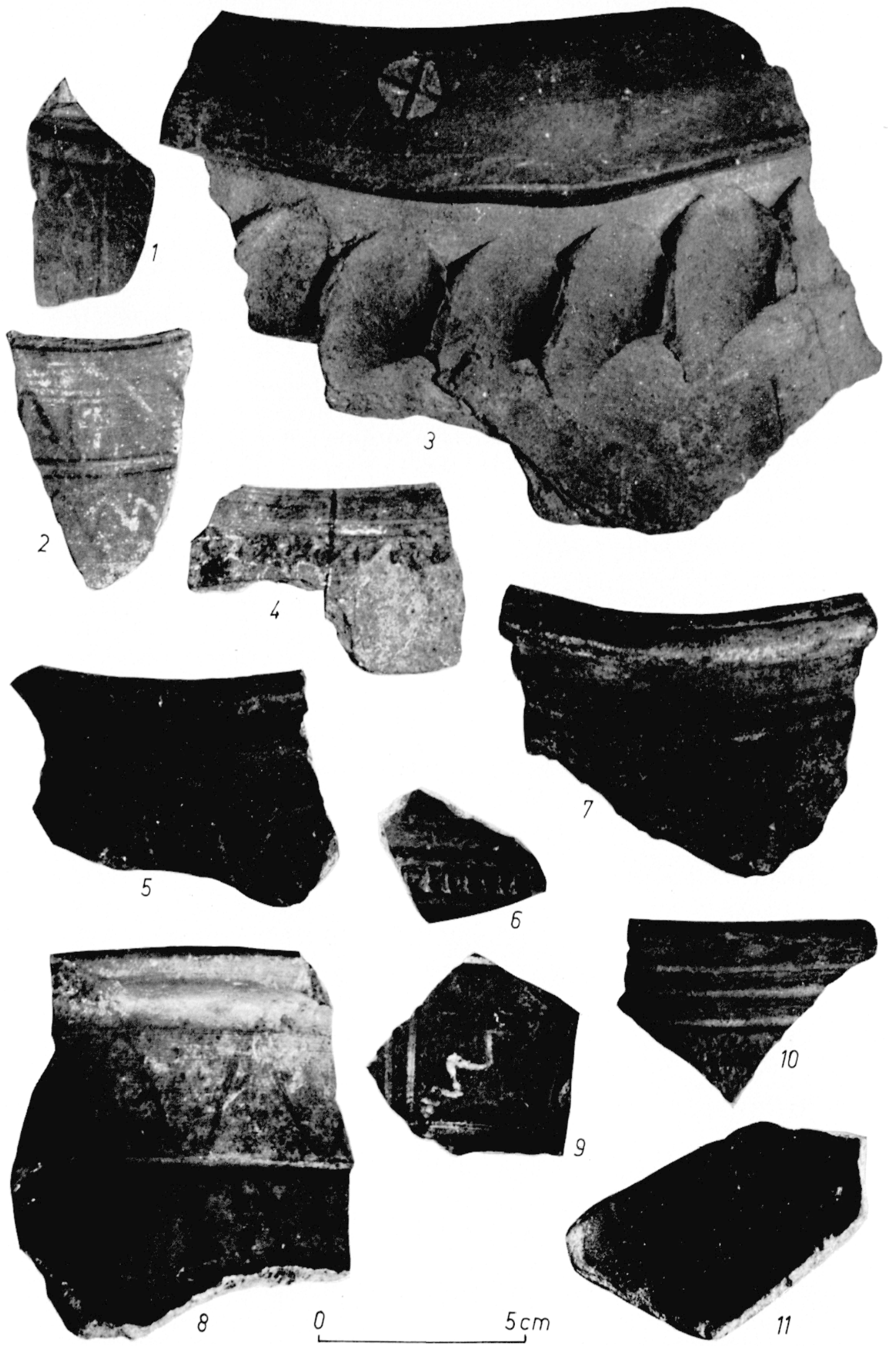

40. Décors sur les différents types de céramique commune. 

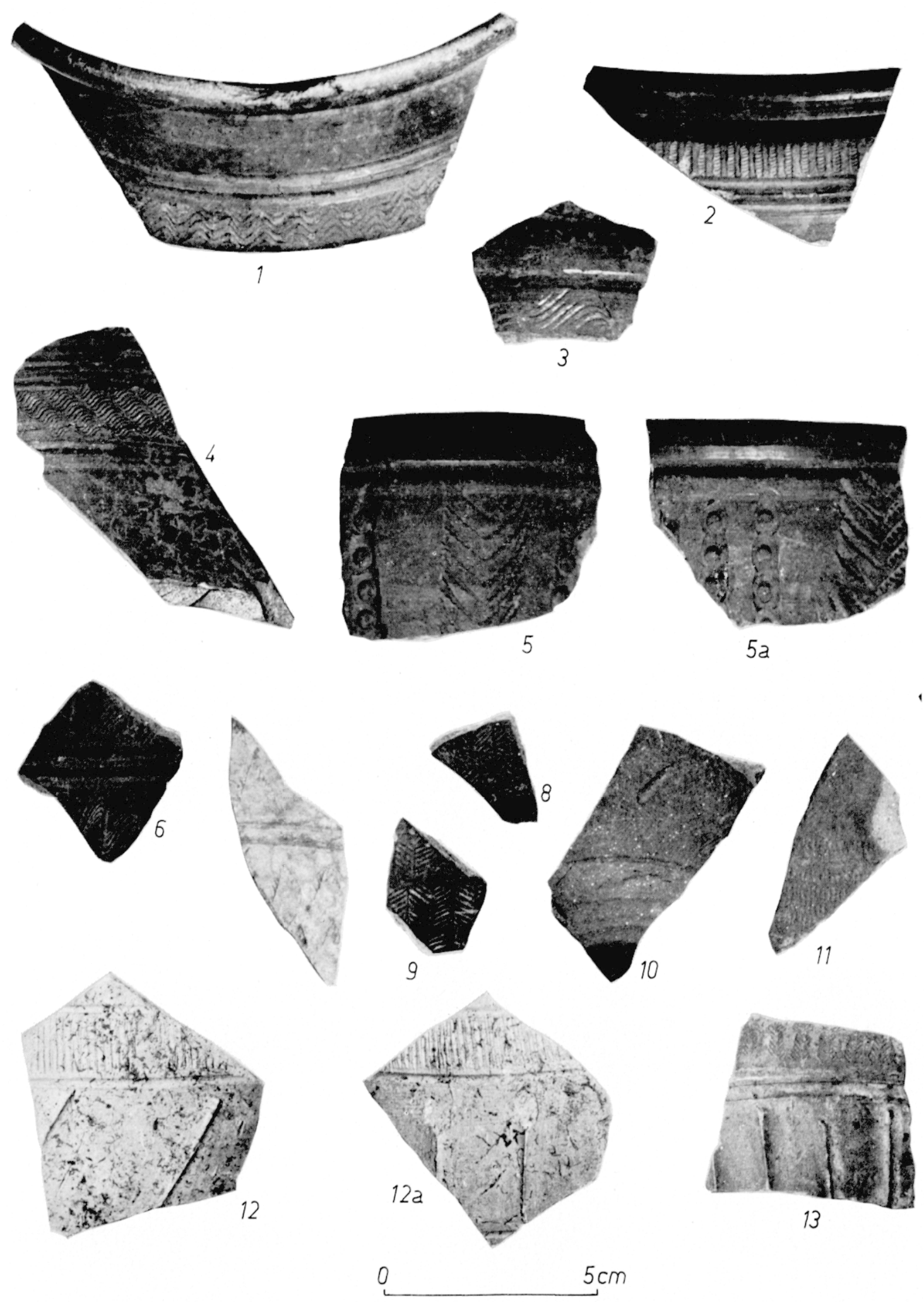

11. Ijecors sur les differents types de comamigue commune. 
Ces poteries sont décorées de motifs simples (par exemple des lignes pointillées), exécutés à la molette. Un tesson montre une série de petits triangles incisés qui ressemblent par leur disposition aux motifs des gobelets d'Aco.

Quelques vases à fond étroit ont leur partie inférieure, sur la face externe et sur une hauteur de 2 à $3 \mathrm{~cm}$, revêtue d'un enduit ocre rouge; la panse est décorée de chevrons entremêlés ou de palmettes ${ }^{144}$. D'autres, du type "peau de crapaud", sont revêtus intérieurement et extérieurement d'un vernis marron foncé ${ }^{145}$.

\section{VII. - LE VERRE}

Les seuls débris que nous possédions viennent d'une sorte de "bol ", d'un diamètre au col de $0,18 \mathrm{~m}$. Son état très fragmentaire ne permet pas une reconstitution exacte de la forme, que l'on peut néanmoins apparenter au type 383 de Kisa ${ }^{146}$, avec la différence que notre pièce possédait probablement un fond rond. D'épaisseur faible à l'amorce du col (environ $0,001 \mathrm{~m}$ ), celle-ci augmente régulièrement vers la base, qui a une épaisseur moyenne de 0,003 m. Le col, finement travaillé, est du type ourlé en dehors ${ }^{147}$. Le verre, bleu verdâtre, est transparent et présente peu d'irisation. Il ne laisse apparaître ni filandres, ni nodules et contient peu de bulles d'air. Par sa technique, cette pièce s'apparente au type Romain I de .Morin Jean ${ }^{148}$.

$$
\therefore
$$

L'analyse du matériel recueilli apporte un certain nombre d'éléments inédits à la connaissance du passé local, ne serait-ce que par la preuve qu'elle fournit, que la ville de Rodumna, communément considérée comme un bourg pauvre et sans importance, possédait une occupation dense sur un périmètre dont les dimensions sont mises en valeur par plusieurs chantiers en cours d'étude. La présence d'imitations de céramiques campaniennes et d'une série de céramiques communes, que nous datons avec une certaine précision de la fin de l'Indépendance gauloise, sont des faits nouveaux qui font reculer de quelques années l'origine de la bourgade qui devait devenir Rodumna. Prise dans son ensemble, la céramique commune présente un mélange intime de vases purement celtiques, mêlés à des poteries fortement marquées par des apports italiques, avec toutes les nuances allant de l'une à l'autre technique.

Il semble donc évident que nous nous trouvons en présence d'un site subissant les premières influences des techniques romaines et ce fait est d'autant plus intéressant qu'il nous permet de suivre, dans les modifications profondes que vont subir les arts de l'argile, les efforts des céramistes gaulois pour s'adapter à la mode nouvelle. En fait, cette mode

(144) E. Rittialisg, op. cit., n. 35, pl. XXXI1I, type 28 A.

(145) R. Ṕ́RICHon, Observalions sur quelques vases sablès découverls à Roanne, à paraittre.

(146) A. Kisa, Das Glas im Alterlüme, I-III, 1908, pl. G.

(147) Morin Jean, La verrerie en Gaule sous l'Empire romain, 1913, p. 30.

(148) Période d'Auguste à la fin de la dynastie des Antonins, cf. Moris Jean, op. cil., n. 147, p. 7. 
touche d'abord à la réramique fine alors que la céramique grossière, par définition strictement utilitaire, reste beaucoup plus traditionnelle. Pour cette dernière. nous avons dressé une statistique des formes, pensant que des études ultérieures permettront de mieux pereceroir cette lente écolution.

La datation précise de la réramigur sigrillée, ses diverses densites selon les périodes d'importation ou d'utilisation, apportent également des indirations qui facilitent l'eture. des autres vestiges.

La grande quantité de céramiques peintes fournie par co site represente un apport a l'étude des vases peints roannais et olfere la possibilite. compte tenu des l rouvailles anciennes, de dresser une premiere classification des déers at des formes permettant de suive l'écolution de re type de vase. On constate en particulier. des importations de céramicques peintes qui se distinguent des productions lorales de facon evidente. L'abondaner des productions peintes locales est exalement à noter dans un milieu spérifiquement gralloromain.

Le sitr lui-mème. placé à la périphérie de l'hahitat, est peu éloquent. Les pochess rontenant les vestiges ont cte peu étudiées mais la densité du materinl recueilli sur cette vaste superficie et sa datation permettent de supposer une occupation tres dense des lieux Irpuis la période augustéenne jusqu'au milieu du ger siècle apres J.-C. Ce dernier fait n'est pas noureau et Joseph Jechelette l'avait lui-mème constatio dans ses fouilles de la nécropole de la rue saint-Jean ainsi que dans celles entreprises a l'emplacement du college:

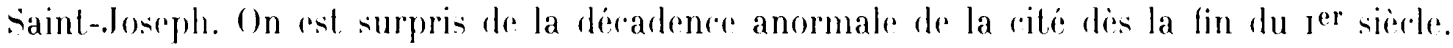
Faut-il supposer. comme l'a fait Joseph Dedhelette, que le commeree des officines arvernes de Lerre sigillée, qui s'effertuait par la vallée de l'Allier, a fait resser les importations de réramiques du sud de la Gaule el délaisser une route commerriale du Rhòne à la Loire passant par Roanne? Ou bien faut-il attribuer cette décarlence à quelque fait politique? les travaux an rours devaient apporter quelques irelaireissements sur cette question. 